Family History of Asthma

Prognostic impact in infants and cost-effectiveness of primary prevention 
(c) Sandra Kuiper, Maastricht 2007

ISBN-㺼: 90-5278-594-5

ISBN-㺼: 978-90-5278-594-3

Cover design: Nathaly Heesakkers

Layout: Tiny Wouters

Production: Datawyse I Universitaire Pers Maastricht

The RAKKER study was supported by the Dutch organisation for Health Research and Development (ZonMw), the Dutch Asthma Foundation (NAF), and by the Royal Netherlands Academy of Sciences (KNAW). 


\section{Family History of Asthma \\ Prognostic impact in infants and cost-effectiveness \\ of primary prevention}

\section{PROEFSCHRIFT}

ter verkrijging van de graad van doctor aan de Universiteit Maastricht, op gezag van de Rector Magnificus, Prof. mr. G.P.M.F. Mols, volgens het besluit van het College van Decanen, in het openbaar te verdedigen op donderdag 25 januari 2007 om 12.00 uur

door

Sandra Kuiper 
Promotoren

Prof. dr. C.P. van Schayck

Prof. dr. J.A. Knottnerus

\section{Copromotoren}

Dr. E. Dompeling

Dr. J.W.M. Muris

Beoordelingscommissie

Prof. dr. E.F.M. Wouters (voorzitter)

Prof. dr. R.C. Aalberse, Universiteit van Amsterdam

Prof. dr. F.J.V.M. Buntinx

Dr. M.C.J.M. van Dongen

Dr. Q Jöbsis 
Aan mijn oma,

Jacoba van Assendelft van Wijck-Prophitius (7 mei 1910 - 15 juni 1995), die de inspiratiebron is geweest om 'de wetenschap in te gaan'.

Aan Jaap, Pim en Lisa 


\section{Abbreviations}

PFH Positive (first-degree) Family History of asthma

NFH Negative Family History of asthma

GP General Practitioner

RCPT Randomided Controlled Clinical Prevention Trial

RCPT-C Randomised Clinical Prevention Trial-Control group

RCPT-IV Randomised Clinical Prevention Trial-Intervention group

RCPT-SIV RCPT-Short Intervention

RCPT-LIV RCPT-Long Intervention

RCAT Optimised Randomised Clinical Adherence Trial

RCAT-IV Randomised Clinical Adherence Trial-Intervention group

RCAT-C Randomised Clinical Adherence Trial-Control group

NH-C Natural History-Control group

ISAAC International Study of Asthma and Allergies in Childhood

ICPC International Classification of Primary Care

ICHPPC-2 International Classification of Health Problems in Primary Care

LRTI Lower Respiratory Tract Infections

URTI Upper Respiratory Tract Infections

EPM Epidemiological asthma diagnosis based Prediction Model

IgE Immunoglobulin E

ELISA Enzyme-Linked Immunosorbent Assay

PBS-T PBS/Tween

$\mathrm{IU} / \mathrm{ml} \quad$ International Units per millilitre

$\mathrm{CO} \quad$ Carbon Monoxide

HDM House Dust Mite

Der 1 Dermatophagoides pteronyssinus allergen 1

ETS Environmental Tobacco Smoke

PPS Postnatal Parental Smoking

BF Breastfeeding

OTC Over The Counter

ICER Incremental Cost-Effectiveness Ratio

$\chi^{2}$-test Chi-square test

MLR Multiple Logistic Regression analysis

OR Odds Ratio

C.I. Confidence Interval

SPSS Statistical Package for the Social Sciences 


\section{Contents}

Chapter 1 General Introduction

Chapter 2 The Primary Prevention of Asthma in Children (PREVASC) Study: Design of a Multifaceted Prevention Program

Chapter 3 Association between a positive family history of asthma and atopy (IgE) in newborns

Chapter 4 The interactive effect of family history and environmental factors on respiratory tract related morbidity in early infancy: The PREVASC program

Chapter 5 Family history modifies the effect of day-care on respiratory morbidity in early infancy: The PREVASC program

Chapter 6 Cost-effectiveness of primary prevention of asthma in high-risk infants: 0-2 years

Chapter 7 General discussion

Summary

Samenvatting

Publications

Dankwoord

Curriculum vitae 



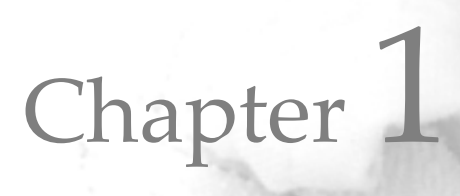

General introduction 
Chapter 1 


\section{Introduction}

The purpose of this thesis was to study the role of a first-degree family history of asthma, as determined in general practice, in infants during their first two years of life. To embed the different research questions of this thesis, this chapter gives an overview of the pathofysiology and clinical presentation of asthma and the state of art concerning the prevalence of asthma and environmental risk factors that may trigger asthma development. Little is known about the specific interactions between family history and environmental triggers. In this thesis we show the results of research on this issue. Insight in the interaction between family history and environmental factors may help us, to understand the mechanisms, and, in the considerations whether family history is a useful instrument for selecting individuals 'at risk' for interventions and economical evaluations.

\section{Asthma}

Asthma, a disease first referred to in the 'old Egyptian' scriptures, is one of the most important chronic diseases in childhood. ${ }^{1}$ It is a complex atopic disorder in which genetic and environmental causes play important roles. ${ }^{2}$ Asthma is a disorder of the airways, in which hypersensitivity to specific and non-specific agents leads to a chronic inflammatory response. Several cell types are involved in the inflammation, i.e. epithelial cells, mast cells, neutrophils, eosinophils and $\mathrm{T}$ lymphocytes.

For many years it has been thought that the most important immunologic mechanism underlying the appearance of allergies and asthma is an imbalanced $\mathrm{T}_{\mathrm{H}} 1 / \mathrm{T}_{\mathrm{H}} 2$ response. Children are normally born with a balance towards $\mathrm{T}_{\mathrm{H}} 2$ responses to foreign antigens, because the $\mathrm{T}_{\mathrm{H}} 2$ mode avoids rejection of the pregnancy. In most children the $\mathrm{T}_{\mathrm{H}} 2$ bias is lost early in life, where after they will produce a more balanced $\mathrm{T}_{\mathrm{H}} 1 / \mathrm{T}_{\mathrm{H}} 2$ response. The idea was that, some children produced less interferon- $\gamma($ IFN- $\gamma)$, a TH1 cell derived cytokine, which stimulates the $T_{H} 1$ and inhibits the $T_{H} 2$ pathway. In these children, the $T_{H} 2$ pathway should remain dominant over the $T_{H} 1$ pathway. ${ }^{3}$ They persisted to produce $\mathrm{T}_{\mathrm{H}} 2$ driven cytokines as interleukin (IL)-4, IL-5, IL-6, IL-9 and IL-13 which have shown to be important for inflammatory cell maturation, activation and proliferation, chemokine expression, $\operatorname{IgE}$ production, mucus secretion and bronchial hyper-responsiveness. ${ }^{4}$

However, since data were conflicting, it is thought that other immunologic mechanisms as the regulation of serum $\mathrm{IgE}$ levels, ${ }^{5}$ the interaction of $T$ regulatory cells with dendritic cells or mechanisms inherent to the innate immune system may play an important role..$^{6,7}$ 
Asthma presents with recurring episodes of wheezing, breathlessness, chest tightness and (nightly) coughing, although a clear diagnostic definition still does not exist. Exacerbations of asthma are episodic, but airway inflammation is chronically present. ${ }^{8,9}$ In children less than four years of age chest tightness is uncommon, whereas breathlessness is difficult to determine by history taking. In this group it is difficult to diagnose asthma objectively, since most children are not able to undergo a lung function test, whereas other objective instruments are lacking. Therefore, to get an impression of a child's asthma status in the first years of life, one can only make a symptom-based diagnosis.

\section{Prevalence}

The prevalence of asthma is high, but varies from country to country. Several reasons for the global differences have been mentioned, including differences in exposure to respiratory infections, indoor and outdoor pollution, diet and socio-economic status, but also hygiene and healthcare in the Western world and genetic differences. ${ }^{3}$ In the past decades a worldwide increase in the prevalence of asthma has been observed. ${ }^{10,11}$ However, recently the first signs of a stabilisation ${ }^{12}$ or even a decrease ${ }^{13,14}$ have been reported. The reasons for these changes in prevalence are poorly understood..$^{14}$

In Dutch children, the asthma prevalence is 6\% in 0-1 year old babies and decreases to $4 \%$ in $4-5$ year old children. ${ }^{15}$ More than one third of all children experience at least one episode of wheezing before they reach the age of three. More than half have stopped wheezing by the age of six, indicating that wheezing alone is not indicative for the development of asthma. ${ }^{16}$

\section{Risk factors}

A variety of risk factors are present, that are thought to influence the susceptibility to the development of asthma. These include host factors such as genetic predisposition, gender and race, as well as environmental factors such as allergen exposure, viral and bacterial infections, diet and tobacco smoke.

Concerning genetic predisposition, it has become clear that multiple major and minor genes on different chromosomes are involved and interact with each other. Some of these genes are immune-response genes while others are IgEregulating genes. ${ }^{17}$ In addition, both immune-response genes and IgEregulating genes may themselves be modulated by environmental factors such as the level and frequency of allergen exposure. ${ }^{18}$ Despite the progress that has been made in the unraveling of genes that are involved in asthma, one cannot 
diagnose asthma based on genetic analysis. It is therefore that in most studies, first-degree family history of atopy or asthma is still used as a proxy for genetic predisposition. Since the genetic background is probably different in children with- and without a first-degree family history of asthma, it is likely that they respond differently to environmental risk factors.

Research concerning exposure to infections from viral and bacterial origin is complicated and expensive, because of the enormous amounts of bacterial and viral strains that may affect the immune response. Therefore, most studies use proxy variables to consider exposure to infections. Examples of these proxy variables are family size and day-care attendance.

\section{Consequences of having asthma}

Asthma exerts a great burden on the patients, their family members, health care services as well as the society as a whole. It is the main cause of school absence $^{19,20}$ and reduces the quality of life of children and their parents. ${ }^{21,22}$ The number of asthma-related physician contacts and hospitalisations is high, which results in substantial costs of treating asthma. In 0-year old babies $20.4 \%$ and, in children aged $1-14$ years $24.1 \%$ of the total health care costs are spent on asthma. ${ }^{23}$

It is therefore of great importance to prevent the development of (severe) asthma.

\section{To whom should intervention be offered?}

As mentioned before, the development of asthma is partly determined by genetic factors, indicating that a first-degree family history of asthma is a possible risk factor of asthma.

Several studies have been performed in which family history was used as risk factor. ${ }^{24}$ In most studies, an association between family history of asthma with a diagnosis of asthma was found. However, the strength of the association had a wide range, which may in part be explained by the variety in study designs and in the way the statistical models were composed.

In a study of Christie et al, the effects of parental asthma, atopy and wheezy bronchitis on outcome in children were studied. The subjects (mean age 14.3 years) who were selected for this study were children from probands who were originally studied as children in 1964. The investigators showed that although total IgE levels were significantly higher in children of atopic probands, specific IgE responsiveness to house dust mite, cat and grass had a 
similar high prevalence in children of both atopic and non-atopic probands. Moreover, they found that in this age group the prevalence of wheezing symptoms in children of non-atopic asymptomatic probands was high. Their most important conclusion was that, during one generation, there had been a significant rise in the prevalence of asthma and specific IgE responsiveness among children without a family history of asthma. In other words the increased asthma prevalence may not only be attributable to infants with a family history of asthma, atopy or wheezy bronchitis. ${ }^{25}$

These findings put 'family history of asthma' as instrument for selecting individuals 'at risk' into a different perspective. It raises the question whether a prenatally initiated intervention program should be directed exclusively to a specified high-risk group (i.e. children with a first-degree family history of asthma), or whether the program should be offered to the entire population.

An advantage of directing a prenatally initiated intervention program to the entire population is that fewer potential cases of asthma will be missed. As a potential disadvantage, there is a risk of giving families erroneous advice regarding restrictions in (for example) keeping pets or the type of feeding the newborn is given, while they will never develop an atopic disease. Moreover, the total intervention costs of a prevention program attributed to the whole population will be enormous, while the chance of adherence to the program might be low, because most parents are not familiar with the disease.

By offering a prevention program to a specified 'high-risk' group exclusively, only those families with the highest risk of having a baby that will develop asthma are included and as a consequence the total intervention costs will be lower. The chance of adherence to the program may be higher in this specific group. However, the chance that children at risk will be missed is increased as well.

To be able to give advice as to whether and to whom prevention should be offered, more insight is needed in the way children with and without a family history of asthma react to environmental risk factors as well as the costs and effectiveness of such prevention programs.

The PREVASC program is a research program that focuses on primary prevention of asthma in children. This program has four major research questions. First of all, it is directed to the predictive value of a positive family history of asthma, assessed in the prenatal period by the general practitioner, for the development of respiratory tract and asthma related morbidity. In addition, it investigates whether a multifaceted, prenatally initiated intervention strategy, based on reducing the exposure to indoor and food allergens and environmental tobacco smoke in children with a positive family history of asthma, leads to a decrease in the occurrence of (severe) asthma. Furthermore, it evaluates whether refinement of the prevention strategy leads 
to an increase in the adherence to the prevention program. Finally, the program studies the health-economic benefits of primary prevention of asthma.

In this thesis an overview is given of the different studies of the prenatally started primary prevention program, PREVASC, performed in a primary care setting (chapter 2). Accordingly, the focus will be on the first main research question, i.e. the role of a family history of asthma (chapters 3 to 5) as well as the last main research question of the program, i.e. the health-economic benefits of primary prevention of asthma (chapter 6). The second and third main research questions are/will be presented in the theses of Huub Schönberger, Tanja Maas and Barbara Gijsbers.

The eventual goal of this part of the research program is to study whether family history of asthma can act as predictor for asthma and whether the prevention program is cost-effective. In a program in which prevention is directed against a specified 'high-risk' group, it is important to know the value of this selection instrument. In addition, when a prevention program is directed against certain risk factors, it is important to know whether there is an interaction between these risk factor and the study groups. Finally, in taking a balanced decision about whether and to whom a prevention program, such as PREVASC, should be offered we need information about the effectiveness and the cost-effectiveness of the program.

Family history of asthma is only a phenotypical feature of genetic predisposition. Therefore, with this instrument there is no guarrantee that an infant who is labelled as 'high-risk' is indeed at higher risk of developing asthma. Therefore another genetically driven risk factor assessed for its additive value in the prediction of 'high-risk was added. In chapter 3 we focused on first-degree family history of asthma as a risk factor of the appearance of total IgE in newborns aged 3-5 days.

Several studies have been performed regarding the association between respiratory tract related morbidity and environmental risk factors such as passive smoking, house dust mite, cat and dog allergens and breastfeeding. In most studies interactions between family history and environmental risk factors have not been taken into account. In, chapter 4, the interactive effects of a family history of asthma and the environmental factors passive smoking, house dust mite exposure and breastfeeding are investigated from an etiological perspective.

Day-care attendance has shown to be related to the development of respiratory tract and asthma related morbidity. In chapter 5 the modifying effect of family history on the association between day-care attendance, as a proxy for 
infections, and respiratory tract related morbidity is evaluated from a preventive perspective.

Chapter 6 focuses on the health economic benefits of primary prevention of asthma. In a randomised controlled trial, 222 infants with a positive family history of asthma received intervention whereas 221 infants with a positive family history of asthma served as controls. From a societal perspective it was studied whether the multifaceted, prenatally started intervention strategy of the PREVASC program was cost-effective for the prevention of asthma in highrisk infants during the first two years of life. For the assessment of asthma, a clinical, general practitioner diagnosis of asthma and an epidemiological asthma diagnosis based on a prediction model were compared using nonparametric bootstrap resample methods.

Finally, in chapter 7 the methods, findings and conclusions of the preceding chapters are evaluated. In addition the clinical implications of the findings are discussed and recommendations for future research are given. 


\section{References}

1. Von Mutius E. The burden of childhood asthma Arch Dis Child 2000; 2(suppl2):II2-5.

2. Von Mutius E. Towards prevention. Lancet 1997;350:SII $14-7$.

3. McGeady SJ. Immunocompetence and allergy. Pediatrics 2004;113:1107-13.

4. Soussi-Gounni A, Kontolemos M, Hamid O. J Allergy Clin Immunol 2001;107(4):575-82.

5. Aalberse RC, Platts-Mills TAE. How do we avoid developing allergy: Modifications of the $\mathrm{T}_{\mathrm{H} 2}$ response from a B-cell perspective. J Allergy Clin Immunol 2004;113:983-6.

6. Belkaid Y, Piccirillo CA, Mendez S, Shevah EM, Sacks DL. CD4+CD25+ regulatory T cells control Leishmania major persistence and immunity. Nature 2002;420:502-7.

7. Akdis CA, Blaser K, Akdis M. Genes of tolerance. Allergy 204;59:897-913.

8. Masoli M, Fabian D, Holt S, Beasley R: Global Initiative for asthma (GINA) program. The global burden of asthma: executive summary of theGINA dissemination committee report. Allergy 2004;59(5):469-78.

9. Dirksen WJ, Geijer RMM, de Haan M, de Koning G, Flikweert S, Kolnaar BGM. Astma bij kinderen. NHG-Standaard. Huisarts Wet 1998;41:130-43.

10. The International Study of Asthma and allergies in Childhood (ISAAC) Steering Committee. Worldwide variation in prevalence of symptoms of asthma, allergic rhinoconjunctivitis, and atopic eczema: ISAAC. Lancet 1998;351:1225-32.

11. Eldeirawi K, Persky VW. History of ear infections and prevalence or asthma in a national sample of children aged 2 to 11 years: The third national health and nutrition examination survey, 1988 to 1994 . Chest 2004;125:1685-9.

12. Braun-Fahrlander C, Gassner M, Grize L, Takken-Sahli K, Neu U, Stricker T, Varonier HS, Wuthrich B, Sennhauser FH. No further increase in asthma, hay fever and atopic sensitisation in adolescents living in Switzerland. Eur Respir J 2004;23:407-13.

13. Mommers M, Gielkens-Sijstermans C, Swaen GMH, Schayck CP van. Trends in prevalence of respiratory symptoms and treatment in Dutch children over a 12 year period: results of the fourth consecutive survey. Thorax 2005;60:97-9.

14. Van Schayck CP, Smit HA. The prevalence of asthma in children: a reversing trend. Eur Respir J 2005;26:647-50.

15. Brunekreef B, Smit J, de Jongste J, Neijens H, Gerritsen J, Postma D. The prevention and incidence of asthma and mite allergy (PIAMA) birth cohort study: design and first results. Pediatr Allergy Immunol 2002;13(15):55-60.

16. Martinez FD, Wright AL, Tsussig LM, Holberg CJ, Halonen M, Morgan WJ. Asthma and wheezing in the first six years of life. N Engl J Med 1995;332:133-8.

17. Marsh DG, Neely JD, Breazeale DR, Ghosh B, Freidhoff LR, Ehrlich-Kautzky E, Schou C, Krishnaswamy G, Beaty TH. Linkage analysis of IL4 and other chromosome 5q31.1 markers and total serum immunoglobulin E concentrations. Science 1994;264(5162):1152-6.

18. Bjorksten B. The intrauterine and postnatal environments. J Allergy Clin Immunol 1999;104:1119-27.

19. Austin JB, Selvaraj S, Russell G. Childhood asthma in the highlands of Scotland - Morbidity and school absence. Scott Med J 2004;49:18-21.

20. Vermeire PA, Rabe KF, Soraiano JB, Maier WC. Asthma control and differences in management practices across seven European countries. Respir Med 2002;96:142-9.

21. Merikallio VJ, Mustalahti K, Remes ST, Valovirta EJ, Kaila M. Comparison of quality of life between asthmatic and healthy school children. Pediatr Allergy Immunol 2005;16(4):331-40.

22. Halterman JS, Yoos HL, Conn KM, Callahan PM, Montes G, Neely TL, Szilagyi PG. The impact of childhood asthma on parental quality of life. J Asthma 2004;41(6):645-53.

23. Polder JJ, Meerding WJ, Koopmanschap MA, Bonneux L, Maas PJ van der. Kosten van ziekten in Nederland 1994. Rotterdam: Erasmus Universiteit, instituut Maatschappelijke Gezondheidszorg/instituut voor Medische Technology Assessment, 1997.

24. Burke W, Fesinmeyer M, Reed K, Hampson L, Carlsten C. Family history as a predictor of asthma risk. Am J Prev Med 2003;24:160-9. 
25. Christie GL, Helms PJ, Godden DJ, ross SJ, Friend JAR, Legge JS, Haites NE, Douglas JG. Asthma, wheezy bronchitis, and atopy across two generations. Am J Respir Crit Care Med 1999;159:125-9. 


\section{Chapter 2}

The Primary Prevention of Asthma in Children (PREVASC) Study: Design of a Multifaceted Prevention Program

Sandra Kuiper, Tanja Maas, Constant P. van Schayck, Jean W.M. Muris, Huub J.A.M. Schönberger, Edward Dompeling, Barbara Gijsbers, Chris van Weel, J. André Knottnerus on behalf of the PREVASC group

Pediatr Allergy and Immunol 2005;16(4):321-31 


\section{Abstract}

The PREVASC study addresses the primary prevention of asthma in infants and small children. The objective of this study is to investigate whether a multifaceted prenatally started intervention strategy in infants with a positive family history leads to a decrease in the occurrence of (severe) asthma and whether a refinement of the prevention strategy leads to an increase in the adherence to the prevention program.

The primary prevention program includes house dust mite impermeable bed coverings, education on breastfeeding, hypoallergenic feeding, timing of introduction of solid food, and smoking cessation.

888 Infants were prenatally included. By the time of inclusion the mothers were 3-7 months pregnant. 27 Infants were excluded from the study and 18 dropped out. Of the remaining 843 infants 535 had a positive first-degree family history of asthma (PFH group), whereas a reference group of 308 (162 boys) infants was not predisposed for asthma in the first degree (NFH group). To evaluate the (cost-) effectiveness of the preventive intervention, 222 (118 boys) infants of the PFH group allocated to the intervention group and 221 (112 boys) allocated to a control group are followed-up. The NFH infants serve as controls to evaluate the predictive value of PFH (firstdegree family history of asthma). The infants are followed from the prenatal stage until they reach the age of six years. The remaining $92 \mathrm{PFH}$ infants were included in an optimised randomised clinical adherence trial' (RCAT). Of these 92 infants 45 (20 boys) were allocated to an intervention group and 47 (24 boys) to a control group. Until now all infants have been followed for at least one year. 


\section{Introduction}

Childhood asthma, a chronic disease of the airways, is predominantly newly diagnosed in infants and small children. Asthma is the main cause of school absence, ${ }^{1,2}$ involves high costs and is known to reduce the quality of life of children and their parents. During the last decades there has been a substantial increase in the prevalence of asthma worldwide, ${ }^{3,4}$ which emphasizes the need to prevent its development. It is generally thought that genetic as well as environmental factors are involved in the development of asthma.5, 6 Since it is not yet possible to influence the genetic factors, prevention programs should focus on influencing the environmental factors. There are reasons to believe that the first signs of sensitisation occur already in the prenatal stage by the interaction between the maternal environment and the foetus. ${ }^{7}$ Therefore it is important to start intervention in the prenatal stage. Several primary prevention studies are being performed, and are still in progress. In most primary prevention studies only one (-10 $^{8}$ intervention was tested whereas in others two single interventions with or without a factorial design were tested, ${ }^{11-13}$ which may lead to underestimation of the effect of prevention. To our knowledge there are three multifaceted primary prevention studies, ${ }^{14-16}$ in which several interventions are combined into one program and compared to one other modality, like usual care.

We report on the objectives and the design of the PREVASC (Prevention of Asthma in Children) a research program focussed on primary prevention of asthma in children. The objectives of this program are to estimate the predictive value of a positive family history of asthma assessed in the prenatal period by the general practitioner (GP) for the development of childhood asthma and, to assess the effectiveness of a prenatally started multi-faceted primary prevention program focused on reducing the exposure to indoor- and food allergens and environmental tobacco smoke in children at high-risk of developing asthma. Furthermore it will be assessed whether the duration of the prevention program has any effect on the development of asthma as measured at six years of age and whether optimising the intervention leads to increased adherence. Finally the health-economic benefits of high-risk identification and primary prevention of asthma will be assessed.

\section{Research plan}

\section{General design}

Our study comprised of three parts, one observational cohort and two intervention studies. 
To assess the clinical effectiveness of the PREVASC prevention program, a randomised clinical prevention trial (RCPT) was started in a group of prenatally selected PFH infants. Additionally a cohort of prenatally selected NFH infants was composed for a natural history study, to assess the clinical course of asthma and allergies in PFH and NFH infants and to assess the predictive value of 'a positive family history'. To be able to identify whether (the parents of) the infants were compliant to the prevention program, the adherence to the intervention was evaluated. In addition, to get a better insight into the determinants of adherence and to improve the preventive program, a 'focus' group approach was applied in a subgroup of trial participants. In addition an 'optimised randomised clinical adherence trial' (RCAT) was evaluated in a newly recruited group of prenatally selected infants with a positive family history of asthma. Cost-effectiveness of the prevention program will be studied on the basis of the RCPT, taking adherence aspects and validity of screening into account.

In the participants section a general description will be given of how the participants were included in the study. In the section concerning the intervention studies and the natural history study the outline of both intervention studies and the natural history study will be described.

\section{Participants}

The infants were recruited prenatally when their mothers were in their first two trimesters of pregnancy. The community based recruitment started in January 1997 and continued until February 2002. For the RCPT this was performed by the primary caregivers (GP and midwives) and by advertisements. For the natural history study recruitment was exclusively performed by the GP, whereas for the optimised RCAT recruitment was performed by midwifes and by advertisements. These complementary ways of recruitment were necessary to include 888 participants.

A 'positive family history of asthma' was defined as 'at least one first-degree family member (i.e. the pregnant woman, the biological father of the unborn child or a sibling) suffering from GP registered asthma', whereas a 'negative family history of asthma' was defined as 'absence of GP registered asthma in first-degree family members'. Asthma was defined according to the International Classification of Primary Care (ICPC) ${ }^{17}$ as recurrent episodes of reversible acute bronchial obstruction with wheeze and/or dry cough. This was checked by the GP and screening questionnaires.

For the RCPT, the natural history study and the RCAT, a family was excluded from the study when there was intra-uterine or neonatal death, major language problems, serious birth defects (illness or malformation) and moving abroad. 


\section{Intervention studies}

In the following specific elements of the various study parts are described. Thereafter aspects that relate to all the three study parts are presented together.

\section{Randomised clinical prevention trial}

The goal of this study was to assess the effectiveness of (the duration of) a prenatally started multi-faceted primary prevention program in children at high risk for development of asthma. The study was designed to follow the PFH children until they reach the age of six. By that time lung function measurement can be performed objectively which makes an objective diagnosis of asthma possible.

\section{Recruitment}

In the first part of the study (the period from the prenatal stage until the age of two) 476 pregnant women were included (Figure 2.1) and after randomisation equally divided over two study groups: an intervention group and a control group. 443 Of the descendants could be followed up, 222 (118 boys) of the intervention group and 221 (112 boys) of the control group.

\section{Intervention first part}

The intervention started prenatally in order to reach a low house dust mite and pet allergen exposure level at the time the child was born. In addition, the intervention focussed on avoidance of prenatal and postnatal passive smoking and on avoidance of food allergens postnatal.

House dust mite (HDM) reduction intervention started before the $7^{\text {th }}$ month of pregnancy. This intervention consisted of advice on ventilation and cleaning as well as application of HDM impermeable covers on the parents' and children's bed. To prevent exposure to pet allergens, the advice was given to keep pets outdoors from the $6^{\text {th }}$ month of pregnancy. Smoking intervention consisted of advice on smoking cessation of the mother as early as possible in pregnancy and no smoking of the father as well as the mother in the presence of the baby postnatal. Dietary intervention contained advice on exclusively breastfeeding (or hypo-allergen formula feeding) for at least six months and postponing introduction of solid food until six months after birth. The RCPT control group received usual care, according to the Guidelines of the Dutch College of General Practitioners that include criteria based diagnosis and an initial treatment with short acting bronchodilators and when no adequate asthma control is achieved with a step-up approach with inhaled corticosteroids in increasing dosage. ${ }^{18}$ 


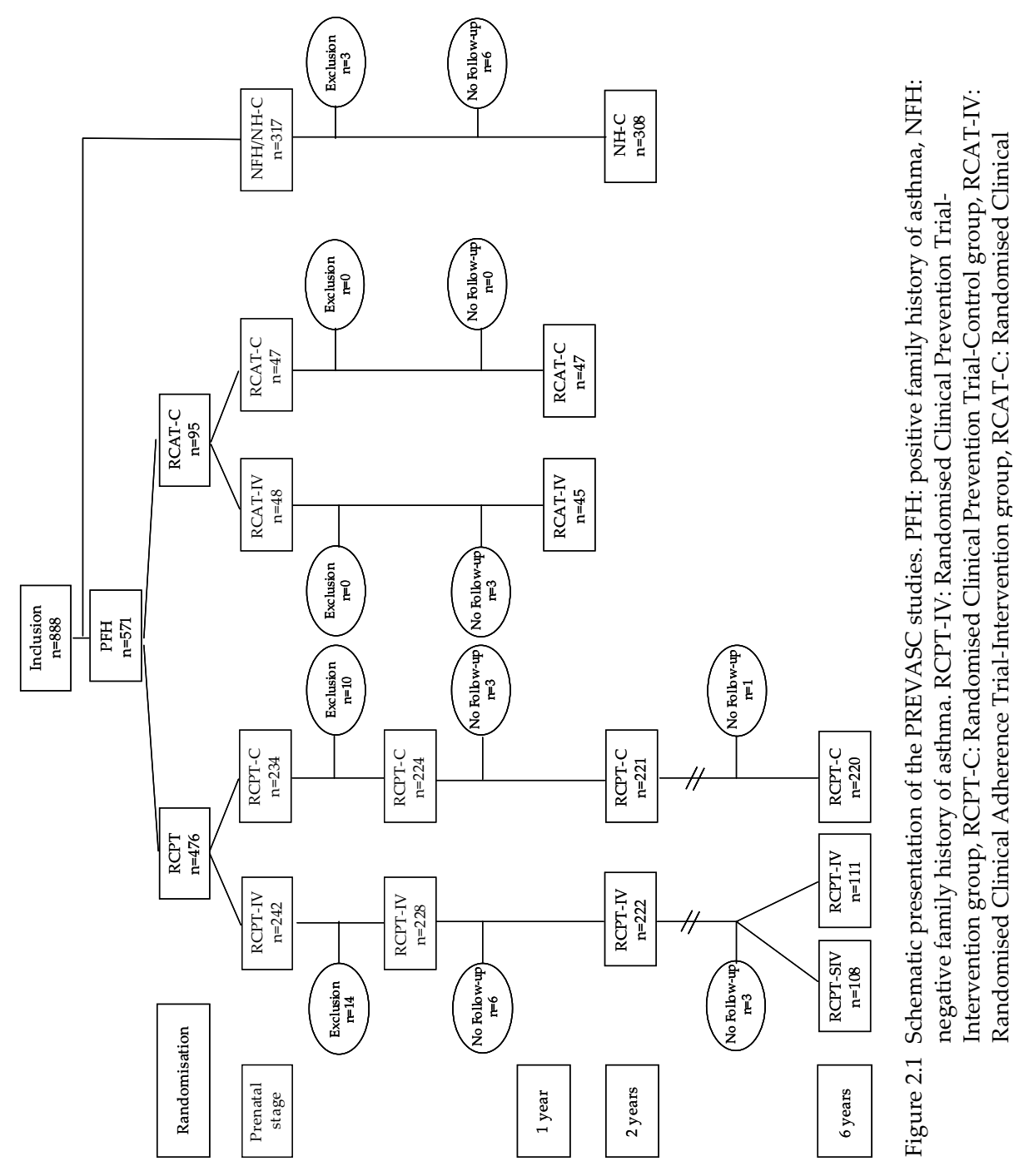




\section{Intervention second part}

In the second part of the study the children are followed from 2-6 years of age. For this part of the study - which is still going on - the children in the original intervention group were randomised again into two groups (Figure 2.1). One group was no longer exposed to advice and HDM impermeable mattress covers (short intervention period). The other group still received an intervention program focused on diminishing allergen and irritant exposure and to keep on using HDM impermeable mattress covers (extended intervention period). The children that participated in the control group in the first part continue to participate in the control group in the second part of the study as well and receive usual care.

\section{Randomised Clinical Adherence Trial}

Eighty-one randomly selected families who participated in the intervention group of the RCPT received an invitation letter for a focus-group interview to investigate which determinants influenced the actual adherence behaviour. For these interviews the stepwise guidelines of van Assema et al. ${ }^{19}$ for conducting a focus-group interview were used.

Recruitment focus groups

43 Households (59 participants) were scheduled to meet at times and locations that might be convenient for the participants. Six groups were mixed as to gender and one group was formed containing only fathers, since fathers may have different opinions and thoughts about breastfeeding and postponement of solid foods, which might be missed in the presence of women.

\section{Focus group observations}

The reasons for the 39 non-respondent households were: interested, but date not convenient $(n=14)$, no time $(n=7)$, location of interview not convenient $(n=3)$, on holiday $(n=2)$, unknown $(n=13)$. No significant differences were found between the participation and no-participation group with respect to level of education, feeding behaviour and family history of asthma.

On the basis of the results of the determinant-analysis, a refined prevention educational program was developed.

Recruitment refined intervention program

In this phase, the RCAT study, 92 families expecting a child at high-risk of developing asthma were selected. 45 Families received intervention and 47 served as controls (Figure 2.1).

\section{Intervention measures}

Educational materials and the educational message to be provided orally by research nurses were refined. The effect of the renewed education on the 
degree of adherence with the advised measures was evaluated in the next phase of this program.

\section{Natural history study}

The goal of this study was to assess the clinical course of asthma and allergies in PFH and NFH children and to assess the predictive value of ' $\mathrm{PFH}^{\text {'. }}$

\section{Recruitment}

For this study 317 pregnant women, without asthma or asthma in the family, were included. 308 (162 boys) of the descendants could be followed up (Figure 2.1).

\section{Clinical follow-up}

The clinical course of symptoms of asthma and allergies over the first two years of life in this cohort was compared with the RCPT control group in order to evaluate the predictive value of a first-degree family history of asthma. The $\mathrm{NFH}$ infants received usual care

\section{Randomisation, withdrawal procedures and blinding}

The women who were recruited by the GP were allocated to the intervention and control group by means of pre-randomisation in clusters, in order to minimize the probability of exchange of information between participants. The clusters were based on the ZIP code of domicile of the participating families in combination with the location of the general practice attended.

Families who were recruited by the GP were screened by the GP. Families who were recruited for the RCPT study by midwives or advertisements completed questionnaires concerning the presence of asthma in their family. Whenever it turned out from the questionnaire that there was no asthma in a ' $\mathrm{PFH}^{\prime}$ family, the GP was contacted. When the GP confirmed the questionnaire outcome, the family was withdrawn from the study. Families who were recruited by midwives or advertisements for the RCAT study were screened by the GP. For the RCPT and the RCAT, blinding for group assignment was performed at family level.

\section{Economical evaluation}

To assess the efficiency of ' $\mathrm{PFH}$ ' identification and the cost-effectiveness of the PREVASC intervention, it will be evaluated whether cost savings (associated with a decrease in (severe) asthma cases and an increase in the quality of life) outweigh the costs of the prevention program. This will be achieved in two steps, by assessing 1 . the cost-effectiveness of the PREVASC intervention among the PFH group, and 2. the cost-effectiveness of the complete PREVASC 
RCPT program including the high-risk identification at the population level. Ad (1): It will be assessed what the PREVASC preventive intervention with its allied costs yields in terms of health outcome and savings concerning direct and indirect health related costs in the PFH group. For this purpose, the clinical course, health outcomes and costs of primary prevention of asthma (PREVASC intervention group) will be compared with the clinical course, health outcomes and costs of usual care (PREVASC control group). To be able to assess the costeffectiveness, information concerning the direct and indirect medical costs, the costs of the prevention program, and the health status of the children will be collected, using information from questionnaires that will be completed by the parents. By use of these questionnaires the use of medical care and products can be measured. This use will be valued against national recommended prices $^{20}$ to be able to determine the costs of care per individual. The health status of the children will be measured using the ISAAC questionnaire as well as the morbidity registration of the GP. When the children have reached the age of six years asthma will objectively be diagnosed, which makes it possible to express asthma as a dichotomous variable. In this way the costs per asthma case prevented can be determined.

Ad (2): By connecting the results ad (1) (the cost-effectiveness of the primary prevention program among the PFH group) to the predictive value of the 'high-risk' identification, the costs of prenatal high-risk identification, the prevalence of a positive family history, and the observed disease course in the absence of intervention in both the PFH control group and the NFH group, the expected cost-effectiveness of the complete PREVASC program at population level will be assessed.

\section{Data collection procedure}

\section{Symptoms/diagnosis}

A positive family history of asthma was determined by the GP and by use of a questionnaire directly at the inclusion. For the RCPT and the 'natural history' study this was re-evaluated at the age of two years. Information on complaints, diagnosis, laboratory tests and medication concerning respiratory morbidity were prospectively registered by the GP at every consultation. Additionally the parents were asked to complete weekly reports, concerning questions about asthma related complaints, OTC medication and asthma related costs, during the first two years of the infants' life and to complete the internationally accepted ISAAC questionnaire ${ }^{21}$ yearly until the age of six (Tables 2.1, 2.2, 2.3). 
Table 2.1 Timing schedule of the measurements of environmental exposures and outcome variables in the RCPT.

\begin{tabular}{|c|c|c|}
\hline Time point & Environmental exposures & Outcome measures \\
\hline $\begin{array}{l}3^{\text {rd }}-5^{\text {th }} \text { month of } \\
\text { pregnancy }\end{array}$ & $\begin{array}{l}\text { - Dust (derp1, canf1, feld1) } \\
\text { - Humidity } \\
\text { - CO }\end{array}$ & \\
\hline $\begin{array}{l}7^{\text {th }}-8^{\text {th }} \text { month of } \\
\text { pregnancy (intervention } \\
\text { group only) }\end{array}$ & $\begin{array}{l}\text { - Humidity } \\
\bullet \mathrm{CO}\end{array}$ & \\
\hline $\begin{array}{l}\text { Weekly from birth } \\
\text { until } 2 \text { years of age }\end{array}$ & $\begin{array}{l}\text { - Type of feeding } \\
\text { - Day-care attendance }\end{array}$ & $\begin{array}{l}\text { - Asthma related complaints } \\
\text { - Health-care consumption } \\
\text { - Absent from work }\end{array}$ \\
\hline $\begin{array}{l}\text { Around } 4 \text { weeks after } \\
\text { birth (intervention group } \\
\text { only) }\end{array}$ & $\begin{array}{l}\bullet \text { Humidity } \\
\bullet \mathrm{CO}\end{array}$ & \\
\hline 3-5 days after birth & & - Total IgE \\
\hline 6 months after birth & - Type of feeding & $\begin{array}{l}\text { - Amount of wheezing episodes in the last } 6 \text { months } \\
\text { - Nightly wheezing in the last } 6 \text { months } \\
\text { - Nocturnal coughing in the last } 6 \text { months } \\
\text { - Doctors diagnosed asthma } \\
\text { - Constitutional eczema } \\
\text { - Food allergy } \\
\text { - Non-viral rhinitis } \\
\text { - Other upper airway infections } \\
\text { - Other lower airway infections } \\
\text { - Dyspnoea }\end{array}$ \\
\hline $\begin{array}{l}\text { 7-9 months after birth } \\
\text { (exactly } 1 \text { year after first } \\
\text { dust sampling) }\end{array}$ & $\begin{array}{l}\text { - Dust (derp1, canf1, feld1) } \\
\text { - Humidity } \\
\text { - CO }\end{array}$ & \\
\hline 1 year after birth & $\begin{array}{l}\text { - Humidity } \\
\text { - CO } \\
\text { - ETS } \\
\text { - Exposure to house dust mite } \\
\text { and animal allergens }\end{array}$ & $\begin{array}{l}\text { - Amount of wheezing episodes in the last } 6 \text { months } \\
\text { - Nightly wheezing in the last } 6 \text { months } \\
\text { - Nocturnal coughing in the last } 6 \text { months } \\
\text { - Specific IgE (derp1, feld1, canf1) } \\
\text { - Doctors diagnosed asthma } \\
\text { - Total IgE } \\
\text { - Constitutional eczema } \\
\text { - Food allergy } \\
\text { - Non-viral rhinitis } \\
\text { - Other upper airway infections } \\
\text { - Other lower airway infections } \\
\text { - Dyspnoea }\end{array}$ \\
\hline 2 years after birth & $\begin{array}{l}\text { - Humidity } \\
\text { - } \mathrm{CO}\end{array}$ & $\begin{array}{l}\text { - Amount of wheezing episodes in the last year } \\
\text { - Nightly wheezing in the last year } \\
\text { - Nocturnal coughing in the last year } \\
\text { - Specific IgE (derp1, feld1, canf1) } \\
\text { - Doctors diagnosed asthma } \\
\text { - Total IgE } \\
\text { - Constitutional eczema in the last year } \\
\text { - Food allergy in the last year } \\
\text { - Non-viral rhinitis in the last year } \\
\text { - Other upper airway infections } \\
\text { - Other lower airway infections } \\
\text { - Dyspnoea }\end{array}$ \\
\hline
\end{tabular}




\begin{tabular}{|c|c|c|}
\hline 3 years after birth & $\begin{array}{l}\text { - ETS } \\
\text { - Allergen exposure }\end{array}$ & $\begin{array}{l}\text { - Amount of wheezing episodes in the last year } \\
\text { - Nightly wheezing in the last year } \\
\text { - Nocturnal coughing in the last year } \\
\text { - Doctors diagnosed asthma } \\
\text { - Doctors diagnosed cows milk allergy } \\
\text { - Other food related allergies diagnosed by a doctor } \\
\text { - Doctors diagnosed inhalation allergies } \\
\text { - Non-viral rhinitis in the last year } \\
\text { - Other upper airway infections in the last year } \\
\text { - Other lower airway infections in the last year } \\
\text { - Dyspnoea in the last year }\end{array}$ \\
\hline 4 years after birth & $\begin{array}{l}\text { - Dust (derp1, canf1, feld1) } \\
\text { - Humidity } \\
\text { - CO } \\
\text { - ETS }\end{array}$ & $\begin{array}{l}\text { - Tidal airway resistance (microRint) } \\
\text { - Amount of wheezing episodes in the last year } \\
\text { - Nightly wheezing in the last year } \\
\text { - Nocturnal coughing in the last year } \\
\text { - Specific IgE (derp1, feld1, canf1) } \\
\text { - Doctors diagnosed asthma } \\
\text { - Doctors diagnosed cows milk allergy } \\
\text { - Other food related allergies diagnosed by a doctor } \\
\text { - Doctors diagnosed inhalation allergies } \\
\text { - Total IgE } \\
\text { - Non-viral rhinitis in the last year } \\
\text { - Other upper airway infections in the last year } \\
\text { - Other lower airway infections in the last year } \\
\text { - Dyspnoea in the last year }\end{array}$ \\
\hline 5 years after birth & $\begin{array}{l}\text { - ETS } \\
\text { - Allergen exposure }\end{array}$ & $\begin{array}{l}\text { - Amount of wheezing episodes in the last year } \\
\text { - Nightly wheezing in the last year } \\
\text { - Nocturnal coughing in the last year } \\
\text { - Doctors diagnosed asthma } \\
\text { - Doctors diagnosed cows milk allergy } \\
\text { - Other food related allergies diagnosed by a doctor } \\
\text { - Doctors diagnosed inhalation allergies } \\
\text { - Non-viral rhinitis in the last year } \\
\text { - Other upper airway infections in the last year } \\
\text { - Other lower airway infections in the last year } \\
\text { - Dyspnoea in the last year }\end{array}$ \\
\hline 6 years after birth & $\begin{array}{l}\text { - ETS } \\
\text { - Allergen exposure }\end{array}$ & $\begin{array}{l}\text { - Asthma } \\
\text { - Specific IgE (derp1, feld1, canf1) }\end{array}$ \\
\hline
\end{tabular}

\section{Mite collection and humidity}

Dust samples were collected (Table 2.1) to measure the compliance with the intervention advice in the intervention group (RCPT and RCAT) and to correlate the intensity of exposure to inhalant allergens with respiratory morbidity (RCPT, RCAT and natural history study) and to evaluate the validity of using the NFH children as control group. The collection was performed in a standardized manner. Samples were taken, using a vacuum cleaner (Bosch BSA1100 1300 Watt) with a special cassette (ALK Abello) containing a Whatman GF/F $70 \mathrm{~mm}$ filter, from the living room floor $\left(2 \times 1 \mathrm{~m}^{2}\right)$, the parents' 
mattress $\left(1 \mathrm{~m}^{2}\right)$ and the mattress of the baby (whole mattress). The samples were kept on $4^{\circ} \mathrm{C}$ until they were analysed for mite, cat and dog allergens by use of ELISA.22-24 Humidity was measured by use of a hygrometer in the parents' bedroom and, when in use, the infants' bedroom.

Table 2.2 Timing schedule of the measurements of environmental exposures and outcome variables in the Natural history study.

\begin{tabular}{|c|c|c|}
\hline Timepoint & Environmental exposures & Primary (1) and secondary (2) outcome measures \\
\hline \multicolumn{2}{|c|}{$\begin{array}{l}\text { Weekly from birth until } 2 \bullet \text { Day-care attendance } \\
\text { years of age }\end{array}$} & $\begin{array}{l}\text { - Asthma related complaints } \\
\text { - Health-care consumption } \\
\text { - Absent from work }\end{array}$ \\
\hline 3-5 days after birth & & - Total IgE \\
\hline 6 months after birth & - Type of feeding & $\begin{array}{l}\text { - Amount of wheezing episodes in the last } 6 \text { months } \\
\text { - Nightly wheezing in the last } 6 \text { months } \\
\text { - Nocturnal coughing in the last } 6 \text { months } \\
\text { - Doctors diagnosed asthma } \\
\text { - Constitutional eczema in the last } 6 \text { months } \\
\text { - Food allergy in the last } 6 \text { months } \\
\text { - Non-viral rhinitis in the last } 6 \text { months } \\
\text { - Other upper airway infections } \\
\text { - Other lower airway infections } \\
\text { - Dyspnoea }\end{array}$ \\
\hline 7-9 months after birth & - Dust (derp1, canf1, feld1) & \\
\hline 1 year after birth & $\begin{array}{l}\text { - ETS } \\
\text { - Exposure to house dust mite } \\
\text { and animal allergens }\end{array}$ & $\begin{array}{l}\text { - Amount of wheezing episodes in the last } 6 \text { months } \\
\text { - Nightly wheezing in the last } 6 \text { months } \\
\text { - Nocturnal coughing in the last } 6 \text { months } \\
\text { - Doctors diagnosed asthma } \\
\text { - Constitutional eczema in the last } 6 \text { months } \\
\text { - Food allergy in the last } 6 \text { months } \\
\text { - Non-viral rhinitis in the last } 6 \text { months } \\
\text { - Other upper airway infections } \\
\text { - Other lower airway infections } \\
\text { - Dyspnoea }\end{array}$ \\
\hline 2 years after birth & & $\begin{array}{l}\text { - Amount of wheezing episodes in the last year } \\
\text { - Nightly wheezing in the last year } \\
\text { - Nocturnal coughing in the last year } \\
\text { - Doctors diagnosed asthma } \\
\text { - Constitutional eczema in the last year } \\
\text { - Food allergy in the last year } \\
\text { - Non-viral rhinitis in the last year } \\
\text { - Other upper airway infections } \\
\text { - Other lower airway infections } \\
\text { - Dyspnoea }\end{array}$ \\
\hline
\end{tabular}

\section{Type of feeding and ETS exposure}

The parents completed questionnaires concerning the type of feeding, environmental allergen exposure and environmental tobacco smoke (ETS) exposure. 
Table 2.3 Timing schedule of the measurements of environmental exposures and outcome variables in the RCAT.

\begin{tabular}{|c|c|c|}
\hline Timepoint & Environmental exposures & Primary and secondary outcome measures \\
\hline $3^{\text {rd }}$ month of pregnancy & $\begin{array}{l}\text { - Dust (derp1) } \\
\text { - Humidity } \\
\text { - CO }\end{array}$ & \\
\hline $7^{\text {th }}$ month of pregnancy & $\begin{array}{l}- \text { Humidity } \\
\text { - } \mathrm{CO}\end{array}$ & \\
\hline 2-3 weeks after birth & $\begin{array}{l}- \text { Humidity } \\
\text { - } \mathrm{CO}\end{array}$ & - Compliance with dietary advices \\
\hline 6 months after birth & $\begin{array}{l}\text { - Dust (derp1) } \\
\text { - Humidity } \\
\text { - CO }\end{array}$ & $\begin{array}{l}\text { - Compliance with dietary advices } \\
\text { - Amount of wheezing episodes in the last } 6 \text { months } \\
\text { - Nightly wheezing in the last } 6 \text { months } \\
\text { - Nocturnal coughing in the last } 6 \text { months } \\
\text { - Doctors diagnosed asthma } \\
\text { - Constitutional eczema in the last } 6 \text { months } \\
\text { - Non-viral rhinitis in the last } 6 \text { months } \\
\text { - Other upper airway infections } \\
\text { - Other lower airway infections }\end{array}$ \\
\hline 1 year after birth & $\begin{array}{l}\text { - Humidity } \\
\text { - } \mathrm{CO}\end{array}$ & $\begin{array}{l}\text { - Amount of wheezing episodes in the last } 6 \text { months } \\
\text { - Nightly wheezing in the last } 6 \text { months } \\
\text { - Nocturnal coughing in the last } 6 \text { months } \\
\text { - Doctors diagnosed asthma } \\
\text { - Constitutional eczema in the last } 6 \text { months } \\
\text { - Non-viral rhinitis in the last } 6 \text { months } \\
\text { - Other upper airway infections } \\
\text { - Other lower airway infections }\end{array}$ \\
\hline
\end{tabular}

$\operatorname{Ig} E$

Blood samples were collected in the RCPT and natural history group to measure the concentration of total immunoglobulin E (IgE). IgE was analysed using the method of Aalberse et al. ${ }^{25}$

\section{Carbon Monoxide}

To study the compliance with the smoking advice in the intervention group, to detect spontaneous smoking cessation by the mother during pregnancy in the control groups and to correlate the intensity of exposure to smoke with respiratory morbidity, Carbon Monoxide was measured in expired air.

\section{Tidal airway resistance and lung function}

To assess the tidal airway resistance by means of an interrupter technique, microRint measurements are performed when the children are four and six years of age, while lung function (FEV1, FVC), reversibility on $\beta 2$-mimetics (change in FEV1 after $400 \mu \mathrm{g}$ salbutamol through a spacer) and bronchial responsiveness to increasing doses of histamine (PC20) will be assessed when the children reach the age of six years. 


\section{Statistical aspects}

\section{Power calculation}

The power calculation of the RCPT study was based on a study of Saarinen et al., ${ }^{26}$ in which it was shown that breastfeeding as preventive measure, in a comparable group of infants as in the RCPT, resulted in a 30\% reduction in the development of asthma. This percentage was chosen in the RCPT as the minimum clinically relevant difference. A minimum amount of 194 infants in the intervention as well as in the control group was required to reduce the asthma incidence with at least $30 \%$ (taking a type I error of 0.05 and a power of 0.80 into account).

The power calculation of the RCAT was based on the number of parents required to measure the compliance of the parents with the optimised prevention program. Based on literature studies ${ }^{27}$ an effect-size of 0.46 was expected. With a minimum of 38 participants in each group a power of 0.80 could be reached (taking a type I error of 0.05 and a drop out of at the most $18 \%$ into account).

The power calculation of the natural history study was based on a sample size that would be large enough to show a statistically significant difference, between the PFH and NFH groups, in the development of asthma at six years of age. ${ }^{28}$ An odds ratio of at least two was assumed for the association of a positive family history of asthma with the risk to develop asthma in descendants. Taking a cumulative asthma incidence of $10 \%$, a maximum drop out of $10 \%$ and a type I error of 0.05 into account a power of 0.80 could be reached with an addition of $308 \mathrm{NFH}$ infants.

\section{Data analysis}

In the RCPT compliance will be evaluated in terms of reduced exposure to $\mathrm{HDM}$, cat and dog allergens as well as reduced smoking and increased breastfeeding.

Differences in proportions between groups in bi-variate analyses will be tested with the $\chi^{2}$ test. Differences in means for continuous normally distributed variables are analysed using the Student's t-test. Multiple logistic and linear regression techniques are used for multivariate analyses with a fixed follow-up time, while Cox proportion hazard analyses will be performed when the follow-up time is variable.

Concerning the cost-effectiveness one way sensitivity analyses regarding important assumptions will be performed. In addition, statistical uncertainty regarding the cost-effectiveness estimates will be assessed using non parametric bootstrap resample methods. By means of the analysis of effect 
modification it will be evaluated whether the effect differs between subgroups. For most analyses a p-value smaller than 0.05 is considered as significant.

Statistical analyses are performed using the Statistical Package for the Social Sciences (SPSS) version 10.0.

\section{Ethics approval and informed consent}

Ethical approval for this study was obtained from the ethics committees of the participating institutes. All participants gave written, informed consent.

\section{Preliminary results of the RCPT}

Preliminary results indicate that infants in the intervention group were significantly more breastfed $(\mathrm{P}=0.001)$ and/or received significantly more hypoallergenic formula feeding than infants in the control group. The first intake of solid food was significantly more often postponed to the age of six months in the intervention group compared to the control group ( $\mathrm{Pp}=0.001)$. No difference was found in the intervention compared to the control group concerning the exposure to tobacco smoke. Measurement of environmental exposure to house dust mite, cat and dog allergens was performed during pregnancy (baseline) and exactly one year later. One year after baseline measurements the concentration of house dust mite, cat and dog allergens, measured at the living room floor (except for dog allergens), the mattress of the parents and the mattress of the baby, were statistically significant decreased in the intervention group, but not in the control group. ${ }^{29}$

\section{Discussion}

The PREVASC study is a longitudinal prospective birth cohort study with its focus on the development of a primary prevention program for asthma in children. The main goal of the PREVASC study is to assess the effectiveness of (the duration of) an intervention program focussed on reducing the exposure to indoor and food allergens and environmental tobacco smoke in children at high-risk of developing asthma. This is investigated in a RCPT. To be able to define to what extent a positive family history of asthma is predictive for the development of asthma, a natural history study was started with PFH and NFH children. Whether the participants are compliant to the prevention program and whether optimising the intervention leads to an increase in adherence is investigated in a RCAT. The health-economic benefits of 'highrisk' identification and primary prevention of asthma will be assessed on the basis of the RCPT, taking compliance aspects and validity of screening into account. 
There are few prospective birth cohort studies in which the effect of primary prevention of asthma is studied. ${ }^{8-16}$ Most of these studies focus on one or two preventive measures. ${ }^{8-13}$ To our knowledge there are three multi-facetted intervention studies, the study of Halken et al., ${ }^{14}$ the CAAP ${ }^{15}$ study and SPACE ${ }^{16}$ study. The PREVASC study differs from these studies in several aspects. In contrast to these studies a NFH group was included in the PREVASC study, which enables an estimation of the high-risk prediction and in addition facilitates the evaluation of the external validity of the primary prevention study. In the PREVASC study ' $\mathrm{PFH}^{\prime}$ was defined as presence of asthma in $1^{\text {st }}$ degree family members. This definition was chosen since asthma in $1^{\text {st }}$ degree family members is expected to be the most predictive risk factor for the development of asthma in descendants ${ }^{30}$ although this is often based on retrospective and cross-sectional data. We expect the strongest effect of the intervention program in children with a positive family history of asthma. Concerning the intervention program, in the PREVASC study the dietary advices for the baby were exclusively breastfeeding for at least six months as well as delay of solid food until six months of age. The mother was not advised to follow a diet. Since the goal of the prevention program was that it should be easy to implement into practice, prevention was based on easily applicable intervention measures. Recruitment was performed predominantly by the GP. The Dutch health care system is organised in such a way that the GP keeps complete medical records of all registered families which makes the GP the most appropriate health care worker to assess whether an unborn child is at high-risk of developing future asthma.

There are however some limitations to our study. Although there is a welldefined cleaning regimen some exposure could not be avoided. However by keeping the cleaning regimen close to daily practice, the HDM reduction that will be reached is realistic and can easily be obtained. In general, we expect that people will better adhere to the intervention program when the intervention is as close to daily practice as possible. In studying a multi-faceted intervention strategy it is impossible to directly investigate the effectiveness of all single intervention measures in all possible combinations (like would be done in a factorial design), since this should result in a sample size that is far too large for in one trial. Moreover synergistic effects can be missed in comparing single interventions only, while the most pronounced clinical effect possible should be expected from a combined intervention. Finally the GP and the parents could not be blinded to the intervention, which might result into classification bias and reporting bias with respect to medical records and questionnaires in relation to health outcome. Therefore it is important to follow the cohort until the children have reached the age of six years, at which age lung function measurement can be performed. 


\section{References}

1. Austin JB, Selvaraj S, Russell G. Childhood asthma in the highlands of Scotland - Morbidity and school absence. Scott Med J 2004;49(1):18-21

2. Vermeire PA, Rabe KF, Soraiano JB, Maier WC. Asthma control and differences in management practices across seven European countries. Respir Med 2002;96(3):142-9.

3. Peat JK, van den Berg RH, Green WF, Mellis CM, Leeder SR, Woolcock AJ. Changing prevalence of asthma in Australian children. BMJ 1994:308:1591-6.

4. Rona RJ, Chin S, Burney PG. Trends in the prevalence of asthma in Scottish and English primary school children 1982-92. Thorax 1995:50:992-3.

5. Heinzmann A, Deichmann KA. Genes for atopy and asthma. Curr Opinion Allergy Clin Immunol 2001:1(5):387-92.

6. Von Mutius E. The environmental predictors of allergic disease. J Allergy Clin Immunol 2000:105:9-19.

7. Warner JA, Jones CA, Jones AC, Warner JO. Prenatal origins of allergic disease. J All Clin Immunol 2000:105:S493-6.

8. Zeiger RS, Heller S, Mellon MH. Effect of combined maternal and infant food-allergen avoidance on development of atopy in early infancy: a randomized study. J All Clin Immunol 1989:84:72-89.

9. Custovic A, Simpson BM, Murray CS, Lowe L, Woodcock A. The national asthma campaign Manchester asthma and allergy study. J All Clin Immunol 2000:105:252-8.

10. Brunekreef B, Smit J, de Jongste J et al. The prevention and incidence of asthma and mite allergy (PIAMA) birth cohort study: Design and first results. Pediatr Allergy Immunol 2002:13(Suppl. 15):55-60.

11. Arshad SH, Matthews S, Gant C, Hide DW. Effect of allergen avoidance on allergic disorders in infancy. Lancet 1992:339:1439-97.

12. Marini A, Agosti M, Motta G, Mosca F. Effects of a dietary and environmental prevention programme on the incidence of allergic symptoms in high atopic risk infants: three years' follow-up. Acta Paediatr Suppl 1996:414:1-21.

13. Mihrshahi S, Peat JK, Webb K et al. The Childhood Asthma Prevention Study (CAPS): Design and research protocol of a randomised trial for the primary prevention of asthma. Control Clin Trials 2001:22:333-54.

14. Halken S, Host A, Hansen LG, Osterballe O. Effect of an allergy prevention programme on incidence of atopic symptoms in infancy. A prospective study of 159 "high-risk" infants. Allergy 1992:47:545-53.

15. Chan-Yeung M, Manfreda J, Kimich-ward H, Ferguson A, Watson W, Becker A. A Randomized Controlled Study on the Effectiveness of a Multifaceted Intervention Program in the Primary Prevention of Asthma in High-Risk Infants. Arch Pediatr Adolesc Med 2000:154:657-63.

16. Halmerbauer G, Gartner C, Schierl M et al. Study on the prevention of allergy in children in Europe (SPACE): allergic sensitization in children at 1 year of age in a controlled trial of allergen avoidance from birth. Pediatr Allergy Immunol 2002:13 (Suppl. 15):47-54.

17. The WONCA classification committee. ICPC-2. International Classification of Primary Care. Oxford University Press, 1998.

18. Dirksen WJ, Geijer RMM, de Haan M, de Koning G, Flikweert S, Kolnaar BGM. Astma bij kinderen. NHG-Standaard. Huisarts en Wetenschap 1998:41:130-43.

19. Van Assema P, Mesters I, Kok G. Het focusgroep-interview: een stappenplan [The focus group interview: stepwise guidelines]. Tijdschrift Sociale Gezondheidszorg. 1992:70:431-7.

20. Oostenbrink JB, Koopmanschap MA, Rutten FFH. Handleiding voor kostenonderzoek. Methoden en richtlijnprijzen voor economische evaluaties in de gezondheidszorg. Amstelveen: College voor zorgverzekeringen: 2000.

21. Asher MI, Keil U, Anderson HR et al. International study of asthma and allergies in childhood (ISAAC): rationale and methods. Eur Respir J 1995:8:483-91. 
22. Van der Heide S, van Aalderen WM, Kauffman HF, Dubois AE, de Monchy JG. Clinical effects of air cleaners in homes of asthmatic children sensitized to pet allergens. J Allergy Clin Immunol 1999:104(2 Pt 1):447-51.

23. Luczynska CM, Arruda LK, Platts-Mills TA, Miller JD, Lopez M, Chapman MD. A two-site monoclonal antibody ELISA for the quantification of the major Dermatophagoides spp. allergens, Der p I and Der f I. J Immunol Methods 1989:118(2):227-35.

24. Ingram JM, Sporik R, Rose G, Honsinger R, Chapman MD, Platts-Mills TA. Quantitative assessment of exposure to $\operatorname{dog}(\mathrm{Can} \mathrm{f} 1$ ) and cat (Fel d 1) allergens: relation to sensitization and asthma among children living in Los Alamos, New Mexico. J Allergy Clin Immunol 1995:96(4):449-56.

25. Aalberse RC, Koshte V, Clemens JG. Immunoglobulin E antibodies that crossreact with vegetable foods, pollen en hymenoptera venom. J Allergy Clin Immunol 1981:68 (5):356-64.

26. Saarinen UM, Kajosaari M. Breastfeeding as prophylaxis against atopic disease: prospective follow-up study until 17 years old. Lancet 1995;346:1065-9.

27. Kok G, van den Borne B, Mullen PD. Effectiveness of health education and health promotion: meta-analyses of effect studies and determinants of effectiveness 1997;30:19-27.

28. Martinez FD, Wright AL, Taussig LM, Holberg CJ, Halonen M, Morgan WJ. Asthma and wheezing in the first six years of life. New Engl J Med 1995;332:133-8.

29. Schönberger HJAM, Maas T, Dompeling E, Knottnerus JA, van Weel C, van Schayck CP. Compliance of asthmatic families with a primary prevention programme of asthma and effectiveness of measures to reduce inhalant allergens - a randomised trial. Clin Exp Allergy 2004;34(7): 1024-31.

30. Burke W, Fesinmeyer M, Reed K, Hampson L, Carlsten Ch. Family history as a predictor of asthma risk. Am J Prev Med 2003:24(2):160-9.

31. Schönberger HJAM, van Schayck CP. Prevention of asthma in genetically predisposed children in primary care - from clinical efficacy to a feasible intervention programme. Clin Exp Allergy 1998:28:1325-31. 


\section{Chapter 3}

\section{Association between a positive family history of asthma and atopy (IgE) in newborns}

Sandra Kuiper, Jean W.M. Muris, Edward Dompeling, Huub J.A.M. Schönberger, Constant P. van Schayck, Geertjan Wesseling, J. André Knottnerus

Published as: Association between first-degree familial predisposition of asthma and atopy $(\mathrm{IgE})$ in newborns. Clin Exp Allergy 2006;36:594-601 


\section{Abstract}

Background

It is generally thought that infants with a positive family history of asthma are at higher risk of developing asthma than infants without this predisposition.

Objective

To investigate whether there is an association between being at high-risk for developing asthma and increased level of total $\operatorname{IgE}$ in newborns and whether total $\operatorname{IgE}$ is influenced by gender, family size, birth season, maternal smoking, birth weight, gestational age and maternal diet.

Methods

221 infants with a positive family history (PFH) and 308 infants with a negative family history (NFH) were prenatally selected in a five-year period. Three to five days after birth, total IgE was measured in capillary heel blood.

Results

Data on total IgE and first-degree family history were available for $170 \mathrm{PFH}$ and $300 \mathrm{NFH}$ infants. There was a statistically significant relationship between PFH (maternal asthma) and increased levels of total IgE in newborns [total IgE cut-off levels: 0.6-0.9 IU/ml (OR=2.1, 95\% C.I.: 1.2-3.7 to 3.0, 95\% C.I.: 1.5-5.9)], between being born in autumn and increased levels of total IgE in newborns [total IgE cut-off levels: $0.5-0.6 \mathrm{IU} / \mathrm{ml}(\mathrm{OR}=2.5,95 \%$ C.I.: $1.2-5.1$ to $2.595 \%$ C.I.: $1.2-5.4)$ ] and between maternal vitamin supplements intake and decreased levels of total IgE in newborns [total IgE cutoff level: $0.9 \mathrm{IU} / \mathrm{ml}(\mathrm{OR}=0.5,95 \%$ C.I.: 0.3-1.0)]. There was no interaction between the effects of maternal asthma and birth season on total IgE, as well as between the effects of maternal asthma and maternal vitamin supplements intake. Gender, family size, maternal smoking, birth weight and gestational age did not influence the associations.

\section{Conclusion}

A positive family history of asthma (maternal asthma) and birth season are positively associated with the presence of increased levels of total IgE at birth, while maternal vitamin supplements intake is negatively associated with the presence of total IgE at birth. 


\section{Introduction}

Asthma is a common chronic disease in childhood and is predominantly newly diagnosed in infants and small children. The prevalence of asthma is high ${ }^{1,2}$ although there are large variations throughout the world. ${ }^{3}$

The development of asthma is partly determined by genetic factors, which suggests that a family history of asthma is a possible risk factor for future asthma. Another factor that is at least partly determined by genetic factors is IgE. The foetus synthesizes $\operatorname{IgE}$ already from the $11^{\text {th }}$ week of gestation. ${ }^{4}$ Moreover, IgE production has been shown to differ between men and women $^{5-9}$ as well as between different races. ${ }^{10}$ In the present study we investigate whether infants with a positive family history of asthma are more often born with increased levels of IgE than infants with a negative family history of asthma.

Several studies have been performed in this field. However, in most studies family history was determined after the study group was selected or after the baby was born using questionnaires that were completed by the parents ${ }^{10-15}$ instead of a physician, which does not exclude possible recall bias. Also in most cases the effect of a first-degree family history of atopy instead of a first-degree family history of asthma was studied.10-12,14 Some of the studies showed an association between a first-degree family history of atopy and newborn IgE.10-14 One study failed to do so. ${ }^{13}$ Johnson $^{15}$ and Kaan ${ }^{16}$ showed in their studies an association between newborn $\mathrm{IgE}$ and maternal asthma. However in the study of Johnson no multivariable adjustment was made for potential confounders, while in the study of Kaan a control group (of infants with a negative firstdegree family history of asthma) was lacking.

Furthermore the presence of newborn IgE seems to be influenced by other factors like gender, ${ }^{9,12,13,15-19}$ birth season, ${ }^{12,16-18,20,21}$ ethnicity, ${ }^{10,14,16,18}$ prenatal parental smoking, , $2,16,18,22-24$ gestational age, ${ }^{12,13,15,17,20}$ birth weight ${ }^{12,15,17}$ and possibly maternal diet during pregnancy ${ }^{25-27}$ that are not taken completely into account in most studies.

In the present study the general practitioner (GP) determined family history of asthma since, in the Netherlands in most cases, all family members share the same physician and the GP registers prospectively whether a family member has asthma. Therefore it was expected that the GP had a comprehensive overview of asthma in a family. Additional to other studies in this field, in this study the effect of a positive family history of asthma on newborn total $\operatorname{IgE}$ (from capillary heel blood) will be assessed by comparing a PFH group with a NFH group. 


\section{Methods}

\section{Recruitment of subjects}

A detailed description of recruitment of participants is given elsewhere.28 Briefly, in a period of 5 years (1997-2002), 793 infants, from 3-7 months pregnant women, were prenatally included in a Dutch primary care setting, for a randomised clinical prevention trial (RCPT) and a natural history study. Recruitment took place in primary care (RCPT and natural history study) and by advertisements (RCPT). From the 793 infants, 27 were excluded because of intra-uterine neonatal death, major language problems in the family, serious birth defects or moving abroad. Fifteen infants were lost to follow-up. 443 Infants had a first-degree family history of asthma (PFH group) and participated in the RCPT. 222 Infants from the RCPT were allocated to an intervention group (not discussed in this paper) ${ }^{28}$ whereas the other 221 of the control group, as well as 308 infants without a first-degree family history of asthma (NFH group), received usual care according to the Guideline of the Dutch College of General Practitioners. ${ }^{29}$ According to these guidelines children with a symptom-based diagnosis receive an initial treatment with short acting bronchodilators and, when no adequate asthma control is achieved, a step-up approach with inhaled corticosteroids in increasing dosage. Fifty-five infants dropped out because mothers refused newborns' blood sampling $(n=11)$ or the baby's blood sample was too small for analysis $(n=44)$. Four infants dropped out because it was not clear which first-degree family member(s) had asthma. For the analysis complete data on total IgE and firstdegree family history of asthma were available for $170 \mathrm{PFH}$ and $300 \mathrm{NFH}$ infants. From the 470 infants that were left for the analyses, information on prenatal maternal smoking was lacking in 12 infants (seven PFH infants and five NFH infants) and information concerning maternal intake of vitamin supplements during pregnancy was lacking in five infants (five PFH infants). From six infants information concerning prenatal maternal smoking as well as maternal intake of vitamin supplements during pregnancy (3 PFH infants and $3 \mathrm{NFH}$ infants) was missing. These infants were included in the bivariate analyses, but excluded from the multiple logistic regression analyses.

' $\mathrm{PFH}^{\prime}$ (first-degree family history of asthma) was defined in our study as 'at least one first-degree family member (i.e. the pregnant woman, the biological father of the unborn child or an older sibling) suffering from general practitioner (GP) registered asthma', whereas ' $\mathrm{NFH}^{\prime}$ was defined as 'absence of GP registered asthma in family members. ${ }^{28}$ The group of infants who had a positive family history of maternal asthma only or maternal asthma as well as asthma in one or more other first-degree family members, were labelled as the maternal asthma group. The group of infants who had a positive family history 
of 'asthma in first-degree family members', in which the mother was not included were labelled as the paternal and/or sibling asthma group.

Asthma was defined according to the International Classification of Primary Care (ICPC) $)^{30}$ as recurrent episodes of reversible acute bronchial obstruction with wheeze and/or dry cough.

\section{Total IgE measurements}

Between 3 and 5 days postpartum, blood samples were collected on a filter paper by use of a heel prick to measure the concentration of total IgE. The analysis of total IgE was performed according to the method of Stapel et al. ${ }^{31}$ In brief, total IgE was determined with an immunoradiometric assay. Absorbed material was cut and eluted by incubation with PBS-T (PBS/Tween-20 (0.1\% $\mathrm{v} / \mathrm{v})$ ) for 16 hours under constant rotation. Eluates were separated from filter paper by centrifugation. Determination of total IgE in eluted blood spots was performed using Sepharose-immobilized reagents and ${ }^{125}$ I-labeled anti-IgE, raised in sheep. Test results were expressed in IU/ml (1 IU representing approximately $2.4 \mathrm{ng}$ of total $\mathrm{IgE}$ ).

The detection limit of the assay was (depending on the size of the blood spot) $0.2 \mathrm{IU} / \mathrm{ml}$ and the cut-off levels chosen for elevated total IgE were 0.5, 0.6, 0.7, 0.8 and $0.9 \mathrm{IU} / \mathrm{ml}$.

\section{Potential confounders and effect modifiers}

Number of siblings was documented at inclusion. Gender, birth season, birth weight and gestational age were registered at the moment the infant was born. Prenatal smoking by the mother was registered by use of a questionnaire after the infant was born.

Information concerning maternal intake of vitamin supplements during pregnancy was collected by use of a questionnaire, which was completed by the mother when the infant was six months of age. With this questionnaire information was obtained concerning the intake of several dietary products like milk, eggs, fish, fruit and vitamin supplements during pregnancy. The questionnaire contained 16 items. Mothers where asked, whether they had consumed more, equal or less of the questioned products during their pregnancy than before their pregnancy.

\section{Statistical methods}

To get an impression of the distribution of total IgE, a scatter plot was generated for the PFH and NFH group. To be able to generate a scatter plot, all values that were below the detection limit were set at $0.01 \mathrm{IU} / \mathrm{ml}$. Mann- 
Whitney $U$ test was performed to compare the median total $\operatorname{IgE}$ values in the PFH and NFH groups.

As the total IgE levels were not normally distributed, even after logarithmic transformation, the remaining analyses were carried out with the total IgE level dichotomised at different cut-off levels. The $\chi^{2}$-test and Student's t-test were used to examine the bivariate relationships of (the presence or absence of) firstdegree family history of asthma with the potential confounders and/or effect modifiers. These tests were also used to examine the bivariate relationships between the dependent variable total $\operatorname{IgE}$ and the independent variable firstdegree family history of asthma as well as the potential confounders and/or effect modifiers gender, family size, birth season, prenatal smoking by the mother, birth weight, pregnancy duration and maternal diet during pregnancy. In a backward multiple logistic regression analysis the simultaneous contributions of the independent variables to the presence of total IgE 3-5 days postpartum were evaluated as follows: first, all variables that could potentially act as confounder were entered in the model. Then linearity was checked for birth weight and pregnancy duration (since these variables were continuous). Finally, stepwise backward regression analyses were performed, in which one by one the least significant variable was dropped. Since the variables family size, birth season and maternal intake of vitamin supplements during pregnancy differed for the PFH and NFH groups, these variables were kept in the models. First order interactions between first-degree family history of asthma with birth season, family size and maternal intake of vitamin supplements during pregnancy were checked. P-values smaller than 0.05 were considered as statistically significant. Statistical analyses were performed using the Statistical Package for the Social Sciences (SPSS) version 11.0.

\section{Ethical approval}

Ethical approval for this study was obtained from the ethics committees of the participating institutes. All participants gave written, informed consent.

\section{Results}

In Table 3.1, the asthma status of first-degree family members in PFH infants is shown. The demographic characteristics of the study population are shown in Table 3.2. For the infants for whom complete data were not available the demographic characteristics were comparable to those of the analysed group. Five infants from the PFH group and fourteen infants from the NFH group were premature at birth (<37 weeks). A statistically significant difference between the PFH and NFH groups was detected for family size (infants from 
the PFH group had more siblings), birth season (in the NFH group most births were in spring and summer) and maternal intake of vitamin supplements during pregnancy (more NFH than PFH mothers consumed vitamin supplements). Total IgE levels ranged from $<0.2 \mathrm{IU} / \mathrm{ml}-23.2 \mathrm{IU} / \mathrm{ml}$ (median $<0.2 \mathrm{IU} / \mathrm{ml}$ ) in the PFH group versus $<0.2 \mathrm{IU} / \mathrm{ml}-7.97 \mathrm{IU} / \mathrm{ml}$ (median $<0.2 \mathrm{IU} / \mathrm{ml}$ ) in the NFH group. Seventy one percent of the PFH infants and 70\% of the NFH infants had undetectable total IgE levels (median [total IgE] $<0.2 \mathrm{IU} / \mathrm{ml}$, geometric mean $<0.2 \mathrm{IU} / \mathrm{ml}$ ). Using the Mann-Whitney $\mathrm{U}$ test, there was no statistically significant difference in total IgE between PFH and NFH infants $(\mathrm{P}=0.47)$ (Figure 3.1).

Table 3.1 Asthma status in first-degree family members of high-risk infants.

\begin{tabular}{lc}
\hline & $\mathrm{n}(\%)$ \\
\hline Mother with asthma n (\% & $50(29.4)$ \\
Father with asthma n (\%) & $32(18.8)$ \\
Sibling with asthma n (\%) & $31(18.2)$ \\
Mother and father with asthma n (\%) & $15(8.8)$ \\
Mother and sibling with asthma n (\%) & $21(12.4)$ \\
Father and sibling with asthma n (\%) & $16(9.4)$ \\
Mother and father and sibling with asthma n (\%) & $5(2.9)$ \\
\hline
\end{tabular}

Table 3.2 Demographic characteristics of the study population.

\begin{tabular}{|c|c|c|c|c|}
\hline & & $\begin{array}{l}\text { PFH group } \\
\mathrm{n}=170\end{array}$ & $\begin{array}{l}\text { NFH group } \\
n=300\end{array}$ & p-value \\
\hline \multicolumn{2}{|l|}{ Mother's age yrs $( \pm S D)$} & $31( \pm 3)$ & $31( \pm 4)$ & 0.73 \\
\hline \multicolumn{2}{|l|}{ Father's age yrs $( \pm S D)$} & $33( \pm 4)$ & $34( \pm 4)$ & 0.31 \\
\hline \multirow[t]{2}{*}{ Gender n (\%) } & Male & $85(50.0)$ & $157(52.3)$ & 0.63 \\
\hline & Female & $85(50.0)$ & $143(47.7)$ & \\
\hline Birth weight in grams & $( \pm \mathrm{SD})$ & $3494( \pm 488)$ & $3457( \pm 580)$ & 0.48 \\
\hline Gestational age in weeks & $( \pm \mathrm{SD})$ & $39.9( \pm 1.5)$ & $39.8( \pm 1.7)$ & 0.62 \\
\hline \multirow[t]{4}{*}{ Birth season $\mathrm{n}(\%)$} & Spring & 39 (22.9) & $90(30.0)$ & 0.002 \\
\hline & Summer & $42(24.7)$ & $101(33.7)$ & \\
\hline & Autumn & $34(20.0)$ & $55(18.3)$ & \\
\hline & Winter & $55(32.4)$ & $54(18.0)$ & \\
\hline \multirow[t]{4}{*}{ Siblings $\mathrm{n}(\%)$} & 0 & $64(37.6)$ & $136(45.3)$ & 0.04 \\
\hline & 1 & $66(38.8)$ & $124(41.3)$ & \\
\hline & 2 & $31(18.2)$ & $32(107)$ & \\
\hline & $\geq 3$ & $9(5.3)$ & $8(2.7)$ & \\
\hline \multicolumn{2}{|c|}{ Prenatal maternal smoking n (\%) } & 19 (11.9) & $32(10.7)$ & 0.77 \\
\hline \multicolumn{2}{|c|}{$\begin{array}{l}\text { Maternal intake of vitamin supplements } \\
\text { during pregnancy } \mathrm{n}(\%)\end{array}$} & $81(50.0)$ & $188(63.0)$ & 0.06 \\
\hline
\end{tabular}




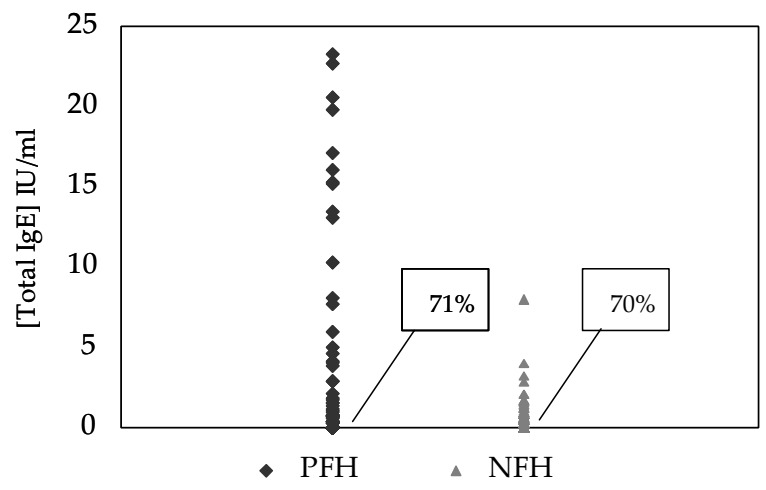

Figure 3.1 Total newborn IgE levels in PHF infants and NFH infants. $71 \%$ of the PFH infants as well as $70 \%$ of the NFH infants had undetectable IgE levels. In the PFH as well as in the NFH group the median total IgE level was $<0.2 \mathrm{IU} / \mathrm{ml}$.

Using bivariate analysis, a statistically significant higher proportion of infants with increased levels of total IgE was found in the group with maternal asthma at a total IgE cut-off level of 0.6, 0.7, 0.8 and $0.9 \mathrm{IU} / \mathrm{ml}$ (Table 3.3). In comparison with other birth seasons there was the tendency that infants born in autumn had more often increased levels of total IgE at all total IgE cut-off levels except $0.9 \mathrm{IU} / \mathrm{ml}$. There also was a tendency that infants with three or more siblings had more often detectable total IgE levels than infants with two or less siblings. However this did not reach statistical significance. Maternal intake of vitamin supplements during pregnancy resulted statistically significantly more often in decreased total IgE levels in infants at a total IgE cut-off level of 0.9 and $0.8 \mathrm{IU} / \mathrm{ml}$ compared to when no vitamin supplements were consumed by pregnant women (Table 3.3). No effect was seen from all other food components studied. Boys had more often detectable total IgE at all total IgE cut-off levels than girls, however, this was not statistically significant. Moreover, the same association was seen in the group of infants with maternal asthma. In this group there was again a tendency of increased total IgE in boys compared to girls, which was not statistically significant (data not shown). No differences were found between total $\mathrm{IgE}$ at birth and prenatal smoking by the mother, birth weight and gestational age at any total IgE cut-off level studied (Table 3.3). 


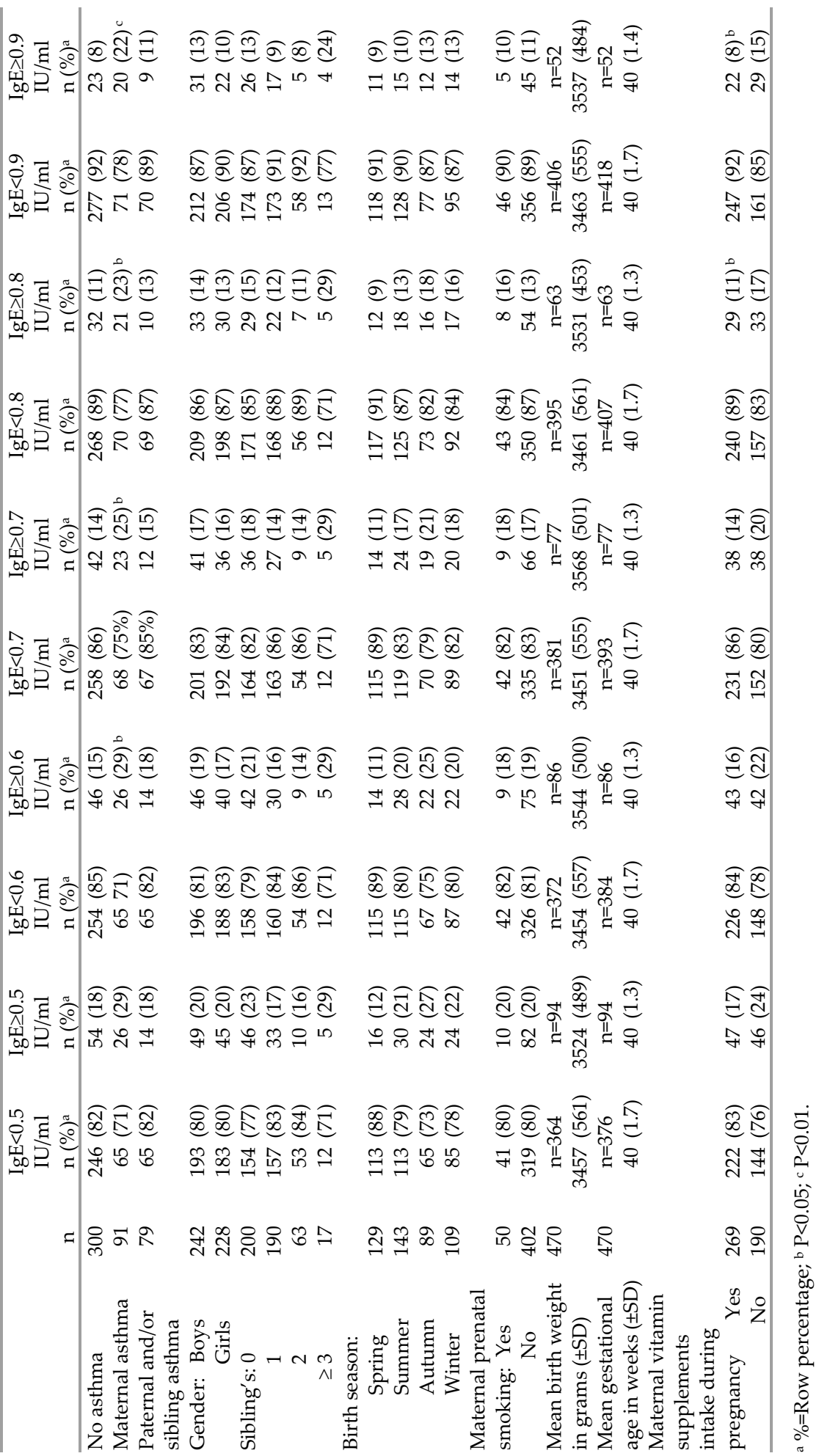


In Table 3.4 the results of the multiple logistic regression analysis are shown. In this table only the variables for which the PFH and NFH group differed are reported. Maternal asthma (versus no asthma in first-degree family members) remained statistically significantly associated with increased total $\operatorname{IgE}$ at a cutoff level of 0.6, 0.7, 0.8 and $0.9 \mathrm{IU} / \mathrm{ml}$ (Table 3.4). Paternal asthma and/or asthma in siblings (versus not asthma in first-degree family members) had no statistically significant contribution to the level of total IgE. Number of siblings was retained in the presented models for comparison, given the interest paid to this variable in literature. At a cut-off level of 0.5 to be born in autumn and winter (versus to be born in spring) were statistically significantly associated with increased total $\mathrm{IgE}$, whereas at a cut-off level of $0.6 \mathrm{IU} / \mathrm{ml}$ to be born in summer and autumn (versus to be born in spring) were statistically significantly associated with increased total IgE (Table 3.4). Maternal intake of vitamin supplements during pregnancy remained significant at a total IgE cutoff level of $0.9 \mathrm{IU} / \mathrm{ml}$, but not at a cut-off level of $0.8 \mathrm{IU} / \mathrm{ml}$ (Table 3.4).

Table 3.4 Summary of backward multiple logistic regression analyses.

\begin{tabular}{|c|c|c|c|c|c|c|}
\hline & & $\begin{array}{c}0.5 \mathrm{IU} / \mathrm{ml} \\
\text { Adjusted OR } \\
\text { (95\% C.I.) }\end{array}$ & $\begin{array}{c}0.6 \mathrm{IU} / \mathrm{ml} \\
\text { Adjusted OR } \\
(95 \% \text { C.I. })\end{array}$ & $\begin{array}{c}0.7 \mathrm{IU} / \mathrm{ml} \\
\text { Adjusted OR } \\
\text { (95\% C.I.) }\end{array}$ & $\begin{array}{c}0.8 \mathrm{IU} / \mathrm{ml} \\
\text { Adjusted OR } \\
\text { (95\% C.I.) }\end{array}$ & $\begin{array}{c}0.9 \mathrm{IU} / \mathrm{ml} \\
\text { Adjusted OR } \\
\text { (95\% C.I.) }\end{array}$ \\
\hline \multicolumn{2}{|l|}{ No asthma } & 1.00 & 1.00 & 1.00 & 1.00 & 1.00 \\
\hline \multicolumn{2}{|c|}{ Maternal asthma } & $1.67(0.94-2.95)$ & $2.06(1.15-3.68)^{*}$ & $1.89(1.03-3.45)^{*}$ & $2.22(1.17-4.22)^{*}$ & $2.99(1.50-5.93)^{* *}$ \\
\hline \multicolumn{2}{|c|}{$\begin{array}{l}\text { Paternal asthma and / } \\
\text { or sibling asthma }\end{array}$} & $0.97(0.49-1.91)$ & $1.19(0.60-2.39)$ & $1.05(0.50-2.17)$ & $1.12(0.51-2.48)$ & $1.53(0.65-3.60)$ \\
\hline \multirow[t]{4}{*}{ Siblings: } & 0 & 1.00 & 1.00 & 1.00 & 1.00 & 1.00 \\
\hline & 1 & $0.72(0.43-1.21)$ & $0.72(0.42-1.24)$ & 0.77 (0.44-1.36) & $0.79(0.42-1.47)$ & $0.65(0.33-1.29)$ \\
\hline & 2 & $0.68(0.31-1.49)$ & $0.66(0.29-1.49)$ & $0.81(0.35-1.84)$ & 0.77 (0.31-1.92) & 0.54 (0.19-1.53) \\
\hline & $\geq 3$ & $1.59(0.51-4.94)$ & $1.76(0.56-5.50)$ & $2.12(0.67-6.63)$ & $2.72(0.85-8.72)$ & $2.11(0.60-7.36)$ \\
\hline \multirow[t]{4}{*}{ Birth season: } & Spring & 1.00 & 1.00 & 1.00 & 1.00 & 1.00 \\
\hline & Summer & $1.96(1.00-3.83)$ & $2.12(1.05-4.29)^{*}$ & $1.77(0.86-3.64)$ & $1.54(0.70-3.40)$ & $1.35(0.58-3.16)$ \\
\hline & Autumn & $2.46(1.19-5.08)^{*}$ & $2.53(1.18-5.42)^{*}$ & $2.13(0.97-4.64)$ & $2.02(0.87-4.70)$ & $1.42(0.57-3.58)$ \\
\hline & Winter & $2.07(1.02-4.21)^{*}$ & $2.07(0.98-4.38)$ & $1.88(0.88-4.01)$ & $1.80(0.80-4.07)$ & $1.47(0.62-3.52)$ \\
\hline \multicolumn{2}{|c|}{$\begin{array}{l}\text { Maternal intake of } \\
\text { vitamin supplements } \\
\text { during pregnancy }\end{array}$} & $0.68(0.43-1.09)$ & $0.70(0.43-1.15)$ & $0.69(0.41-1.14)$ & $0.60(0.35-1.05)$ & $0.53(0.29-0.97)^{*}$ \\
\hline
\end{tabular}

${ }^{*} \mathrm{P}<0.05$; ${ }^{* *} \mathrm{P}<0.01$. All variables that were studied in the bi-variate analyses were entered in the multiple logistic regression models. With a stepwise backward regression procedure all variables that had no statistically significant effect on IgE were dropped one by one. With each step it was checked whether the omitted variable was a confounder. Since amount of siblings, birth season and maternal intake of vitamin supplements during pregnancy differed between PFH- and NFH group, they were kept in the models. The group of infants who had a positive family history of maternal asthma only or maternal asthma as well as asthma in one or more other first-degree family members, were labelled as the maternal asthma group. The group of infants who had a positive family history of 'asthma in first-degree family members', in which the mother was not included were labelled as the paternal and/or sibling asthma group. 


\section{Discussion}

Elevated total IgE levels were more often found in PFH newborns than in NFH newborns. The PFH and NFH group differed in family size, birth season and maternal consumption of vitamin supplements during pregnancy, which made those variables potential confounders in this study. After controlling for these and other potential confounders, multiple logistic regression analysis revealed that maternal asthma and born in autumn remained associated with elevated total IgE, whereas maternal intake of vitamin supplements during pregnancy remained associated with decreased total IgE. We found that the odds ratio for detectable total IgE in PFH newborns with maternal asthma compared to NFH newborns increased with increasing total IgE cut-off levels, indicating that the higher the total IgE cut-off level, the better PFH newborns could be distinguished from NFH newborns. Paternal asthma and/or asthma in siblings had no significant contribution to the level of total $\operatorname{IgE}$ in newborns compared to NFH. We did not find a significant difference between the group with maternal asthma and the group with paternal and/or sibling asthma.

Our study is the first that used a GP registered population. Accordingly we had the advantage that an impression could be obtained of the newborn total IgE pattern in a primary care population. We expected that a GP had a comprehensive overview of asthma in a family, since in the Netherlands, in almost all cases, all family members share the same physician and the GP registers prospectively whether a family member has asthma.

A disadvantage of this selection procedure may be that in some cases a sibling below the age of six years could not have been given a definite asthma diagnosis. Another important point is the chance of underestimation of the asthma risk due to the selection procedure used. When asthma in siblings is involved in defining 'high-risk', an underestimation of the risk in smaller families compared to larger families will exist. However when the definition of high-risk is exclusively based on asthma in the parents, the underestimation might be even more pronounced. To account for the mentioned possible underestimation of the risk in our design, we controlled for family size in the multiple logistic regression analysis.

It has been suggested that cord-blood may be contaminated with maternal blood and that high levels of cord-blood total $\operatorname{IgE}$ could be due to this contamination. ${ }^{12,15,32}$ Lilja et al. ${ }^{32}$ showed that in $50 \%$ of infants with cord-blood total $\mathrm{IgE} \geq 0.9 \mathrm{kU} / \mathrm{l}$ the total $\mathrm{IgE}$ concentrations decreased below this value on days $4-5$ and that there was a correlation between maternal total IgE and cordblood total IgE concentrations. In order to prevent for maternal contamination we collected capillary heel blood for total IgE detection at day 3-5 after birth.

We found that maternal asthma was associated with elevated total $\operatorname{IgE}$ at all total IgE cut-off levels studied except $0.5 \mathrm{IU} / \mathrm{ml}$. An association between maternal asthma and total IgE in newborns was also found by two other study 
groups. ${ }^{15,16}$ In other studies an association was found between maternal atopy and total IgE in newborns, ${ }^{11,12,14}$ however one study failed to do so. ${ }^{13}$ In most studies the total IgE cut-off level that was chosen differed, which makes comparison difficult. We examined our data at various total IgE cut-off levels. A total IgE cut-off level of $0.9 \mathrm{IU} / \mathrm{ml}$ was chosen because this cut-off level represents the clinical cut-off level, a cut-off level of $0.5 \mathrm{IU} / \mathrm{ml}$ was chosen to be able to better compare our findings with those of others, since this cut-off level was used in most studies. We chose the cut-off levels 0.6-0.8 IU/ml to investigate a possible dose-response relationship.

Birth season was also associated with detectable newborns total IgE, which is in agreement with others. ${ }^{16-18,20}$ There is however no agreement on the season that most affects newborns total IgE. We found the highest percentage of elevated total IgE in the autumn in PFH as well as in NFH infants. In the PFH group a more or less cyclic pattern of birth season and newborn total IgE was observed. Halonen et al. ${ }^{18}$ and Kimpen et al. ${ }^{20}$ found in an unselected population a cyclic sinusoidal pattern of month of birth with total $\operatorname{IgE}$ with the highest values in Spring 18,20 as well as in Winter ${ }^{21}$ and the lowest values in Autumn. Hansen et al. ${ }^{17}$ found the lowest values in October, but no cyclic total IgE pattern throughout the year. Kaan et al. ${ }^{16}$ and Bjerke et al..$^{21}$ found the highest proportion of newborns with detectable total $\operatorname{IgE}$ in winter and late autumn respectively. These seasonal differences between the study groups are probably partly due to the climate differences throughout the world.

We asked mothers whether they consumed several food components during their pregnancy and tested whether these were associated with newborn total IgE. None of the components showed a relationship with newborn total IgE, except the consumption of vitamin supplements. Unfortunately information concerning the frequency and duration of vitamin supplements intake as well as the composition of the vitamin supplements was not collected. The consumption of vitamin supplements remained significant in the multiple logistic regression analysis. However, at this moment we are not able to give a satisfactory explanation for this finding, therefore further research is necessary in order to confirm this observation.

Although more male than female newborns had detectable total IgE, there was no significant effect of gender on total newborn IgE in the group as a whole as well as in the group with maternal asthma, which is in accordance with some other studies. ${ }^{15,16}$ However, in other studies an association of gender and total newborn IgE was found.12,13,17-19 A difference of these studies with our study and the studies of Kaan ${ }^{16}$ and Johnson ${ }^{15}$ was that the size of the study populations in the former studies was larger, which might be responsible for the differences found. We saw no effect of prenatal maternal smoking and gestational age. However only $10 \%$ of the mothers smoked during pregnancy 
and nineteen infants were pre-term. Therefore we were not able to assess the effects of these phenomena on total newborn IgE.

There are several studies in which maternal atopy or asthma and birth season have been shown to affect total IgE in newborns. With this primary care study we tried to add another piece of the puzzle. We confirm at different total IgE cut-off levels, in a GP registered population where we compared PFH infants to NFH infants, the results of former studies. We found an association of total IgE in newborns with birth season and maternal asthma, which confirms the idea that besides a genetic pathway an environmental pathway plays a role. 


\section{References}

1. The International Study of Asthma and allergies in Childhood (ISAAC) Steering Committee. Worldwide variation in prevalence of symptoms of asthma, allergic rhinoconjunctivitis, and atopic eczema: ISAAC. Lancet 1998;351:1225-32.

2. Eldeirawi K, Persky VW. History of ear infections and prevalence of asthma in a national sample of children aged 2 to 11 years. Chest 2004;125:1685-92.

3. Beasley R, Crane J, Lai CKW, Pearce N. I. Epidemiology and genetics of asthma. Prevalence and etiology of asthma. J Allergy Clin Immunol 2000;105:S466-72.

4. Miller DL, Hirvonen T, Gitlin D. Synthesis of IgE by the human conceptus. J Allergy Clin Immunol 1973;52:182-8.

5. Klink M, Cline MG, Halonen M, Burrows B. Problems in defining normal limits for serum IgE. J Allergy Clin Immunol 1990;85:440-4.

6. Barbee RA, Halonen M, Lebowitz M, Burrows B. Distribution of IgE in a community population sample: correlations with age, sex and allergen skin test reactivity. J Allergy Clin Immunol 1981;68:106-11.

7. Grassi J, Didierlaurent A, Stadler BM. Quantitive determination of total and specific human IgE with the use of monoclonal antibodies. J Allergy Clin Immunol 1986;77:808-22.

8. Kjellman NI. Atopic allergy and serum IgE concentrations in randomly selected children followed up from 8 to 12 years of age. Allergy 1984;39:443-50.

9. Vankrunkelsven P. Verband van leeftijd en geslacht met astma, rhinitis, specifieke allergiën en serum-IgE. Omgevingsfactoren en allergie: aan de hand van een patiëntenbestand met 20.000 dossiers. Leuven 1999. p.18-34, ISBN 90-75828-04-7.

10. Haus M, Heese HD, Weinberg EG, Potter PC, Hall JM, Malherbe D. The influence of ethnicity, an atopic family history, and maternal ascariasis on cord blood serum $\operatorname{IgE}$ concentrations. J Allergy Clin Immunol 1988;82:179-89.

11. Michel FB, Bousquet J, Greillier P, Robinet-Levy M, Coulomb Y. Comparison of cord blood immunoglobulin $\mathrm{E}$ concentrations and maternal allergy for the prediction of atopic diseases in infancy. J Allergy Clin Immunol $1980 ; 65: 422-30$.

12. Bergmann RL, Schulz J, Günther S, Dudenhausen JW, Bergmann KE, Bauer CP, et al. Determinants of cord-blood IgE concentrations in 6401 German neonates. Allergy 1995;50: 65-71.

13. Croner S, Kjellman N-I M, Erkisson B, Roth A. IgE screening in 1701 newborn infants and the development of atopic disease during infancy. Arch Dis Childhood 1982;57:364-8.

14. Magnusson CGM. Cord serum IgE in relation to family history and as predictor of atopic disease in early infancy. Allergy 1988;43:241-51.

15. Johnson CC, Ownby DR, Peterson EL. Parental history of atopic disease and concentration of cord blood IgE. Clin Exp allergy 1996;26:624-9.

16. Kaan A, Dimich-Ward H, Manfreda J, Becker A, Watson W, Ferguson A, et al. Cord blood IgE: its determinants and prediction of development of asthma and other allergic disorders at 12 months. Ann Allergy Asthma Immunol 2000;84:37-42.

17. Hansen LG, Host A, Halken S, Holmskov A, Husby S, Lassen LB, et al. Cord blood IgE. I. IgE screening in 2814 newborn children. Allergy 1992;47:391-6.

18. Halonen M, Stern D, Lyle S, Wright A, Taussig L, Martinez FD. Relationship of total serum IgE levels in cord and 9-month sera of infants. Clin Exp Allergy 1991;21:235-41.

19. Kimpen J, Callaert H Embrechts P, Bosmans E. Influence of sex and gestatonal age on cord blood IgE. Acta Paediatr Scand 1989;78:233-8.

20. Kimpen J, Callaert H, Embrechts P, Bosmans E. Cord blood IgE and month of birth. Arch Dis Child 1987;62:478-82.

21. Bjerke $T$, Hedegaard $M$, Henriksen $T B$, Nielsen BW, Schiotz PO. Several genetic and environmental factors influence cord blood IgE concentrations. Pediatr Allergy Immunol 1994;5:88-94.

22. Magnusson CGM. Maternal smoking influences cord serum $\operatorname{IgE}$ and $\operatorname{IgD}$ levels and increases the risk for subsequent infant allergy. J Allergy Clin Immunol 1986;78:898-904. 
23. Ownby DR, Johnson CC, Peterson EL. Maternal smoking does not influence cord serum IgE or IgD concentrations. J Allergy Clin Immunol 1991;88:555-60.

24. Oryszczyn M-P, Godin J, Annesi I, Hellier G, Kauffmann F. In utero exposure to parental smoking, cotinine measurements, and cord blood IgE. J Allergy Clin Immunol 1991;87: 1169-74.

25. Mihrshahi S, Peat JK, Webb K, Oddy W, Marks GB, Mellis CM. Effect of omega-3 fatty acid concentrations inplasma on symptoms of asthma at 18 months of age. Pediatr Allergy and Immunol 2004;15 (6):517-22.

26. Diez U, Schlink U, Reuter W, Borte M, Reichardt P, Muller D, et al. Fatty acids in colostrum from mothers of children at high risk of atopy in relation to clinical and laboratory signs of allergy in the first year of life. Allergy 2004;59 (4):394-400.

27. Dunstan JA, Mori TA, Barden A, Beilin LJ, Taylor AL, Holt PG, et al. Maternal fish oil supplementation in pregnancy reduces inteleukin-13 levels in cord blood of infants at high risk of atopy. Clin Exp Allergy 2003;33 (4):442-8.

28. Kuiper S, Maas T, van Schayck CP, Muris JWM, Schönberger HJAM, Dompeling E, et al. The primary prevention of asthma in children (PREVASC) study: Design of a multifaceted prevention program. Pediatr Allergy Immunol 2005;16:321-31.

29. Dirksen WJ, Geijer RMM, de Haan M, de Koning G, Flikweert S, Kolnaar BGM. Astma bij kinderen. NHG-Standaard. Huisarts Wet 1998;41:130-43.

30. The WONCA classification committee. ICPC-2. International Classification of Primary Care. Oxford, Oxford University Press, 1998.

31. Stapel SO, Eysink PED, de Vrieze J, Aalberse RC. IgE testing in capillary blood. Pediatr Allergy Immunol 2004;15:230-3.

32. Lilja G, Johansson SGO, Kusoffsky E, Öman H. IgE levels in cord blood and at 4-5 days of age: relation to clinical symptoms of atopic disease up to 18 months of age. Allergy 1990;45: 436-44. 


\section{Chapter 4}

The interactive effect of family history and environmental factors on respiratory tract related morbidity in early infancy: The PREVASC program

Sandra Kuiper, Jean W.M. Muris, Edward Dompeling, Arnold D.M. Kester, Geertjan Wesseling, J. André Knottnerus, Constant P. van Schayck 


\section{Abstract}

Background

Family- and environmental factors affect the development of asthma and respiratory morbidity. How these factors interact is unknown.

Objective

To clarify the interactive effect of a family history of asthma and environmental factors on the occurrence of respiratory morbidity in infancy.

Methods

221 Infants with a positive family history and 308 infants with a negative family history were prenatally selected and followed until the age of two. Exposure to environmental risk factors and the occurrence of respiratory morbidity were recorded. Using multiple logistic regression analysis, increased risk was expressed in odds ratios adjusted for relevant co-variables.

Results

Infants with a positive family history had more respiratory morbidity than infants with a negative family history with adjusted ORs ranging from 1.7 (95\%CI=1.0-2.8) for expiratory wheezing to 4.9 (95\%CI=1.7-13.6) for croup. Parental smoking increased the OR of a positive family history for wheezing ever $(\mathrm{OR}=5.8,95 \% \mathrm{CI}=2.5-13.8)$ and attacks of wheezing $(\mathrm{OR}=6.8,95 \% \mathrm{CI}=2.7-16.9)$, as did Derp1 $(\mathrm{OR}=10.2,95 \% \mathrm{CI}=2.8-36.3$ and $\mathrm{OR}=7.1,95 \% \mathrm{CI}=7.1-21.0)$. Exposure to both parental smoking and Derp1 further increased this OR $(\mathrm{OR}=30.8,5 \% \mathrm{CI}=6.9-137.2$ and $\mathrm{OR}=26.2,95 \% \mathrm{CI}=5.9-115.6)$. Breastfeeding decreased the ORs of positive family history for tonsillitis and acute otitis media: in formula-fed infants the increased OR for these diagnoses in positive family history versus negative family history infants $(\mathrm{OR}=9.2,95 \% \mathrm{CI}=2.1-39.7$ and $\mathrm{OR}=2.9,95 \% \mathrm{CI}=1.1-7.2)$ disappeared in breastfed infants $(\mathrm{OR}=1.8,95 \%=0.8-3.8$ and $\mathrm{OR}=0.7,95 \% \mathrm{CI}=0.4-1.3)$.

\section{Conclusion}

Parental smoking and Derp1 increased the effect of a positive family history on respiratory morbidity, while breastfeeding reduced this effect. Our findings may shed more light on the controversy concerning the effect of environmental factors. 


\section{Introduction}

Asthma is one of the most important chronic diseases in childhood. ${ }^{1}$ The prevalence of childhood asthma is high (4-6\% in Dutch infants aged 1-5 years). ${ }^{2}$ For several decades, a steady increase in the asthma prevalence has been observed worldwide. ${ }^{3,4}$ However, recently the first signs of a stabilisation ${ }^{5,6}$ or even a decrease in prevalence ${ }^{2}$ have been reported.

Asthma exerts a great burden on the patients, their family members, health care services as well as the society as a whole. Asthma is the main cause of school absence. ${ }^{7-8}$ The number of asthma-related physician contacts and hospitalisations are high, which results in substantial costs of treating asthma (in the Netherlands, $20.4 \%$ of the total health care costs in 0 -year old babies and $24.1 \%$ in infants and children aged $1-14$ years). ${ }^{9}$ The chance to develop asthma is determined by genetic as well as environmental factors. Since specific genes for asthma have not been identified completely, the focus has been on family history of asthma.

Studies performed thus far have indicated a wide range for the association of a positive family history of asthma with a diagnosis of asthma (ORs ranging from 1.5 to 9.7$).{ }^{10}$ This may be explained by varying definitions of family history and definitions of asthma in these studies. Moreover, the definition of asthma in first-degree family members was mainly based on parental report, which may introduce reporting bias. Finally, the differences may be explained by the differences in potential confounders or effect modifiers that were included in the models.

With regard to the environmental factors, passive smoking, house dust mite, cat and dog allergens are thought to be associated with sensitisation and allergic disease, whereas breastfeeding is thought to have a protective effect.11-15 However, some authors have shown opposite effects with regards to these factors. ${ }^{16-18}$

Whether environmental factors modify the effect of a positive family history of asthma (PFH) on respiratory tract related morbidity is unknown. This knowledge could lead to a better understanding of underlying pathophysiological mechanisms. In studying young children it is not possible to use asthma as an objective outcome measure, since asthma cannot be diagnosed objectively in the first years of life. Therefore in our study we used outcome measures that are considered to be related to the development of asthma, i.e. all respiratory tract related morbidity (especially wheezing) as well as eczema. The general practitioner (GP) and the parents registered these data prospectively during the first two years of the infants' lives. In this respect our study differs from most other studies in which information concerning morbidity in the children is based exclusively on parental reports and/or physical examination at the end of the study period..$^{19-23}$ Moreover, the Dutch 
health care system is organized in such a way that every citizen is registered in a general practice, and the GP keeps complete medical records of all families in the registered general population; this makes Dutch general practice an outstanding setting to assess comprehensively whether an unborn child has a positive family history of asthma and is therefore at high-risk of developing asthma. We capitalised on this opportunity by carrying out a primary carebased study. ${ }^{24}$

It is supposed that infants with a positive family history of asthma (PFH) and infants with a negative family history of asthma (NFH) have different genetic backgrounds, which may result in different responses to environmental factors. ${ }^{25}$ Therefore, we hypothesized that the effect of a positive family history of asthma on respiratory tract and asthma-related morbidity is modified by relevant environmental factors, such as parental smoking, allergen exposure, and breastfeeding.

\section{Methods}

\section{Recruitment of subjects}

As previously described, ${ }^{26} 793$ children were recruited prenatally in primary care for a prospective birth cohort study. Of these 793 infants, 27 were excluded because of intra-uterine death, major language problems in the family, serious birth defects or moving abroad. Fifteen infants were lost to follow-up. 443 Infants had a positive family history of asthma (PFH) and participated in a randomised controlled prevention trial (RCPT), the PREVASC study. ${ }^{27} 222$ Infants from the RCPT who were allocated to the intervention group were not included in the present study. The remaining 221 who were allocated to a control group, as well as 308 infants with a negative family history of asthma (NFH), received usual care (according to the Guideline of the Dutch College of General Practitioners). ${ }^{28}$ In our study a PFH was defined as 'at least one $1^{\text {st }}$ degree family member (i.e. the pregnant woman, the biological father of the unborn child or a sibling) suffering from GP registered asthma', whereas NFH was defined as 'absence of GP registered asthma in first-degree family members. ${ }^{29}$ Asthma was defined according to the International Classification of Primary Care (ICPC) $)^{30}$ as recurrent episodes of reversible acute bronchial obstruction with wheeze and/or dry cough. 


\section{Data collection}

\section{Parental registered morbidity}

At six months, one year and two years of age, parents completed the Dutch version of the International Study of Asthma and Allergies in Childhood (ISAAC) questionnaire. ${ }^{26}$

\section{GP registered morbidity}

Standardized information on respiratory symptoms and diagnoses was prospectively registered in a standardised manner by the GP at every consultation during the two years ${ }^{26,27}$. All problems were coded using the ICPC $^{30}$, following the criteria of the International Classification of Health Problems in Primary Care (ICHPPC-2). ${ }^{31}$

\section{Dust sampling}

In order to measure postnatal exposure to inhaled allergens (Derp1, Feld1 and Canf1), dust samples were collected when the infants were $6^{\text {th }}-9^{\text {th }}$ months of age in a standardised manner. ${ }^{32}$ Samples were taken using a vacuum cleaner (Bosch BSA1100 1300 Watt) with a special cassette (ALK Abello) containing a Whatman GF/F $70 \mathrm{~mm}$ filter, from the living room floor $\left(2 \times 1 \mathrm{~m}^{2}\right)$, the parents' mattress $\left(1 \mathrm{~m}^{2}\right)$ and the mattress of the baby (whole mattress). The samples were kept at $4{ }^{\circ} \mathrm{C}$ until they were analysed for mite, cat and dog allergens by use of ELISA.

For statistical analysis, the individual concentrations in $\mathrm{ng} / \mathrm{g}$ dust of the three locations were added, and weighted averages were taken. The weighted averages were based on information concerning the time an infant spends on average at every location. ${ }^{33,34}$ Since Derp1, Feld1 as well as Canf1 were not normally distributed, even after logarithmic transformation, these variables were categorized into two categories; $<2000 \mathrm{ng} / \mathrm{g}$ dust, $\geq 2000 \mathrm{ng} / \mathrm{g}$ dust. ${ }^{35}$

\section{Definition of outcome measures}

Symptoms reported at 6,12 and 24 months included various types of wheezing and coughing. Diagnoses reported at 6,12 and 24 months were allergic rhinitis, allergic rhinoconjunctivitis, doctor-diagnosed otitis media, doctor-diagnosed tonsillitis and flu or serious cold.

Physical examination findings and diagnoses registered by the GP at every consultation included expiratory wheezing, acute bronchitis, bronchiolitis, pneumonia, croup, acute otitis media, otitis media with effusion, tonsillitis, eczema and asthma. 


\section{Potential confounders and effect modifiers}

Potential confounders of the relationship between family history and respiratory morbidity as well as effect modifiers were considered. The number of older siblings was documented at inclusion. Characteristics registered at birth included gender, birth weight and birth season. Perinatal and other factors were registered by use of questionnaires at six months and one year of age and included prenatal maternal smoking, postnatal parental smoking and breastfeeding. Day-care attendance was registered in weekly reports by the parents.

\section{Statistical methods}

In bi-variate analysis, means for continuous normally distributed variables were compared with Student's t-test. Differences in proportions between the $\mathrm{PFH}$ and NFH groups for dichotomous variables were evaluated using the $\chi^{2}$ test.

In multiple logistic regression analyses the simultaneous contributions of the studied risk factors with correction for potential confounders (day-care attendance, number of siblings, gender birth season, birth weight, breastfeeding, prenatal maternal smoking, postnatal parental smoking, Derp1, Feld1, Canf1) to the various outcome variables (respiratory tract and asthmarelated symptoms and diagnoses) were evaluated. To assess effect modification, first order interactions between family history of asthma and breastfeeding, prenatal maternal smoking, postnatal parental smoking, Derp1, Feld1 and Canf1 were included. Interaction terms that were not statistically significant were dropped from the model in a stepwise backward manner.

P-values smaller than 0.05 were considered as statistically significant. Statistical analysis was performed using SPSS version 11.0.

\section{Ethics}

Ethical approval for this study was obtained from the ethics committees of the participating institutes. All participating parents gave written, informed consent.

\section{Results}

\section{General characteristics}

Ten infants from the PFH group and fifteen infants from the NFH group were premature at birth (<37 weeks), of which respectively eight and six infants were 
born before 36 weeks of gestation. As shown in Table 4.1, NFH infants were mostly born in spring and summer, whereas birth of $\mathrm{PFH}$ infants was approximately equally distributed for all seasons $(\mathrm{P}=0.01)$. $\mathrm{PFH}$ infants had significantly more siblings and lower levels of Derp1 and Canf1 than NFH infants $(\mathrm{P}=0.02, \mathrm{P}=0.006$ and $\mathrm{P}=0.000$ respectively). For the other characteristics analysed the groups were similar. The imbalanced characteristics were included in the multiple logistic regression analyses.

Table 4.1 Demographic characteristics of the study population.

\begin{tabular}{|c|c|c|}
\hline & $\begin{array}{l}\text { Positive familyhistory } \\
\mathrm{n}=221\end{array}$ & $\begin{array}{l}\text { Negative family history } \\
\mathrm{n}=308\end{array}$ \\
\hline Mother's age yrs (mean \pm SD) & $31(4)$ & $31(4)$ \\
\hline Father's age yrs $($ mean $\pm \mathrm{SD})$ & $33(4)$ & $34(4)$ \\
\hline Gender (female) n (\%) & $112(50.7)$ & $162(52.6)$ \\
\hline Birth weight in grams (mean \pm SD) & 3494 (533) & 3455 (579) \\
\hline Gestational age in weeks (mean $\pm \mathrm{SD}$ ) & $39.7(1.7)$ & $39.8(1.7)$ \\
\hline \multicolumn{3}{|l|}{ Birth season ${ }^{a} \mathrm{n}(\%)$} \\
\hline Spring & $51(23.1)$ & $94(30.5)$ \\
\hline Summer & $61(27.6)$ & $104(33.8)$ \\
\hline Autumn & $48(21.7)$ & $55(17.9)$ \\
\hline Winter & 61 (27.6) & $55(17.9)$ \\
\hline \multicolumn{3}{|l|}{ Siblingsa $\mathrm{n}(\%)$} \\
\hline 0 & $84(38.0)$ & $140(45.5)$ \\
\hline 1 & $85(38.5)$ & $127(41.2)$ \\
\hline 2 & $40(18.1)$ & $33(10.7)$ \\
\hline 3 & $8(3.6)$ & $8(2.6)$ \\
\hline 4 & $2(0.9)$ & \\
\hline 5 & $2(0.9)$ & \\
\hline \multicolumn{3}{|l|}{ Allergen exposure } \\
\hline Breastfeeding ever $n(\%)$ & $157(75.5)$ & $225(74.3)$ \\
\hline Prenatal smoking by the mother $\mathrm{n}(\%)$ & $22(10.8)$ & $35(11.7)$ \\
\hline Postnatal parental smoking $\quad \mathrm{n}(\%)$ & $61(29.9)$ & $95(31.7)$ \\
\hline \multicolumn{3}{|l|}{ Der p1 ng/g dust ${ }^{b}$} \\
\hline Geometric mean & 291 & 455 \\
\hline Median & 321 & 685 \\
\hline Maximum & 74463 & 21395 \\
\hline \multicolumn{3}{|l|}{ Fel d1 ng/g dust } \\
\hline Geometric mean & 672 & 518 \\
\hline Median & 447 & 504 \\
\hline Maximum & 665385 & 18479 \\
\hline \multicolumn{3}{|l|}{ Can f1 ng/g dust ${ }^{b}$} \\
\hline Geometric mean & 430 & 682 \\
\hline Median & 229 & 798 \\
\hline Maximum & 333782 & 44477 \\
\hline
\end{tabular}

Demographic characteristics: Comparison of the PFH and NFH groups. a $\mathrm{P}<0.05$; ${ }^{b} \mathrm{P}<0.01$ 


\section{Family history of asthma}

PFH infants had significantly more respiratory tract and asthma-related symptoms than NFH infants except for a GP diagnosis bronchitis, otitis media with effusion and eczema (Table 4.2).

Table 4.2 Respiratory tract and asthma-related morbidity in infants with a positive or negative family history of asthma in the first two years of life as documented by the parents and the GP.

\begin{tabular}{|c|c|c|c|c|c|}
\hline \multirow[b]{2}{*}{ Parental report } & \multicolumn{3}{|c|}{$\begin{array}{l}\text { Positive family } \\
\text { history }\end{array}$} & \multirow{2}{*}{$\begin{array}{c}\text { Negative family } \\
\text { history }\end{array}$} & \multirow[t]{2}{*}{$\begin{array}{c}\text { Adjusted OR } \\
(95 \% \text { C.I. })^{\mathbf{b}}\end{array}$} \\
\hline & $\mathrm{n}$ & $\mathrm{n}(\%)$ & $\mathrm{n}$ & & \\
\hline Attacks of wheezing ever & 197 & $105(53.3)$ & 294 & $70(23.8)$ & $2.3(1.2-4.1)$ \\
\hline Awakening by wheezing ever & 192 & $74(38.5)$ & 292 & $43(14.7)$ & $3.8(2.2-6.7)$ \\
\hline Awakening by cough ever & 186 & $85(45.7)$ & 276 & $64(23.2)$ & $2.9(1.7-4.8)$ \\
\hline $\begin{array}{l}\text { Non-productive cough at } \\
\text { night }\end{array}$ & 190 & $101(53.2)$ & 276 & $79(28.6)$ & $3.0(1.8-5.0)$ \\
\hline Allergic rhinitis & 197 & $139(70.6)$ & 298 & $132(44.3)$ & $3.1(1.9-4.9)$ \\
\hline Allergic rhino conjunctivitis & 182 & $45(24.7)$ & 291 & $29(10.0)$ & $2.7(1.4-5.1)$ \\
\hline Doctor diagnosed otitis media & 186 & $70(37.6)$ & 291 & $67(23.0)$ & $3.5(1.3-9.4)$ \\
\hline Doctor diagnosed tonsillitis & 188 & 37 (19.7) & 291 & $26(8.9)$ & $9.2(2.1-39.7)$ \\
\hline $\begin{array}{l}\text { Flu or serious cold } \\
\text { GP records }\end{array}$ & 207 & $161(77.8)$ & 294 & $151(51.4)$ & $3.3(2.0-5.3)$ \\
\hline Expiratory wheezing & 221 & $73(33.0)$ & 308 & 60 (19.5) & $1.7(1.0-2.8)$ \\
\hline Acute bronchitis & 221 & 43 (19.5) & 308 & 48 (15.6) & $1.5(0.8-2.8)$ \\
\hline Bronchiolitis & 221 & $19(8.6)$ & 308 & $11(3.6)$ & $3.3(1.2-9.1)$ \\
\hline Pneumonia & 221 & $13(5.9)$ & 308 & $5(1.6)$ & $3.8(1.3-10.8)^{\mathrm{a}}$ \\
\hline Croup & 221 & $22(10.0)$ & 308 & $7(2.3)$ & $4.9(1.7-13.6)$ \\
\hline Acute otitis media & 221 & $64(29.0)$ & 308 & $72(23.4)$ & $2.9(1.1-7.2)$ \\
\hline Otitis media with effusion & 221 & $35(15.8)$ & 308 & $32(10.4)$ & $1.2(0.4-3.9)$ \\
\hline Tonsillitis & 221 & $11(5.0)$ & 308 & $2(0.6)$ & $8.0(1.8-36.5)^{a}$ \\
\hline Eczema & 221 & $52(23.5)$ & 308 & $48(15.6)$ & $1.7(1.0-3.1)$ \\
\hline Asthma & 221 & $63(28.5)$ & 308 & $24(7.8)$ & $4.4(2.3-8.4)$ \\
\hline
\end{tabular}

a There were not enough infants with the diagnoses pneumonia and tonsillitis to perform a multiple logistic regression analysis. Therefore the unadjusted odds ratios are given for pneumonia and tonsillitis. ${ }^{\mathbf{b}}$ Adjustment for day-care attendance, number of siblings, gender, breastfeeding, birth season, birth weight, prenatal maternal smoking and postnatal parental smoking, Derp1, Feld1, Canf1.

\section{Interaction between family history and environmental exposure}

Statistically significant interactions between family history and postnatal exposure to Derp1 as well as parental smoking were seen for wheezing ever $(\mathrm{P}=0.015$ and $\mathrm{P}=0.023$ respectively) and attacks of wheezing $(\mathrm{P}=0.046$ and $\mathrm{P}=0.033$ respectively). PPS and Derp1 modified the effect of a PFH on wheezing ever and attacks of wheezing. Exposure to PPS or Derp1 increased the ORs of PFH for wheezing ever and attacks of wheezing. Moreover, when infants were exposed to both PPS and Derp1 the ORs for these symptoms were even further increased (Figure 4.1, 4.2). 


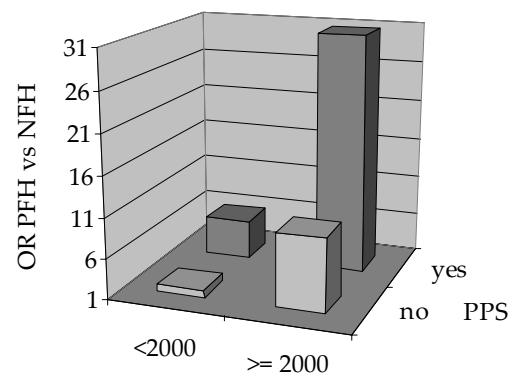

[Derp1] ng/g dust

Figure 4.1 Wheezing ever.

Effect of family history on wheezing ever in infants (not) exposed to Derp1 and PPS. PFH: infants with a positive family history, NFH: infants with a negative family history. 95\% CI (Derp1<2000/PPSno)=1.1-3.4, 95\% CI (Derp1<2000/PPSyes)=2.5-13.8,

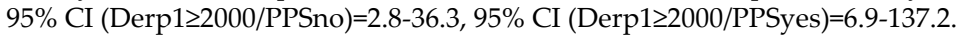

Adjusted for the other reported risk factors as well as day-care attendance, number of siblings, gender, birth season, birth weight, prenatal maternal smoking, Feld1 and Canf1.

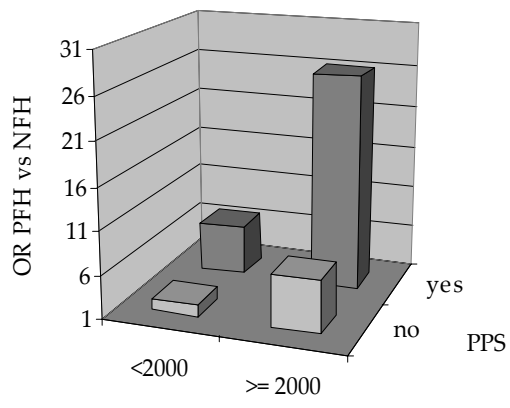

[Derp1] ng/g dust

Figure 4.2 Attacks of wheezing.

Effect of family history on attacks of wheezing in infants (not) exposed to Derp1 and PPS. PFH: infants with a positive family history, NFH: infants with a negative family history. 95\% CI (Derp1<2000/PPSno) $=(1.2-4.1)$, 95\% CI $\quad$ Derp1<2000/PPSyes $)=(2.7-$

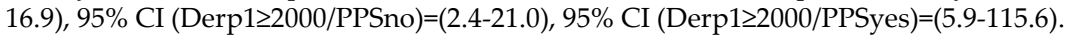
Adjusted for the other reported risk factors as well as day-care attendance, number of siblings, gender, birth season, birth weight, prenatal maternal smoking, Feld1 and Canf1.

Significant interactions between family history and breastfeeding were also observed for parentally reported tonsillitis and otitis media ( $\mathrm{P}=0.042$ and $\mathrm{P}=0.046$ respectively) as well as for GP registered acute otitis media $(\mathrm{P}=0.011)$. The ORs of PFH compared to NFH for (acute) otitis media and tonsillitis were significantly higher than 1.0 in formula-fed infants but not in breastfed infants (Figure 4.3). The OR of breastfeeding compared to formula feeding for (acute) otitis media was significantly lower in PFH infants $(\mathrm{P}=0.002)$. 


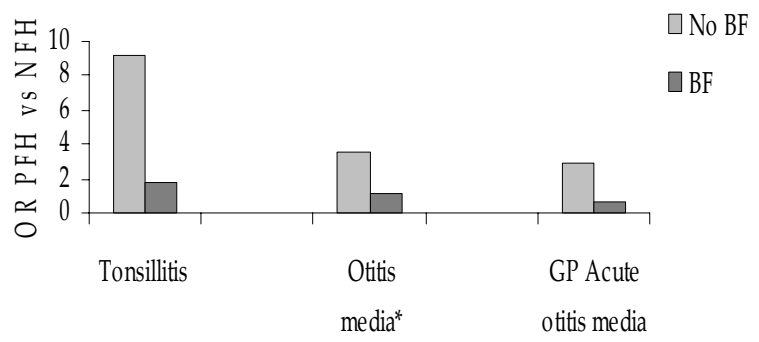

Figure 4.3 Effect of family history on parentally reported tonsillitis and otitis media as well as GP registered, acute otitis media in infants who were breastfed or received formula feeding. PFH: infants with a positive family history, NFH: infants with a negative family history. No BF: Exclusively formula feeding, BF: Breastfeeding. Tonsillitis: $95 \%$ CI $(\mathrm{NoBF})=(2.1-39.7), 95 \%$ CI $($ BFyes $)=(0.8-3.8)$, Parentally reported otitis media: $95 \%$ $\mathrm{CI}(\mathrm{NoBF})=(1.3-9.4), 95 \% \mathrm{CI}$ (BFyes) $=(0.6-2.0)$, GP registered acute otitis media: $95 \% \mathrm{CI}$ $(\mathrm{NoBF})=(1.1-7.2), 95 \% \mathrm{CI}(\mathrm{BFyes})=(0.4-1.3)$. Adjusted for the other reported risk factors as well as day-care attendance, number of siblings, gender, birth season, birth weight, prenatal maternal smoking, Feld1 and Canf1.

\section{Discussion}

Family history of asthma as determined in primary care was a significant risk factor for the occurrence of respiratory tract and asthma-related morbidity during the first two years of life. However, our most intriguing finding was that the relation PFH and respiratory morbidity was modified by postnatal exposure to parental smoking, house dust mite and breastfeeding. Parental smoking and house dust mite exposure increased the effect of PFH on 'wheezing ever' and 'attacks of wheezing'. Moreover, when these infants were exposed to both postnatal parental smoking and house dust mite this increase was even more pronounced. Finally, the significant effect of PFH compared to NFH on tonsillitis and (acute) otitis media in formula-fed infants disappeared in breastfed infants. In PFH infants, the effect of breastfeeding compared to formula feeding was lowered for (acute) otitis media, indicating that breastfeeding may be protective in PFH infants.

\section{Family history of asthma}

Our findings are in agreement with those of Bosken et al. ${ }^{36}$ who demonstrated that more infants with a parental history of asthma had respiratory tract related morbidity during the first 18 months of life than infants without such a history. Other groups showed similar results in populations using other 
definitions of family history. ${ }^{19,20}$ In contrast to the Isle of Wight ${ }^{19}$ and the NacMaas ${ }^{20}$ study we observed only a marginal effect of $\mathrm{PFH}$ on a doctors diagnosis of eczema. In the NacMaas study the appearance of eczema was observed only with a bi-variate analysing technique. Using this technique we confirmed a significant effect of PFH on a doctors diagnosis of eczema $(\mathrm{OR}=1.7$, 95\% CI=1.1-2.6). However, this effect disappeared when confounding and effect modification were taken into account. A difference with the Isle of Wight study is that they included other potential confounders in their study, which may be an explanation for the differences in results. However, the most important reason for the differences observed is likely the definition of family history.

As previously shown, ${ }^{37-39}$ the strongest predictor for asthma or any other atopic condition is the same condition in first-degree family members. Litonjua et al. ${ }^{37}$ showed in a population of children with a median age of 3.5 years that a family history of asthma increased the risk of developing asthma but not eczema, whereas the greatest (family) risk associated with eczema was a family history of eczema. The underlying thought for this phenomenon is that there are different inheritance mechanisms for asthma and other allergic diseases, although these mechanisms may be interrelated with one another. ${ }^{39-41}$

The increased occurrence of respiratory morbidity in PFH compared to NFH infants is probably a result of environmental exposure together with genetic susceptibility. However, in addition to the combined action of genes and environment there are other mechanisms, like those of geometric origin, which might be involved.

It is possible that PFH infants have impaired airway geometry more frequently than NFH infants, which could result possibly in the occurrence of more respiratory tract and asthma-related morbidity. Dezateux et al. ${ }^{42}$ studied infants who were previously healthy at eight weeks of age. They demonstrated, prior to any respiratory illness, a significant diminished specific airway function in infants who developed at least one episode of wheezing by their first birthday compared to those who did not develop a wheezing episode during this period.

Moreover, they showed that infants with lower levels of specific airway conductance were more likely to have recurrent wheezing in the first year and to start wheezing at an earlier age. Finally, infants with a family history of asthma had significantly reduced specific airway conductance and subsequently developed more wheezing.

If this is the case, a small trigger from, for example, environmental origin will lead to respiratory morbidity in PFH infants more easily than in NFH infants. 


\section{Environmental factors}

The postnatal effects of exposure to parental smoking on children's health have long been recognized. ${ }^{43}$ In accordance with others we found that parental smoking was associated with wheezing. ${ }^{44,45}$ In addition we found that for infants exposed to parental smoking, the risk of PFH for wheezing ever and attacks of wheezing was higher than that risk in unexposed.

In an observational study of Platts-Mills et al. ${ }^{46}$ an association was found between Derp1 exposure with respiratory tract and asthma-related morbidity. However, in randomised controlled intervention studies, avoidance of Derp1 did not always result in less respiratory tract and asthma-related morbidity in infants. 19,20,21,22,23,26 An explanation for these inconclusive findings may be that the effect of the presence or absence of a positive family history of asthma was not always compared.

In a birth cohort study, Johnson et al ${ }^{47}$ showed that parental history was an important independent variable in the relationship between early Derp1 exposure and atopic outcomes in children aged 6-7 years. Exposure to Derp1 during infancy was associated with an increased risk for sensitisation in the presence of a positive parental history, but was protective among children without a parental history of atopic disease. These findings were comparable with our findings. We observed an increase in the effect between PFH and wheezing ever as well as with attacks of wheezing in infants who were exposed to high levels of Derp1 compared to those exposed to low levels of Derp1.

It has been shown that breastfeeding protects against several respiratory tract related disorders, including acute otitis media. ${ }^{48-51}$ However, the interactive effect of breastfeeding and a family history of asthma has not been studied before. Our study confirmed the protective effect of breastfeeding as to acute otitis media, but this effect was only observed in PFH infants and not in NFH infants.

\section{Strengths and weaknesses}

Our study uses a GP-registered population. We chose this design because Dutch general practice has a comprehensive overview of asthma in the families in the registered general population. In this study the GP recorded prospectively whether parents and siblings had asthma, based on standardised ICHPPC-2 criteria. ${ }^{31}$ In most other studies, the mother reported data on family history.19,21,36 Objective information concerning the father's history was therefore often lacking, which may have lead to reporting bias in these studies. A disadvantage of our study is the chance of underestimation of the asthma risk due to the selection procedure used. When asthma in siblings is involved in defining PFH, an underestimation of the risk in smaller families compared to 
larger families will exist. However when the definition of PFH is based exclusively on asthma in the parents, the underestimation might be even more pronounced. Burke et al. showed that a broader definition of PFH resulted in a higher specificity than when a narrow definition was used. ${ }^{10}$ To account for the possible underestimation of the risk in our design, we controlled for family size in the multiple logistic regression analysis.

In this study we had the opportunity to collect information regarding respiratory tract and asthma-related morbidity and the occurrence of asthma in a primary care population in early infancy. Information was collected over a two-year period at different time-intervals: every six months during the first year and after that on an annual basis with the internationally accepted ISAAC questionnaire and with information from the medical records.

Since we did multiple comparisons we considered corrections according to Bonferroni. However, our results were all in the same direction and, in addition, we found more significant interactions than would be expected by chance. Therefore, as testing was hypothesis-based it is not likely that the results were coincidental.

In conclusion, our general practice-based study demonstrated that respiratory tract and asthma-related morbidity occurred more often in PFH infants. Postnatal parental smoking and Derp1 increased the effect of PFH on 'wheezing ever' and 'attacks of wheezing'. Breastfeeding was protective against (acute) otitis media in PFH infants.

Our findings may shed more light on the controversy concerning the effect of environmental factors. Moreover, our findings may have important implications for asthma health care management, e.g. for how to advise parents of PFH or NFH infants concerning preventive measures. Furthermore, we recommend building further on this study by following the infants until at least the age of six, when an objective asthma diagnosis can be made. 


\section{References}

1. Von Mutius E. The burden of childhood asthma Arch Dis Child 2000; 2(suppl2):II2-5.

2. Van Schayck CP, Smit HA. The prevalence of asthma in children: a reversing trend. Eur Respir J 2005;26:647-50.

3. The International Study of Asthma and allergies in Childhood (ISAAC) Steering Committee. Worldwide variation in prevalence of symptoms of asthma, allergic rhinoconjunctivitis, and atopic eczema: ISAAC. Lancet 1998;351:1225-32.

4. Eldeirawi K, Persky VW. History of ear infections and prevalence or asthma in a national sample of children aged 2 to 11 years: The third national health and nutrition examination survey, 1988 to 1994. Chest 2004;125:1685-9.

5. Braun-Fahrlander C, Gassner M, Grize L, Takken-Sahli K, Neu U, Stricker T, Varonier HS, Wuthrich B, Sennhauser FH. No further increase in asthma, hay fever and atopic sensitisation in adolescents living in Switzerland. Eur Respir J 2004;23:407-13.

6. Mommers M, Gielkens-Sijstermans C, Swaen GMH, Schayck CP van. Trends in prevalence of respiratory symptoms and treatment in Dutch children over a 12 year period: results of the fourth consecutive survey. Thorax 2005;60:97-9.

7. Austin JB, Selvaraj S, Russell G. Childhood asthma in the highlands of Scotland - Morbidity and school absence. Scott Med J 2004;49:18-21.

8. Vermeire PA, Rabe KF, Soraiano JB, Maier WC. Asthma control and differences in management practices across seven European countries. Respir Med 2002;96:142-9.

9. Polder JJ, Takken J, Merding WJ, Kommer GJ, Stokx LJ. Cost of illness in the Netherlands. [RIVM report 270751005/2002] Available from www.rivm.nl/kostenvanziekten.

10. Burke W, Fesinmeyer M, Reed K, Hampson L, Carlsten C. Family history as a predictor of asthma risk. Am J Prev Med 2003;24:160-9.

11. DiFranza JR, Aligne CA, Weitzman M. Prenatal and postnatal environmental tobacco exposure and children's health. Pediatrics 2004;113:1007-15.

12. Wahn U, Lau S, Bergmann R, Kulig M, forster J, Bergmann K, Bouer CP, GuggenmoosHolzmann I. Indoor allergen exposure is a risk factor for sensitization during the first three years of life. J Allergy Clin Immunol 1997;99:763-9.

13. Vanto T, Koivikko A. Dog hypersensitivity in asthmatic children. Acta Paediatr Scand 1983;72:571-5.

14. Warner JA, Little SA, Pollock I, Longbottom JL, Warner JO. The influence of exposure to house dust mite, cat and pollen allergens in the homes on primary sensitisation in asthma. Pediatr Allergy Immunol 1991;1:79-86.

15. Chantry CJ, Howard CR, Auinger P. Full breastfeeding duration and associated decrease in respiratory tract infection in US children. Pediatrics 2006;117:425-32.

16. Sears MR, Green JM, Willan AR, Taylor DR, Flannery E, Cowan JO, Herbison GP, Poulton R. Long-term relation between breastfeeding and development of atopy and asthma in children and young adults: a longitudinal study. Lancet 2002;360:901-7.

17. Hesselmar B, Aberg N, Aberg B, Eriksson B, Bjorksten B. Does early exposure to cat or dog protect against later allergy development? Clin Exp Allergy 1999;29:611-17.

18. Burr ML, Merrett TG, Dunstan FDJ, Maguire MJ. The development of allergy in high-risk children. Clin Exp Allergy 1997;27:1247-53.

19. Arshad SH, Stevens M, Hide DW. The effect of genetic and environmental factors on the prevalence of allergic disorders at the age of two years. Clin Exp Allergy 1993;23:504-11.

20. Custovic A, Simpson BM, Simpson A, Kissen P, Woodcock A. Effect of environmental manipulation in pregnancy and early life on respiratory symptoms and atopy during first year of life: a randomised trial. Lancet 2001;358:188-93.

21. Koopman LP, Strien RT van, Kerkhof M, Wijga A, Smit HA, de Jongste JC, Gerritsen J, Aalberse RC, Brunekreef B, Neijens HJ. Placebo-controlled trial of house dust miteimpermeable mattress covers: effects on symptoms in early childhood. Am J Respir Crit Care Med 2002;166:307-13. 
22. Mihrshahi S, Peat JK, Marks GH, Mellis CM, Tvey ER, Webb K, Britton WJ, Leeder SR. Eighteen-month outcomes of house dust mite avoidance and dietary fatty acid modification in the childhood astha prevention study (CAPS). J Allergy Clin Immunol 2003;111:162-8.

23. Becker A, Watson W, Ferguson A, Dimich-Ward H, Chan-Yeung M. The Canadian asthma primary prevention study: Outcomes at 2 years of age. J Allergy Clin Immunol 2004;113:650-6.

24. Knottnerus JA. Between iatrotropic stimulus and interiatric referral: the domain of primary care research. J Clin Epidemiol 2002;55:1201-6.

25. McCunney RJ. Asthma, genes and air pollution. J Occup Environ Med 2005;47:1285-91.

26. Kuiper S, Maas T, van Schayck CP, Muris JWM, Schönberger HJAM, Dompeling E, Gijsbers B, van Weel C, Knottnerus JA. The primary prevention of asthma in children (PREVASC) study: Design of a multifaceted prevention program. Pediatr Allergy Immuol 2005;16(4):321-31.

27. Schönberger HJAM, Dompeling E, Knottnerus JA, Maas T, Muris JWM, van Weel C, van Schayck CP. The clinical effectiveness of the PREVASC intervention. Eur Respir J 2005 ;25: 660-70.

28. Dirksen WJ, Geijer RMM, de Haan M, de Koning G, Flikweert S, Kolnaar BGM. Astma bij kinderen. NHG-Standaard. Huisarts Wet 1998;41:130-43.

29. Schönberger HJ, van Schayck CP. Prevention of asthma in genetically predisposed children in primary care-- from clinical efficacy to a feasible intervention programme. Clin Exp Allergy 1998;28:1325-31.

30. The WONCA classification committee. ICPC-2. International Classification of Primary Care. Oxford, Oxford University Press, 1998.

31. Classification Committee of WONCA. ICHPPC-2 defined International Classification of Health Problems in Primary Care. Oxford: Oxford University Press, 1983.

32. Van der Heide S, van Aalderen WM, Kauffman HF, Dubois AE, de Monchy JG. Clinical effects of air cleaners in homes of asthmatic children sensitized to pet allergens. J Allergy Clin Immunol 1999;104(2 Pt 1):447-51.

33. Nelson EA, Taylor BJ, Jenik A, Vance J, Walmsley K, Pollard K et al. International child care practices study: infant sleeping environment. Early Human Development 2001;62:43-55.

34. Lindgren C, Thompson JM, Haggblom L, Milerad J. Sleeping position, breastfeeding, bedsharing and passive smoking in 3-month-old Swedish infants. Acta Paediatr 1998;87: 1028-32.

35. Platts-Mills TA, Thomas WR, Aalberse RC, Vervloet D, Champman MD. Dust mite allergens and asthma: report of a second international workshop. J Allergy Clin Immunol 1992;89: 1046-59.

36. Bosken $\mathrm{CH}$, Hunt WC, Lambert WE, Samet JM. A parental history of asthma is a risk factor for wheezing and nonwheezing respiratory illnesses in infants younger than 18 months of age. Am J Respir Crit Care Med 2000;161:1810-15.

37. Litonjua AA, Carey VJ, Burge HA, Weiss ST, Gold DR. Parental history and the risk for childhood asthma. Does mother confer more risk than father? Am J Respir Crit Care Med 1998;158:176-81.

38. Dold S, Wjst M, von Mutius E, Reitmeir P, Stiepel E. Genetic risk for astma, allergic rhinitis, and atopic dermatitis. Arch Dis Child 1992;67:1018-22.

39. Gray L, Peat JK, Belousova E, Xuan W, Woolcock AJ. Family patterns of asthma, atopy and airway hyperresponsiveness: an epidemiological study. Clin Exp Allergy 2000;30:393-9.

40. Grossman J. One airway, one disease. Chest 1997;111:11S-6S.

41. Corren J. Allergic rhinitis and asthma: how important is the link? J Allergy Clin Immunol 1997;99:S781-6.

42. Dezateux C, Stocks J, Dundas I, Fletcher ME. Impaired airway function and wheezing in infancy. The influence of maternal smoking and a genetic predisposition to asthma. Am J Respir Crit Care Med 1999;159:403-10.

43. Cameron P. The presence of pets and smoking as correlates of perceived disease. J Allergy 1967;40:12-5.

44. Strachan D, Cook D. Health effects of passive smoking 6: parental smoking and childhood asthma: longitudinal and case-control studies. Thorax 1998;53:204-12. 
45. Willatt DJ. Children's sore throats related to parental smoking. Clin Otolaryngol 1996;11: 317-21.

46. Platts-Mills TA, Vaughan JW, Carter MC, Woodfolk JA. The role of intervention in established allergy: avoidance of indoor allergens in the treatment of chronic allergic disease. J Allergy Clin Immunol 2000;106;787-804.

47. Johnson CC, Ownby DR, Havstad SL, Peterson EL. Family history, dust mite exposure in early childhood, and risk for pediatric atopy and asthma. J Allergy Clin Immunol 2004;114:105-10.

48. Benefits of breastfeeding. Dept of Health and Human Service Office on Women's Health. Nutr Clin Care 2003;6:125-31.

49. Chantry CJ, Howard CR, Auinger P. Full breastfeeding duration and associated decrease in respiratory tract infection in US children. Pediatrics 2006;117:425-32.

50. Baraibar R. Incidence and risk factors of acute otitis media in children. Clin Microbiol Infect 1997;3 Suppl 3:S13-22.

51. Rodrigo C. Prevention of acute otitis media. Clin Microbiol Infect 1997;3 Suppl 3:S55-8. 


\section{Chapter 5}

Family history modifies the effect of day-care on respiratory morbidity in early infancy: The PREVASC program

Sandra Kuiper, Constant P. van Schayck, J. André Knottnerus, Jean W.M. Muris, Arnold D.M. Kester, Huub J.A.M. Schönberger, Tanja Maas, Geertjan Wesseling, Edward Dompeling 


\section{Abstract}

Background

Day-care attendance and family history of asthma have been shown to increase the risk of respiratory morbidity in early infancy. Although it is likely that infants with different genetic backgrounds will respond differently to environmental stimuli, it remains unclear what the relationship is between day-care and morbidity.

\section{Objective}

To study whether family history of asthma modifies the contribution of day-care attendance to respiratory morbidity in infants aged $0-2$.

\section{Methods}

221 Prenatally selected infants with a positive family history (PFH) and 308 with a negative family history (NFH), prospectively followed to two years of age. Outcome measures: respiratory morbidity from weekly parental reports, ISAAC questionnaire and standardized recordings from general practitioners, based on international ICHPPC criteria. Relationships between respiratory morbidity and both family history and day-care attendance were investigated and adjusted for potential confounders.

Results

Respiratory morbidity was considerably higher in PFH than NFH infants. Day-care attendance had no statistically significant effect on appearance and frequency of symptoms in PFH infants, but was associated with increased nocturnal cough (OR=5.1,95\% CI=2.9-9.0), cough on exertion $(\mathrm{OR}=2.4,95 \% \mathrm{CI}=1.4-4.0)$, cold $(\mathrm{OR}=4.7,95 \% \quad \mathrm{CI}=2.7-8.4)$, attacks of wheezing (OR=2.8,95\% $\mathrm{CI}=1.5-5.0)$, awakening by cough $(\mathrm{OR}=2.9,95 \% \mathrm{CI}=1.6-5.5)$ and allergic rhinoconjunctivitis $(\mathrm{OR}=2.4,95 \% \mathrm{CI}=1.1-5.4)$ in NFH infants.

\section{Conclusion}

In the fist two years of life, day-care attendance increases the risk of respiratory morbidity in NFH infants more than in PFH infants. In PFH infants this increase is not statistically significant. Although definite conclusions cannot be drawn, this could indicate that PFH and NFH infants respond differently to day-care attendance. Should these observations be replicated in further studies in children at shool age, it could lead to different advice on day-care attendance for families with and without asthma. 


\section{Introduction}

In the past two decades a substantial increase in the prevalence of atopy and asthma has been observed in infants, $, 1,2$ although some studies have reported a recent stabilisation in prevalence ${ }^{3,4}$ or even a decrease in the past few years. ${ }^{5}$ The reasons for these changes in prevalence are poorly understood. Asthma is a complex disease in which genetic and environmental causes as well as their interactions play an important role. ${ }^{6}$ Various studies have assessed risk factors or protective factors for the development of asthma. . $^{70}$ The attendance of daycare has been shown to be related to the development of respiratory morbidity, atopic sensitisation, allergy, and asthma. ${ }^{11-14}$ Preschool children visiting daycare demonstrated more frequent wheeze ${ }^{12}$ and more upper as well as lower respiratory tract infections than those who did not. ${ }^{13}$ In contrast to these observations an inverse effect was seen in children of school age who attended day-care in early life. Among these children day-care attendance reduced the risk of frequent wheeze, ${ }^{12}$ atopy ${ }^{11}$ and asthma. ${ }^{12,14}$ Comparable findings were reported for children with one or more siblings.12-15 A common explanation is that more frequent infections in early life acquired during day-care lead towards a more favourable Th1-based immune response. ${ }^{16}$ Ball et al. described more viral infections and consequently more respiratory symptoms and virus associated wheeze in infants attending day-care, but less asthma in children of school age. ${ }^{12}$ It is thought that first-degree family history of asthma increases the risk of asthma substantially. Although specific genes have not yet been fully identified, it is supposed that several genes on different chromosomes (i.e. $2 q, 5 q, 6 p, 12 q$ and $13 q$ ) are involved. Due to the genetic differences it may be likely that infants with and without a family history of asthma respond differently to environmental stimuli and infections. Currently little is known about differences in response to day-care exposure of infants with a positive family history of asthma (PFH infants) and those with a negative family history of asthma (NFH infants). ${ }^{17}$

We prospectively followed prenatally selected PFH and NFH infants up to the age of two with respect to respiratory morbidity..$^{18}$ In this study, the hypothesis was that a family history of asthma modifies the effect of day-care attendance on the development of respiratory symptoms and diagnoses in infants aged 0-2 years. 


\section{Methods}

\section{Recruitment of subjects}

As recently described, ${ }^{18} 793$ infants were included in a prospective birth cohort study. From these infants, 27 were excluded, 15 were lost to follow-up. 443 Infants had a family history of asthma and participated in a randomised controlled clinical prevention trial. ${ }^{19}$ For the current study only PFH infants $(n=221)$ who were allocated to the control group were used, as well as $308 \mathrm{NFH}$ infants. Both groups received usual care. ${ }^{20} \mathrm{PFH}$ was defined as 'having at least one first-degree family member suffering from General Practitioner (GP) registered asthma', whereas NFH was defined as 'absence of GP registered asthma in first-degree family members'.$^{21}$

\section{Outcome measures}

\section{ISAAC questionnaire}

At six months, one year and two years of age parents completed the International Study of Asthma and Allergies in Childhood questionnaire. 18,22

\section{Weekly reports}

Parents registered respiratory morbidity on a weekly base. ${ }^{18,19}$ Early frequent wheeze was defined as at least three separate periods with two weeks of wheezing or six separate periods with at least one week of wheezing.

\section{GP diagnoses}

Respiratory morbidity was registered by the GP at every consultation. ${ }^{18,19}$ Diagnoses were based on the criteria of the International Classification of Health Problems in Primary Care. ${ }^{23}$

$\operatorname{Ig} E$

At age two, blood samples were collected to measure the concentration of total and allergen-specific IgE to mite, cat and dog allergens. IgE was determined as described elswhere. ${ }^{24}$ The cut-off level for total IgE was $\geq 9.4 \mathrm{IU} / \mathrm{ml}$, which was the median total IgE value of the PFH and NFH group together. The cut-off level of allergen-specific IgE was $\geq 0.35 \mathrm{IU} / \mathrm{ml}$.

\section{Family history, day-care attendance and co-variables}

Family history of asthma and sibling number were determined directly at inclusion..$^{21}$ Information on day-care attendance was sampled from the weekly 
reports. Gender, birth season, birth weight, parental smoking, and data on exposure to allergens were registered as described elswhere. ${ }^{18}$

\section{Statistical methods}

Means for continuous normally distributed variables were analysed with the Student's t-test. Differences in proportions between the groups for dichotomous variables were evaluated using the $\chi^{2}$ test. Continuous, not normally distributed, variables from the weekly reports were analysed using the Mann Whitney U test.

In multiple logistic regression analysis (MLR) the contributions of the independent variables (family history, day-care attendance, sibling number, gender, breastfeeding, birth season, birth weight, prenatal maternal and postnatal parental smoking) to the various outcome variables (respiratory morbidity, total and specific IgE) were evaluated. First order interactions between family history, day-care attendance and sibling number were included. Interaction terms that were not significant were dropped from the model, in a stepwise backward manner. The interaction term family history of asthma and day-care attendance was retained in the model since this concerns the main research question.

For the MLR analysis the continuous variables from the weekly reports were dichotomised based on the median values of the PFH and NFH group together. P-values smaller than 0.05 were considered as statistically significant. Statistical analysis was performed using SPSS version 11.0.

\section{Ethics}

The ethics committees of the participating institutes approved the study. All participating parents gave, informed consent.

\section{Results}

\section{Subject characteristics}

Information on day-care attendance was missing from $32 \mathrm{PFH}$ and $26 \mathrm{NFH}$ infants (non-responders). In the non-responders group only prenatal maternal smoking (PFH infants: 25\%, NFH infants: 21\%) and postnatal parental smoking (PFH infants: 35\%, NFH infants: 21\%) deviated from the responders group. No statistically significant difference in day-care attendance was observed in the participants group between PFH and NFH infants, apart from the fact that PFH infants had statistically significantly more siblings and more births in winter period than NFH infants (Table 5.1). Within PFH and within NFH a distinction 
was made between infants with and without day-care attendance. Within the PFH groups there was a statistically significant difference for number of siblings. A significant difference was also observed for postnatal smoking by the parents, being highest in the PFH infants not visiting day-care.

Table 5.1 Demographic characteristics of the study population.

\begin{tabular}{|c|c|c|c|c|c|c|}
\hline & \multicolumn{3}{|c|}{ Total group } & \multicolumn{3}{|c|}{ Subgroups } \\
\hline & \multicolumn{2}{|c|}{ PFH } & \multirow{2}{*}{$\begin{array}{l}\text { NFH } \\
\text { Day-care } \\
\text { attendance } \\
n=80\end{array}$} & \multicolumn{2}{|l|}{ PFH } & \multirow{2}{*}{$\begin{array}{l}\text { NFH } \\
\text { No day-care } \\
\text { attendance } \\
n=173\end{array}$} \\
\hline & $n=221$ & $\mathrm{n}=308$ & & $\begin{array}{c}\text { No day-care } \\
\text { attendance } \\
n=109\end{array}$ & $\begin{array}{c}\text { Day-care } \\
\text { attendance } \\
n=109\end{array}$ & \\
\hline Mother's age yrs, mean (SD) & $31(4)$ & $31(4)$ & $31(4)$ & $31(4)$ & $31(3)$ & $31(4)$ \\
\hline Male gender $\mathrm{n}(\%)$ & $112(50.7)$ & $162(52.6)$ & $41(51.3)$ & $54(49.5)$ & $48(48.0)$ & $89(51.4)$ \\
\hline Birth weight, mean (SD) grams & $3494(533)$ & 3455 (579) & $3508(531)$ & $3495(547)$ & $3490(631)$ & $3445(556)$ \\
\hline Gestational age, mean (SD) weeks & $39.7(1.7)$ & $39.8(1.7)$ & $39.9(1.7)$ & $39.6(1.7)$ & $39.6(1.8)$ & $39.9(1.7)$ \\
\hline \multicolumn{7}{|c|}{ Birth season $\mathrm{n}(\%)$} \\
\hline Spring & $51(23.1)^{\mathrm{a}}$ & $94(30.5)$ & $16(20.0)$ & $30(27.5)$ & $29(29.0)$ & $52(30.1)$ \\
\hline Summer & $61(27.6)$ & $104(33.8)$ & $21(26.3)$ & $28(25.7)$ & $32(32.0)$ & $60(34.7)$ \\
\hline Autumn & $48(21.7)$ & 55 (17.9) & $16(20.0)$ & $25(22.9)$ & $23(23.0)$ & $29(16.8)$ \\
\hline Winter & $61(27.6)$ & $55(17.9)$ & $27(33.8)$ & $26(23.9)$ & $16(16.0)$ & $32(18.5)$ \\
\hline \multicolumn{7}{|l|}{ Siblings n (\%) } \\
\hline 0 & $84(38.0)^{\mathrm{a}}$ & $140(45.5)$ & $42(52.5)^{b}$ & $33(30.3)$ & $52(52.0)$ & $71(41.0)$ \\
\hline 1 & $85(38.5)$ & $127(41.2)$ & $30(37.5)$ & $42(38.5)$ & $40(40.0)$ & $73(42.2)$ \\
\hline 2 & $40(18.1)$ & $33(10.7)$ & $6(7.5)$ & $25(22.9)$ & $6(6.0)$ & $24(13.9)$ \\
\hline 3 & $8(3.6)$ & $8(2.6)$ & $2(1.8)$ & $5(4.6)$ & $2(2.0)$ & $5(2.9)$ \\
\hline 4 & $2(0.9)$ & & & $2(1.8)$ & & \\
\hline 5 & $2(0.9)$ & & & $2(1.8)$ & & \\
\hline Prenatal maternal smoking n (\%) & $22(10.8)$ & 35 (11.7) & $4(5.1)$ & $13(12.3)$ & $8(7.4)$ & $23(13.3)$ \\
\hline Postnatal parental smoking n (\%) & $61(29.9)$ & $95(31.7)$ & $13(16.7)^{\mathrm{b}}$ & $41(38.7)$ & $31(28.7)$ & $55(31.8)$ \\
\hline
\end{tabular}

$\mathrm{PFH}$ (infants with a positive family history); NFH (infants with a negative family history); Comparison of $\mathrm{PFH}$ and NFHk infants: a $\mathrm{P}<0.05$;. Comparison of $\mathrm{PFH}$ infants with and without day-care attendance ${ }^{\mathrm{b}} \mathrm{P}<0.01$.

\section{Influence of family history}

PFH infants had statistically significantly more respiratory symptoms of coughing, wheezing as well as shortness of breath and colds than NFH infants, as recorded in both the weekly reports and the ISAAC questionnaire (Table 5.2 and 5.3). Also a GP diagnosis of the lower respiratory tract infections, asthma, bronchiolitis, eczema, pneumonia and croup, as well as the upper respiratory tract infection tonsillitis and presence of expiratory wheezing were statistically significantly more present in PFH than in NFH infants (Table 5.4). 


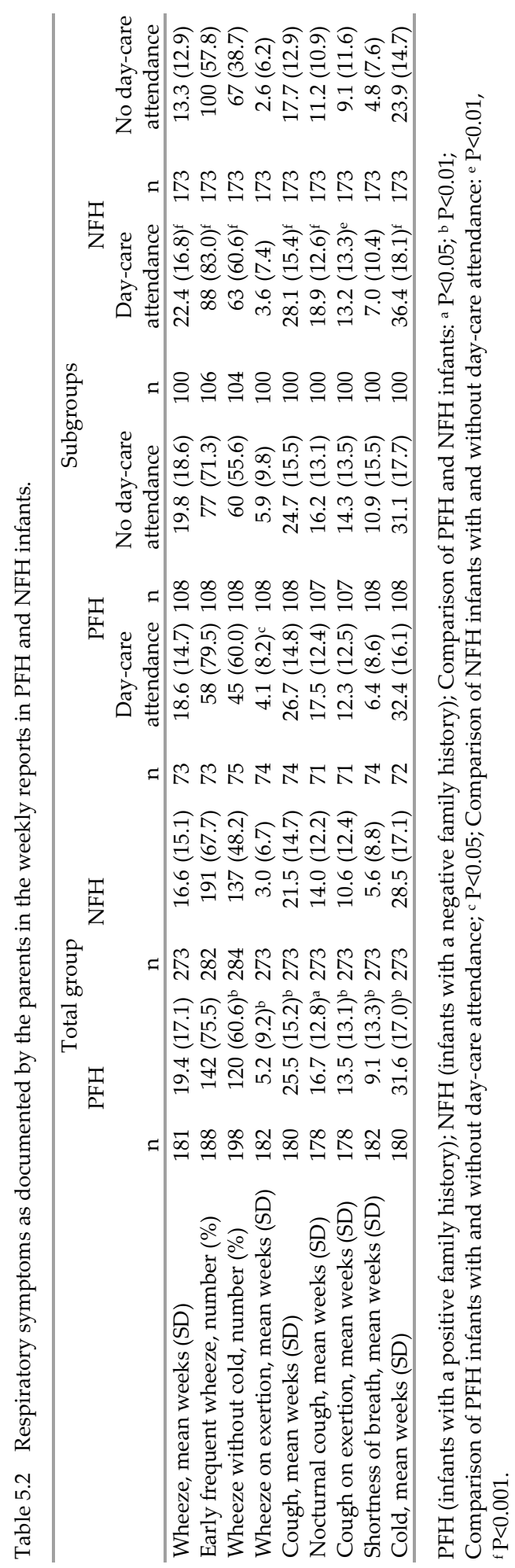




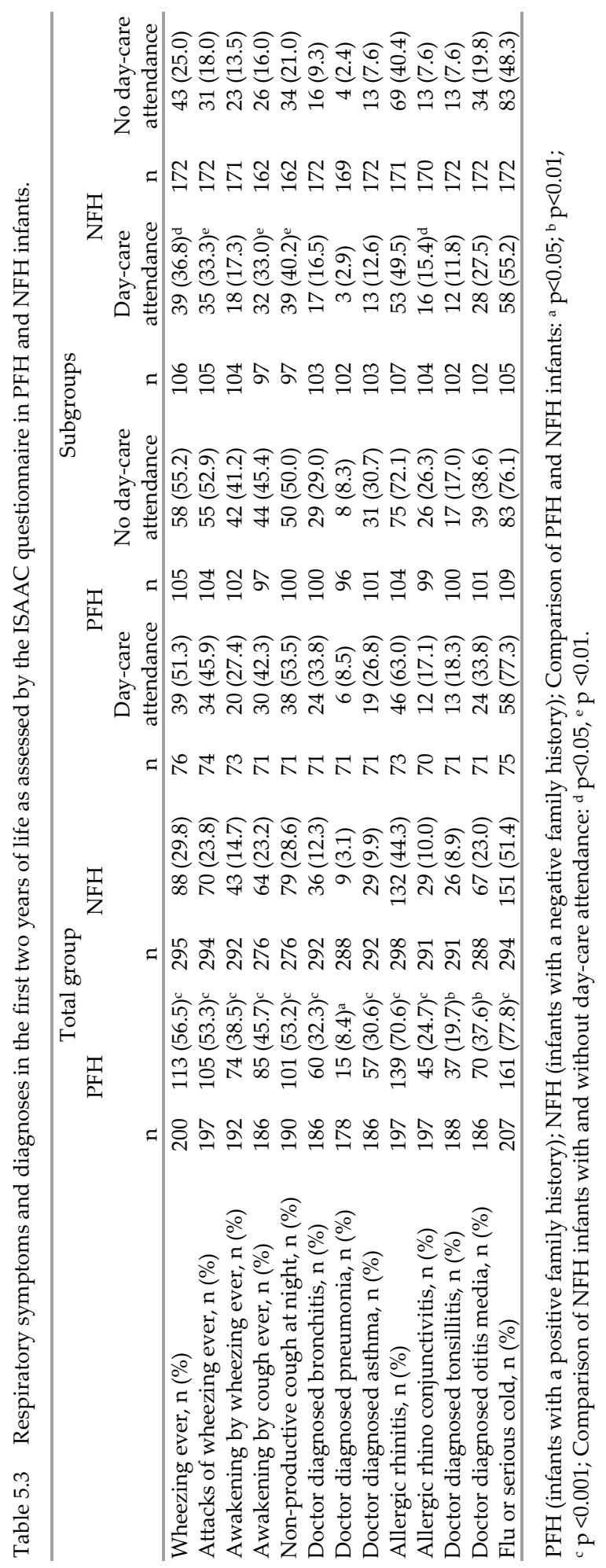




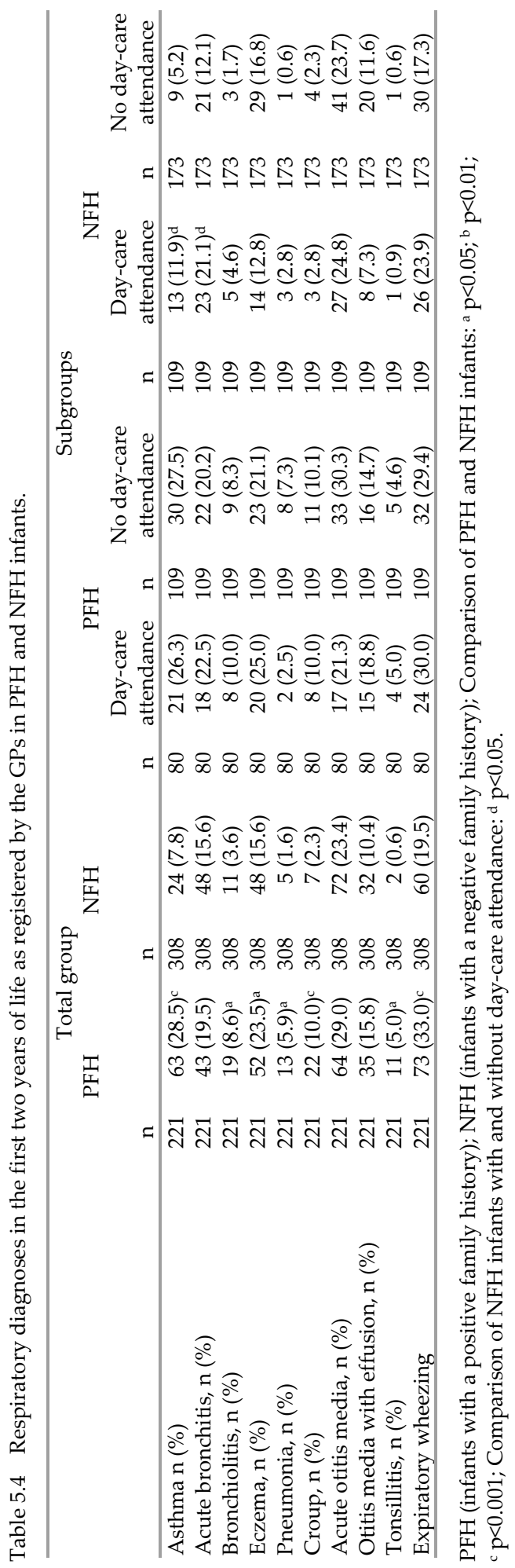




\section{Influence of day-care in NFH infants}

NFH infants who attended day-care had significantly more respiratory symptoms and GP diagnoses than those who did not attend day-care. As documented in the weekly reports, day-care was more often accompanied by presented symptoms of coughing, wheezing and mean weeks with cold (Table 5.2). Moreover as reported in the ISAAC questionnaire, wheezing ever, attacks of wheezing ever, wakening-up by cough, non-productive cough at night and allergic rhino conjunctivitis were more present in infants attending day-care than in those who did not (Table 5.3). Finally, infants attending day-care were more often diagnosed by the GP with asthma or acute bronchitis (Table 5.4).

\section{Influence of day-care in PFH infants}

In PFH infants, day-care attendance was not associated with more respiratory morbidity. There was even a tendency that PFH infants visiting day-care had less respiratory morbidity than those not visiting day-care (Table 5.2, 5.3, 5.4). However this reached only significance for wheeze on exertion in bivariate analyses (Table 5.2), but not after adjusting for potential confounders and effect modifiers (data not shown).

\section{Atopic sensitisation}

At the age of two, total IgE $\geq 9.4 \mathrm{IU} / \mathrm{ml}$ was statistically significantly more often present in PFH infants compared with NFH infants (Odds ratio 1.81 [95\% C.I. $1.26-2.60]$ ). Only a small percentage of the infants had elevated levels of allergen-specific IgE to house dust mite, cat and dog allergens. No statistically significant differences were seen in specific IgE at the age of two in PFH infants in comparison with NFH infants.

The number of infants with sensitisation for a specific allergen was low at the age of two and varied from $1.9 \%$ for PFH infants not attending day-care to $7.8 \%$ for PFH infants attending day-care. No differences in specific IgE were found between PFH and NFH infants with or without day-care attendance. Moreover, no statistically significant interaction was found between family history and day-care attendance on total or specific IgE.

\section{Interaction between day-care and family history of asthma}

Multiple logistic regression analyses confirmed that day-care attendance had no significant effect on respiratory morbidity in PFH infants, but was associated with more respiratory symptoms in NFH infants. For the symptoms nocturnal cough, cough on exertion, attacks of wheezing ever, awakening by wheeze and cough ever, as well as for cold, allergic rhinitis and allergic 
rhinoconjunctivitis the interaction between day-care and first-degree family history was statistically significant (Figure 5.1, 5.2).

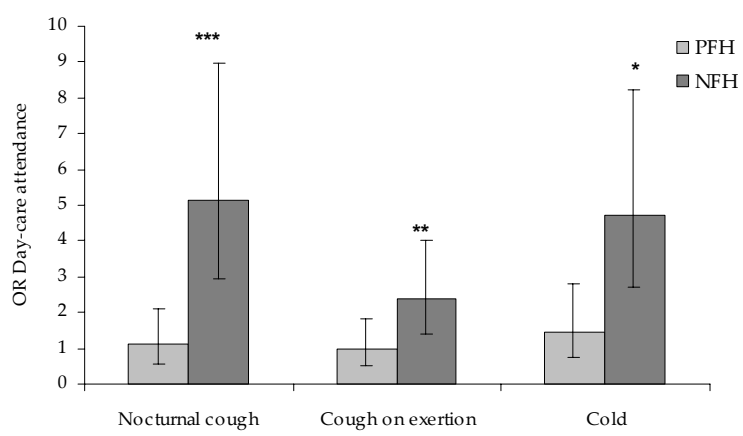

Figure 5.1 Effect of day-care attendance (compared to no day-care attendance) on weekly reported respiratory morbidity in PFH and NFH infants. Only significant effects are shown. PFH: infants with a positive family history, NFH: infants with a negative family history. ${ }^{* * *} \mathrm{P}<0.001,{ }^{* *} \mathrm{P}<0.01,{ }^{*} \mathrm{P}<0.05$.

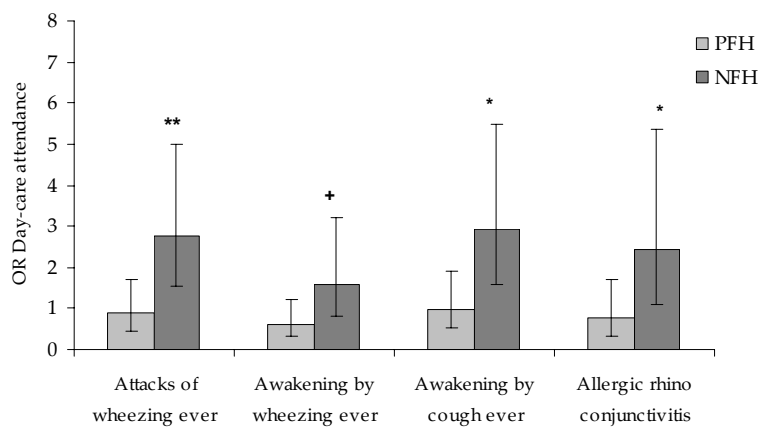

Figure 5.2 Effect of day-care attendance (compared to no day-care attendance) on respiratory morbidity in PFH and NFH infants as reported in the ISAAC questionnaire. Only significant effects are shown. PFH: infants with a positive family history, NFH: infants with a negative family history. ${ }^{* *} \mathrm{P}<0.01,{ }^{*} \mathrm{P}<0.05,+\mathrm{P}=0.050$.

A statistically significant interaction between day-care and family history of asthma was also present for the variable allergic rhinitis from the ISAAC questionnaire. In this case PFH infants not attending day-care were at higher risk to develop allergic rhinitis than $\mathrm{PFH}$ infants who did attend day-care (Figure 5.3).

\section{Influence of family size}

For most variables, there was no influence of the presence of siblings, which was however, statistically significantly related to the dependent variable 'colds' from the weekly reports (Odds ratio 2.16 [95\% C.I. 1.39-3.34]). Presence of 
siblings was also significantly related to the variables doctor diagnosed otitis media (Odds ratio 2.08 [95\% C.I. 1.28-3.38]), acute bronchitis (Odds ratio 1.75 [95\% C.I. 1.01-3.03]) as well as allergic rhino conjunctivitis (Odds ratio 2.08 [95\% C.I. 1.12-3.87]) from the ISAAC questionnaire. Moreover, a statistically significant interaction between family history of asthma and family size was present for non-productive cough at night from the ISAAC questionnaire as well as GP registered otitis media and total IgE at the age of two. PFH infants with at least one sibling had more complaints of non-productive cough at night and GP registered otitis media than $\mathrm{PFH}$ infants without sibs (Odds ratio 2.47 [95\% C.I. 1.24-4.93] and Odds ratio 3.29 [95\% C.I. 1.43-7.55] respectively) and NFH infants with siblings (Odds ratio 3.37 [95\% C.I. 1.46-7.79] and Odds ratio 1.88 [95\% C.I. 1.00-3.52] respectively). Moreover, PFH infants with siblings had more often a total IgE level $>9.4 \mathrm{IU} / \mathrm{ml}$ at the age of two than PFH infants without siblings (Odds ratio 2.33 [95\% C.I. 1.37-3.97]).

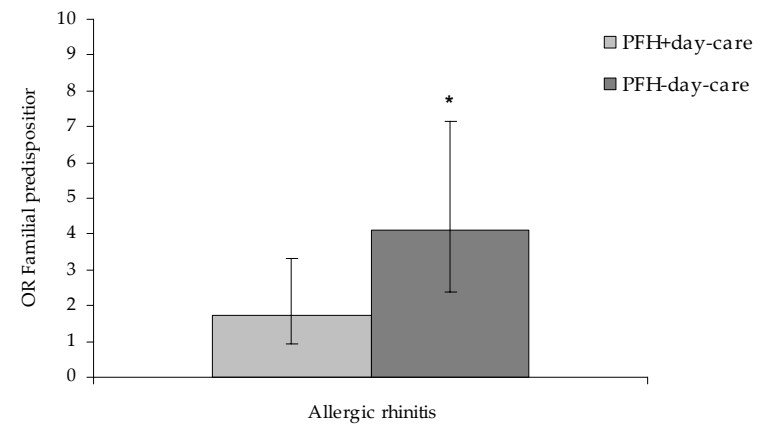

Figure 5.3 Effect of PFH on allergic rhinitis in infants attending day-care or not attending daycare as reported in the ISAAC questionnaire. PFH+day-care: PFH children attending day-care, PFH-day-care: PFH infants, who do not attend day-care. ${ }^{*} \mathrm{P}<0.05$

\section{Discussion}

In this study we give a description of wheezing and coughing patterns as well as lower and upper respiratory tract morbidity in PFH and NFH infants, attending or not attending day-care during the first two years of life.

We found that in NFH infants day-care attendance increased respiratory symptoms and diagnoses. In PFH infants day-care attendance did not statistically significant increase respiratory morbidity. In NFH infants, day-care attendance was associated with more wheezing, coughing, colds, asthma and acute bronchitis. Accordingly, a significant interaction between day-care and first-degree family history was evident for several respiratory symptoms and diagnoses. Such an interaction was not found for atopic sensitisation. Our data 
were adjusted for number of siblings, gender, birth season, breastfeeding, birth weight, prenatal maternal smoking and postnatal parental smoking. The observations were consistent in all three sources: the parental reports, the ISAAC questionnaire, and the GP records. Our data demonstrate that PFH and NFH infants respond differently to day-care attendance.

These findings are in agreement with those of other studies ${ }^{12} 25$ in which it was shown that day-care attendance leads to more wheezing in early life. However, as was not investigated by others, we add that this effect differs for PFH and NFH infants. Concerning lower- (LRTI) and upper respiratory tract infections (URTI), the PIAMA study reported that in infants attending day-care, the risk of developing LRTI was markedly increased by parental allergic status. ${ }^{13}$ This is in contrast with our findings. An explanation for this may be the difference in the definition of the PFH group. In the PIAMA study, family history was defined as allergy in at least one parent, whereas in our study, family history was defined as exclusively asthma in at least one parent and/or sibling. Moreover, in the PIAMA study the results represent morbidity at, a single moment in time, one year of age, whereas our findings are based on information concerning morbidity recorded on at least a weekly basis, during the first two years of life.

Another important study in this field, the study of Celedon et al. ${ }^{26}$, reported that day-care attendance was associated with more URTI and LRTI. In this study family history did not modify the effect of day-care on doctor-diagnosed URTI as well as LRTI, which is, except for colds and allergic rhinoconjunctivitis, in agreement with our study.

Three different sources of outcome measures were used in this study, each with specific advantages and disadvantages. The ISAAC questionnaire is internationally validated and has been applied in many countries worldwide. A disadvantage is that it assesses information in a retrospective manner, which makes it sensitive to recall bias. The GP registration of diagnoses and symptoms has the advantage of a more objective, prospective evaluation by GPs, based on standardized ICHPPC-2 criteria. However, it only assesses the presented morbidity to GPs of parents seeking medical care. An advantage of the weekly reports is the sampling of prospective information at regular, frequent time intervals with low risk of underreporting of symptoms. A disadvantage is that parents may give other meanings and interpretation to symptoms like wheezing or breathlessness than investigators or doctors may do. However, the consistency of the study results is apparent from the great degree of similarity between the data of the three different sources. Data of the ISAAC questionnaire, the weekly reports and the GP diagnoses all confirm that day-care attendance did not increase the risk on symptoms and diagnoses in infants with a family history of asthma and for some symptoms even seemed 
to protect, whereas it did increase the risk in families without such a predisposition.

A disadvantage apart from the outcome sources is that selection bias could play a role. It may be that PFH infants are taken from day-care more often than NFH infants because of (severe) respiratory morbidity. However, since the percentages of $\mathrm{PFH}$ and $\mathrm{NFH}$ infants attending day-care were comparable and these percentages did not change over the two-year period we do not expect that selection bias is an issue in our study.

Parents and GPs were not blinded for the study groups. It cannot be ruled out that parents and GPs of PFH infants are more focused on respiratory morbidity than parents than GPs of NFH infants. Therefore, part of the registered symptom differences found between the PFH and NFH infants may be contributed to this phenomenon. However, this does not explain the different effects of day-care attendance in PFH and NFH infants.

Since we did multiple comparisons we considered corrections according to Bonferroni. However, our results were all in the same direction and, in addition, we found more significant interactions than would be expected by chance. Therefore, as testing was hypothesis-based, it is not likely that the results were coincidental.

Several explanations are possible for our main findings: It is supposed that infants with and without a family history of asthma have a different genetic background. Although specific genes have not yet been fully identified it is thought that genes on several chromosomes are involved, which probably control different asthma aspects. ${ }^{27}$ These genetic differences may result into different responses from their immune systems to environmental factors.

It may be that differences in response to day-care between PFH and NFH subjects are explained by differences in wheezing phenotypes between these infants. It is likely that the PFH group contained a higher percentage of infants with persistent wheezing or true asthma compared to a higher number of transient wheezers in the NFH group. In the study of Ball et al.,12 day-care attendance has been demonstrated to increase the risk of transient wheezing in association with viral infections during the first years of life, whereas it diminished the risk of persistent wheeze or asthma. ${ }^{12}$ Therefore, the results of our study may resemble those of Ball et $\mathrm{al}^{, 12}$ in that an increase was found in viral-infection associated transient wheezing but probably a decrease in persistent wheezing or true asthmatics in infants who attended day-care. In order to investigate this, we are planning to follow these infants until they reach the age of six, by the time an objective diagnosis of asthma can be made. Respiratory complaints and diagnoses were much more frequent in the PFH subjects. It may be that day-care attendance in PFH infants does not further increase respiratory symptoms because of a 'ceiling effect' (no room for deterioration). These findings were confirmed with posthoc analyses, in which 
no effect was observed of day-care attendance on respiratory morbidity in $\mathrm{PFH}$ infants exposed to a high load of allergens. Additionally, in NFH infants daycare attendance and a high load of allergen exposure significantly worsened respiratory morbidity.

In conclusion, in our study, family history of asthma modifies the symptomatic response to day-care attendance in infants aged 0-2 years, as day-care attendance is associated with increased respiratory symptoms and diagnoses in NFH infants. In PFH infants, exposure to day-care did not exert a statistically significant effect. Although we cannot draw definite conclusions from these observations, it could be that PFH and NFH infants respond differently to daycare attendance. 


\section{References}

1. The International Study of Asthma and allergies in Childhood (ISAAC) Steering Committee. Worldwide variation in prevalence of symptoms of asthma, allergic rhinoconjunctivitis, and atopic eczema: ISAAC. Lancet 1998;351:1225-32.

2. Beasley R, Crane J, Lai CK, Pearce N. Prevalence and etiology of asthma. J Allergy Clin Immunol 2000;105:S466-72.

3. Braun-Fahrlander C, Gassner M, Grize L, Takken-Sahli K, Neu U, Stricker T, Varonier HS, Wuthrich B, Sennhauser FH. No further increase in asthma, hay fever and atopic sensitisation in adolescents living in Switzerland. Eur Respir J 2004;23(3):407-13.

4. Mommers M, Gielkens-Sijstermans C, Swaen GMH, Schayck CP van. Trends in prevalence of respiratory symptoms and treatment in Dutch children over a 12 year period: results of the fourth consecutive survey. Thorax 2005;60:97-9.

5. Van Schayck CP, Smit HA. The prevalence of asthma in children: a reversing trend. Eur Respir J 2005;26:647-50.

6. Von Mutius E. Towards prevention. Lancet 1997;350:SII 14-7.

7. Debley JS, Smith JM, Redding GJ, Critchlow CW. Childhood asthma hospitalization risk after cesarean delivery in former term and premature infants. Ann Allergy Asthma Immunol 2005;94:228-32.

8. Klintberg B, Berglund N, Lilja G, Wickman M, van Hage-Hamsten M. Fewer allergic respiratory disorders among farmers'children in a closed birth cohort from Sweden. Eur Respir J 2001;17(6):1151-7.

9. Sporik R, Hill DJ, Thompson PJ, Stewart GA, Carlin JB, Nolan TM, Kemp AS, Hosking CS. The Melbourne House dust Mite Study: long-term efficacy of house dust mite reduction strategies. J Allergy Clin Immunol 1998;101:451-6.

10. Wright AL, Holberg CJ, Taussig LM, Martinez FD. Factors influencing the relation of infant feeding to asthma and recurrent wheeze in childhood. Thorax 2001;56(3):192-7.

11. Krämer U, Heinrich J, Wijst M, Wichmann HE. Age of entry to day nursery and allergy in later childhood. Lancet 1999;353:450-4.

12. Ball TM, Castro-Rodriguez JA, Griffith KA, Holberg CJ, Martinez FD, Wright AL. Siblings, day-care attendance and the risk of asthma and wheezing during childhood. N Engl J Med 2000;343:538-543.

13. Koopman LP, Smit HA, Heijnen ML, Wijga A, van Strien RT, Kerkhof M, Gerritsen J, Brunekreef B, de Jongste JC, Neijens HJ. Respiratory infections in infants: interaction of parental allergy, childcare, and siblings - The PIAMA study. Pediatrics 2001;108(4):943-8.

14. Infante-Rivard C, Amre D, Gautrin D, Malo JL. Family size, day-care attendance, and breastfeeding in relation to the incidence of childhood asthma. Am J Epidemiol 2001;153:653-8.

15. Posonby AL, Couper D, Dwyer T, Carmichael A, Kemp A. Relationship between early life respiratory illness, family size over time and the development of asthma and hay fever: a seven year follow up study. Thorax 1999;54:664-9.

16. Prescott SL, Macaubas C, Smallacombe T, Holt BJ, Sly PD, Holt PG. Development of allergenspecific T-cell memory in atopic and normal children. Lancet 1999;353:196-200.

17. Van Schayck CP, Knottnerus JA. Can the 'hygiene hypothesis' be explained by confounding by behaviour? J Clin Epidemiol 2004;57:435-7.

18. Kuiper S, Maas T, Schayck CP van, Muris JWM, Schönberger HJAM, Dompeling E, Gijsbers B, van Weel C, Knottnerus JA. The primary intervention of asthma in children study: design of a multifaceted prevention program. Pediatr Allergy Immunol 2005;26:321-31.

19. Schönberger HJAM, Dompeling E, Knottnerus JA, Maas T, Muris JWM, van Weel C, van Schayck CP. The clinical effectiveness of the PREVASC intervention. Eur Respir J 2005;25: 660-70.

20. Dirksen WJ, Geijer RMM, de Haan M, de Koning G, Flikweert S, Kolnaar BGM. Astma bij kinderen. NHG-Standaard. Huisarts Wet 1998;41:130-43. 
21. Schönberger HJ, Schayck CP van. Prevention of asthma in genetically predisposed children in primary care-- from clinical efficacy to a feasible intervention programme. Clin Exp Allergy 1998;28(11):1325-31.

22. Koopman LP, Strien RT van, Kerkhof M, Wijga A, Smit HA, de Jongste JC, Gerritsen J, Aalberse RC, Brunekreef B, Neijens HJ. Placebo-controlled trial of house dust miteimpermeable mattress covers: effects on symptoms in early childhood. Am J Respir Crit Care Med 2002;166:307-13.

23. Classification Committee of WONCA. ICHPPC-2 defined International Classification of Health Problems in Primary Care. Oxford: Oxford University Press, 1983.

24. Stapel SO, Eysink PE, Vrieze J, Aalberse RC. IgE testing in capillary blood. Pediatr Allergy Immunol 2004;15(3):230-3.

25. Marbury, MC, Maldonado G, Waller L. Lower respiratory Illness, recurrent wheezing, and day care attendance. Am J Respir Crit Care Med 1997;155:156-61.

26. Celedon JC, Litonjua AA, Weiss ST, Gold DR. Day care attendance in the first year of life and illnesses of the upper and lower respiratory tract in children with a family history of atopy. Pediatrics 1999;104:495-500.

27. McCunney RJ. Asthma, genes and air pollution. J Occup Environ Med 2005;47:1285-91. 


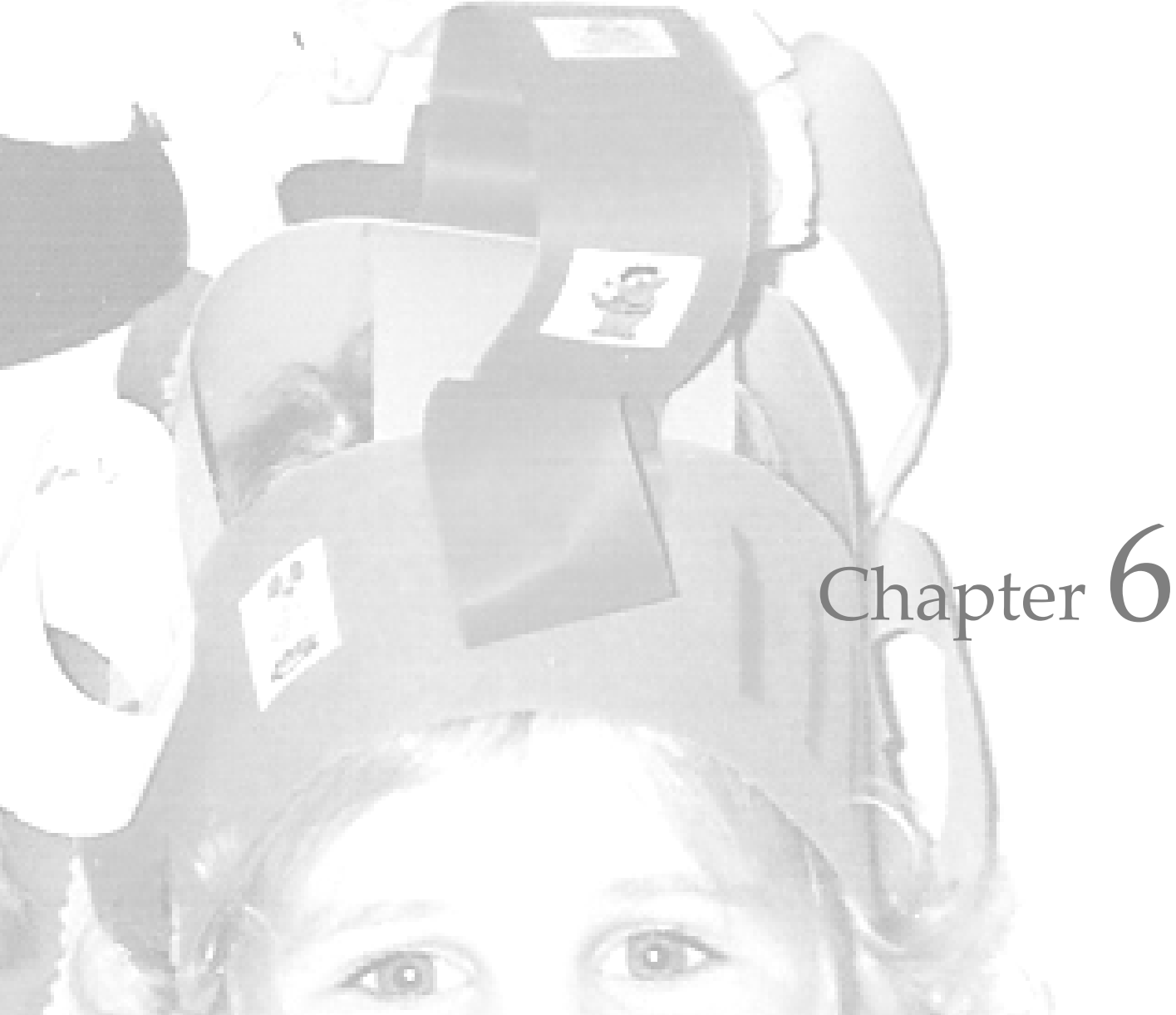

Cost-effectiveness of primary prevention of asthma in high-risk infants: $0-2$ years

Sandra Kuiper, Johan L. Severens, Jean W.M. Muris, Edward Dompeling, J. André Knottnerus, Constant P. van Schayck 


\section{Abstract}

\section{Background}

To investigate the societal perspective based cost-effectiveness of primary prevention of asthma in infants with a positive family history of asthma up to two years of age (PREVASC), using a clinical, general practitioner (GP) asthma diagnosis and an Epidemiological asthma diagnosis based Prediction Model (EPM).

\section{Methods}

476 infants were selected for a randomised controlled trial (242 intervention, 234 controls). Weekly reports assessed healthcare resource use. Uncertainty around the incremental cost-effectiveness ratios was determined with bootstrap analyses.

Results

$26.8 \%$ Intervention infants and $25.5 \%$ controls had a GP asthma diagnosis, whereas $69.9 \%$ and $63.5 \%$ respectively had an EPM asthma diagnosis. With both definitions there was no difference in asthma diagnosis between intervention and control infants ( $\mathrm{OR}=1.1,95 \%$ C.I.:0.6-1.8 and $\mathrm{OR}=1.3$, 95\% C.I.:0.8-2.2). Mean total costs in the intervention and control group were $€ 1564$ (IQ-range: $€ 669-€ 6499$ ) and $€ 967$ (IQ-range $€ 29-€ 7136$ ). The incremental cost-effectiveness ratio of the program was $-€ 46,157$ for the GP diagnosis and $-€ 9,671$ for the EPM definition, both indicating inferiority of the experimental situation. All bootstrap replications indicated that the PREVASC program is more costly, with a chance of $37 \%$ and $13 \%$ respectively that the program was more effective than usual care.

\section{Conclusion}

Primary prevention of asthma is in the first two years of life not cost-effective with both models. 


\section{Introduction}

Health care costs in the Netherlands are high. The most recent official national numbers date from 1999,1 at which moment the health care costs amounted $€ 36$ billion, of which $1.6 \%$ ( $€ 594$ million) was spent on asthma and chronic obstructive pulmonary disease (COPD). The Dutch health care costs increase about $2.4 \%$ every year. ${ }^{1}$ This yearly increase in health care costs can be partly attributed to demographic factors and partly to other factors like the application of more advanced techniques to diagnose and/or treat disorders, but also to the increase in prevalence's observed in several diseases.

Asthma is predominantly newly diagnosed in children. The prevalence of asthma is high, ${ }^{2,3}$ although there are large variations in asthma prevalence throughout the world. ${ }^{4}$ Moreover, asthma is the main cause of school absence, ${ }^{5}$ and reduces the quality of life of children and their parents. ${ }^{6,7}$ The costs of treating childhood asthma are substantial $(20.4 \%$ of the total health care costs in 0-year old baby's and $24.1 \%$ in infants and children aged $1-14$ years)..$^{1}$ It is therefore of great importance to prevent the development of asthma.

It is thought that the development of asthma is affected by genetic as well as environmental factors. ${ }^{89}$ Since it is not possible yet to influence the genetic factors, prevention programs should focus on eliminating the environmental triggers. There are reasons to believe that the first signs of sensitisation occur already in the prenatal stage by the interaction between the maternal environment and the foetus, ${ }^{10}$ which indicates that intervention should start already before birth.

The PREVASC (primary PREVention of ASthma in Children) study is a Dutch longitudinal prospective birth cohort study in which the effectiveness of a multi-faceted intervention strategy (on reducing the exposure to indoors and food allergens and environmental tobacco smoke) was tested in a randomised trial. ${ }^{11}$ As shown by Schönberger et al. ${ }^{11}$ the intervention was effective for asthma symptoms at two years, but not for a GP diagnosis of asthma. The PREVASC study was originally set up to establish a difference in effect instead of establishing equivalence. Moreover, the power calculation of the study was based on a difference in effects and not on costs. Therefore, the study had not enough power to simply perform a cost minimization analysis. ${ }^{12,13}$ Instead, 'since absence of evidence is not evidence of absence', a cost effectiveness analysis had to be performed. ${ }^{14}$ In this paper we describe whether this multifaceted prenatally started intervention strategy in infants with a positive family history of asthma is, based on a societal perspective, cost-effective for the prevention of asthma in the first two years of life. 


\section{Methods}

\section{Recruitment of subjects}

A detailed description of the trial profile and subject selection are given elsewhere. ${ }^{15}$ Briefly, in the period 1997 to 2000, 476 unborn infants with a positive family history of asthma, from 3-7 months pregnant women were recruited for a randomised clinical prevention trial (RCPT). All unborn infants were randomised and equally allocated to an intervention or a control group, and followed until they reached the age of two. From the descendants twentyfour were excluded because of intra-uterine neonatal death, major language problems in the family, serious birth defects or moving abroad, whereas nine infants were lost to follow-up. Reasons for this loss to follow-up were, notasthma related co-morbidity, morbidity in other family members, a postnatal depression in the mother, or unwilling to complete weekly reports for a long time. Of the remaining 443 infants, 222 (118 boys) received intervention whereas the other 221 (112 boys) received usual care according to the guidelines of the Dutch College of General Practitioners. According to these guidelines children with a symptom-based diagnosis receive an initial treatment with short acting bronchodilators and, when no adequate asthma control is achieved, a step-up approach with inhaled corticosteroids in increasing dosage. ${ }^{16}$

Infants were defined as having a positive family history of asthma when 'at least one first-degree family member (i.e. the mother, the father or a sibling) was suffering from GP registered asthma'. Asthma in first-degree family members was defined, according to the International Classification of Primary Care (ICPC), ${ }^{17}$ as recurrent episodes of reversible acute bronchial obstruction with wheeze and/or dry cough. This was checked by the GP and screening questionnaires. Infants were treated according to the 'intention to treat' principle.

\section{Intervention}

A detailed description of the intervention is given elsewhere. ${ }^{11}$ Briefly, the intervention focussed on avoidance of prenatal and postnatal passive smoking and on reduction of the exposure to inhaled or food allergens. In order to reach a low house dust mite and pet allergen exposure level at the time the child was born, this intervention started prenatally.

\section{Outcome measure}

Information on asthma diagnosis, diagnostic tests and medication concerning respiratory morbidity, was prospectively registered by the GP at every 
consultation during the two years. The parents were asked to complete weekly reports concerning questions about 'over the counter' (OTC) medication and asthma related costs, during the first two years of the infants' life.

Two different asthma diagnoses were used. A clinical diagnosis of asthma was given by the GP (GP diagnosis). In an epidemiological asthma diagnosis based Prediction Model (EPM), the asthma diagnosis was based on the criteria from Castro-Rodriguez et al (stringent version). ${ }^{18}$

\section{Intervention costs}

Included in the intervention costs were the home visits of the research nurse, house dust mite impermeable materials, hypoallergenic formula feeding, and education material (Table 6.1).

Table 6.1 Prices of intervention measures.

\begin{tabular}{lc}
\hline & Euro \\
\hline Salary research nurse & $16.08 /$ hour $^{\mathrm{a}}$ \\
House dust mite impermeable materials & \\
Mattress covers parents' bed & $235.06^{\mathrm{b}}$ \\
Mattress covers infants' bed & $67.61^{\mathrm{b}}$ \\
Pillowcases parents' bed & $44.80^{\mathrm{b}}$ \\
Continental quilts parents' bed & $131.14^{\mathrm{b}}$ \\
Infants' sleeping bags & $89.00^{\mathrm{b}}$ \\
Solid feeding & \\
Hypoallergenic formula feeding & $20.96 /$ canc $^{\mathrm{b}}$ \\
$\quad$ Regular formula feeding & $11.38 /$ can $^{\mathrm{c}}$ \\
Education material & $2.19 /$ brochure \\
\hline
\end{tabular}

a Mean value salary administration Academic Hospital Maastricht, the Netherlands; b SanaLife (SanaLife B.V., Wijchen, the Netherlands) c Royal Dutch Numico N.V.; (Royal Dutch Numico N.V., N.V. Nutricia, Zoetermeer, the Netherlands).

All home visits of the research nurse lasted one hour. House dust mite impermeable mattress covers for the parents' and the infants' bed, house dust mite impermeable pillowcases for the parents' bed, house dust mite impermeable continental quilts for the parents' bed as well as house dust mite impermeable infants' sleeping bags, were supplied (SanaLife B.V., Wijchen, the Netherlands).

Whenever it was impossible for a mother to breastfeed her baby for at least six months, she was advised to feed the infant with hypoallergenic formula feeding (Royal Dutch Numico N.V., N.V. Nutricia, Zoetermeer, the Netherlands). Education material was offered in the form of six different brochures. 


\section{Other health service costs}

The volume of healthcare resource use was assessed with weekly reports (completed by the parents) and GP registrations. Medical and non-medical costs could be calculated by multiplying the volumes with a fixed price, which were estimated according to the Dutch manual of cost analysis in health care research. ${ }^{19}$ When no univocal price was available, the weighted average of prices was taken, for instance the weighted average of hospital admission was obtained by adding the cost prise of hospital admission in an academic hospital (i.e. multiplying the cost prise of hospital admission/day with the percentage of beds in such hospital) and the cost price of hospitalisation in a peripheral hospital. As a reference year the year 2003 was used. Direct medical costs included all types of GP contacts (i.e. telephone consultation, practice consultation and home visits), outpatient appointment costs with a medical specialist, hospital admission, diagnostic tests and drug prescription (Table 6.2). Direct non-medical costs included OTC medication, travelling costs and nursing aids, whereas indirect non-medical costs were represented by absence from paid work (Table 6.2).

Table 6.2 Other health service unit prices.

\begin{tabular}{lc}
\hline & Euro \\
\hline Telephone consultation & $10.10^{\mathrm{a}}$ \\
GP consultation & $20.20^{\mathrm{a}}$ \\
Home visit & $40.40^{\mathrm{a}}$ \\
Outpatient appointment with a medical & \\
specialist & $85.78^{\mathrm{b}}$ \\
Hospital admission & $359.24^{\mathrm{c}}$ \\
Diagnostic tests & $37.00^{\mathrm{d}}$ \\
$\quad \begin{array}{l}\text { Chest X-ray } \\
\text { Phadiatop }\end{array}$ & $16.63^{\mathrm{d}}$ \\
$\quad$ Skin test & $63.00^{\mathrm{d}}$ \\
OTC medication & \\
$\quad$ Cough mixtures & out of pocket \\
$\quad$ Nose drops & out of pocket \\
$\quad$ Eardrops & out of pocket \\
Anti-pyretic & out of pocket \\
Traveling costs & \\
$\quad$ Car & $0.16 / \mathrm{km}^{\mathrm{a}}$ \\
$\quad$ Parking costs & out of pocket \\
$\quad$ Public transportation & out of pocket \\
Nursing aids & out of pocket \\
Absence from paid work per hour & $34.98^{\mathrm{a}}$ \\
\hline
\end{tabular}

a Oostenbrink JB et al. ${ }^{19}$, b weighted average (proportion of consultations to regular and academic hospitals ${ }^{20}$ ): $€ 85.78 / 15 \mathrm{~min}$, c weighted average (proportion of beds in regular and academic hospitals): 359.24/day, d Van Leusden HAIM $^{21}$, prices for medication were obtained from the pharmacotherapeutic compass 22 . 


\section{Statistical methods}

For the cost-effectiveness analysis only those cases were used of which at least $75 \%$ of all information was available. For these cases the possible missing information regarding costs or symptoms from the diary for each individual respondent was completed using the following imputation method ((sum score/ $\mathrm{N}$ completed weeks) ${ }^{*}$ total amount of weeks = imputed value). In order to assess possible differences between symptoms and diagnosis in the intervention and the control group, descriptive analyses were performed. In addition, differences in asthma status between the groups were tested with the $\chi^{2}$ test. P-values smaller than 0.05 were considered as significant. Statistical analyses were performed using the Statistical Package for the Social Sciences (SPSS) version 11.0. Since the cost data were heavily skewed to the right, differences in costs could not be tested by use of means. Statistical uncertainty regarding the cost-effectiveness estimates was assessed using non-parametric bootstrap resample methods (Excel 2000, Redmond, WA).

\section{Power calculation}

A power calculation was performed for the effectiveness of the primary prevention program. The calculation was based on a study of Saarinen et al. ${ }^{23}$ in which was shown that breastfeeding as preventive measure, in a comparable group of infants as in the PREVASC study, resulted in a 30\% reduction in the development of asthma. This percentage was chosen as the minimal clinically relevant difference to be achieved by a more complex intervention program. At least 194 infants in the intervention as well as in the control group were required to detect a reduction in the asthma incidence in our cohort of $30 \%$ or more.

\section{Results}

140 Parents did not fulfill the criterion of completing at least $75 \%$ of all information (non-complete cases). One infant was excluded from the analyses because of prolonged stay in the hospital for not asthma related illness. For the analyses 302 infants were available (complete cases), 153 in the intervention group and 149 in the control group. In Table 6.3 the demographic characteristics of the complete cases as well as of the non-complete cases are shown.

Nine infants from the intervention group and six infants from the control group with complete case records were premature at birth ( $<37$ weeks). No statistically significant difference between the complete case intervention- and control group was detected for any of the demographic characteristics. 
Table 6.3 Demographic characteristics of the study population.

\begin{tabular}{|c|c|c|c|c|c|}
\hline & \multicolumn{2}{|c|}{ Responders } & \multicolumn{2}{|c|}{ Non-responders } \\
\hline & & $\begin{array}{l}\text { Intervention } \\
\text { group }\end{array}$ & $\begin{array}{l}\text { Control } \\
\text { group }\end{array}$ & $\begin{array}{l}\text { Intervention } \\
\text { group }\end{array}$ & $\begin{array}{l}\text { Control } \\
\text { group }\end{array}$ \\
\hline \multicolumn{2}{|l|}{$\mathrm{n}$} & 153 & 149 & 68 & 72 \\
\hline \multicolumn{2}{|c|}{ Mean age mother yrs (SD) } & $31(4)$ & $31(4)$ & $30(4)$ & $30.53(3,615)$ \\
\hline \multicolumn{2}{|c|}{ Mean age father yrs (SD) } & $33(4)$ & $34(4)$ & $33(4)$ & $32,72(4)$ \\
\hline \multirow[t]{2}{*}{ Gender n (\%) } & Male & $79(51.6)$ & $73(49.0)$ & $38(55.9)$ & $39(54.2)$ \\
\hline & Female & $74(48.4)$ & $76(51.0)$ & $30(44.1)$ & $33(45.8)$ \\
\hline \multicolumn{2}{|c|}{ Mean birth weight in grams (SD) } & 3387 (517) & 3525 (518) & $3400(551)$ & 3522 (954) \\
\hline \multicolumn{2}{|c|}{ Mean gestational age in weeks (SD) } & $39.7(1.6)$ & $39.9(1.6)$ & $39.7(1.9)$ & $39.4(1.9)$ \\
\hline \multirow[t]{4}{*}{ Birth season $\mathrm{n}(\%)$} & Spring & $5(22.9)$ & $37(24.8)$ & 12 (17.6) & $14(19.4)$ \\
\hline & Summer & $44(28.8)$ & $37(24.8)$ & $18(26.5)$ & $24(33.3)$ \\
\hline & Autumn & $38(24.8)$ & $31(20.8)$ & $18(26.5)$ & $17(23.6)$ \\
\hline & Winter & $36(23.5)$ & $44(29.5)$ & $20(29.4)$ & 17 (23.6) \\
\hline \multirow[t]{6}{*}{ Siblings $\mathrm{n}(\%)$} & 0 & $67(43.8)$ & $59(39.6)$ & $20(29.4)$ & $25(34.7)$ \\
\hline & 1 & $61(39.9)$ & $57(38.3)$ & $31(45.6)$ & $28(38.9)$ \\
\hline & 2 & $24(15.7)$ & $24(16.1)$ & $12(17.6)$ & $16(22.2)$ \\
\hline & 3 & $1(0.7)$ & $6(4.0)$ & $4(5.9)$ & $2(2.8)$ \\
\hline & 4 & & $2(1.3)$ & $1(1.5)$ & \\
\hline & 5 & & $1(0.7)$ & & $1(1.4)$ \\
\hline
\end{tabular}

$26.8 \%$ Infants from the intervention group and $25.5 \%$ from the control group had a GP asthma diagnosis. Using the EPM definition about 2.5 times more infants were diagnosed with asthma as with the GP diagnosis (69.9\% infants in the intervention group and $63.5 \%$ in the control group). No statistically significant difference in asthma incidence was observed between the intervention and control group with the GP diagnosis as well as with the EPM definition ( $\mathrm{OR}=1.1, \quad 95 \%$ C.I.: $0.6-1.8$ and $\mathrm{OR}=1.3$, 95\% C.I.: $0.8-2.2$ respectively). Intervention costs were not equal to zero in the control group since several families took spontaneous intervention measures (Table 6.4). Forty families in the control group used house dust mite impermeable materials. Among these families, 22 families had house dust mite impermeable mattress covers for the parents' bed, 13 had a house dust mite impermeable mattress cover for the infant's bed, 18 had house dust mite impermeable pillowcases at the parents' bed, 8 families had continental quilts at the parents' bed bag and 10 families had a sleeping bag for the infant.

Concerning dietary intervention in the first six months of life, infants in the intervention group were on average breastfed for $9.7( \pm 9.1)$ weeks, whereas infants in the control group were on average breastfed for $10.8( \pm 10.0)$ weeks. Hypoallergenic formula feeding was fed for a mean of $10.3( \pm 10.1)$ weeks in the intervention group compared to $2.7( \pm 6.3)$ weeks in the control group. 'Regular' formula feeding was given with a mean of $1.8( \pm 5.0)$ weeks to $23 \%$ of the infants in the intervention group compared to a mean of $9.1( \pm 10.4)$ weeks to $55 \%$ of the infants in the control group. 
Table 6.4 Mean intervention costs (Euro)/ infant in the first 2 years of life.

\begin{tabular}{lcc}
\hline & $\begin{array}{c}\text { Intervention group } \\
\text { Mean (range) }\end{array}$ & $\begin{array}{c}\text { Control group } \\
\text { Mean (range) }\end{array}$ \\
\hline Home visits by a research nurse & $48^{\mathrm{b}}$ & $16^{\mathrm{b}}$ \\
Education material & $13^{\mathrm{b}}$ & $0^{\mathrm{b}}$ \\
House dust mite impermeable materials & $567^{\mathrm{b}}$ & $60(0-523)$ \\
Dietary intervention & $291(0-482)$ & $177(0-482)$ \\
Total intervention costs $^{\mathrm{a}}$ & $920(629-1111)$ & $253(16-953)$ \\
\hline
\end{tabular}

a Dietary intervention lasted for 26 weeks. ${ }^{\mathrm{b}}$ Intervention costs were standard for all participants. Note: In case no range is indicated this concerns cost related to protocolised items, being identical for all participants

The volume of health care resources was on average similar in both groups (Table 6.5). In the intervention group slightly more GP practice consultations and hospital admission days, but less home visits from the GP were observed as compared to the control group. Additionally, in the intervention group we found less absence from paid work by the parents than in the control group.

Table 6.5 Mean use of health care resources in the first 2 years of life.

\begin{tabular}{lcc}
\hline & $\begin{array}{c}\text { Intervention group }(\mathrm{n}=153) \\
\text { Mean (range) }\end{array}$ & $\begin{array}{c}\text { Control group }(\mathrm{n}=149) \\
\text { Mean (range) }\end{array}$ \\
\hline Direct costs & & \\
$\quad$ GP contacts & $1.6(0.0-18.0)$ & $1.5(0.0-21.0)$ \\
$\quad$ Telephone consultation & $4.3(0.0-24.0)$ & $4.1(0.0-18.0)$ \\
$\quad$ Practice consultation & $0.05(0.0-1.0)$ & $0.1(0.0-2.0)$ \\
$\quad$ Home visit & $0.3(0.0-3.0)$ & $0.3(0.0-3.0)$ \\
Outpatient specialist contacts & $0.7(0.0-14.0)$ & $0.5(0.0-13.0)$ \\
Hospital admissions (days) & $0.1(0.0-4.0)$ & $0.1(0.0-2.0)$ \\
Diagnostic tests & $1.0(0.0-7.0)$ & $1.0(0.0-9.0)$ \\
Drug prescriptions & $0.5(0.0-10.0)$ & $0.5(0.0-7.0)$ \\
$\quad$ Antibiotics & $0.8(0.0-5.0)$ & $0.6(0.0-5.0)$ \\
$\quad$ Inhaled corticosteroids & $0.9(0.0-14.0)$ & $0.8(0.0-29.0)$ \\
$\quad$ Bronchodilators & $0.01(0.0-1.0)$ & $0.01(0.0-1.0)$ \\
$\quad$ Dermatological preparations & & \\
$\quad$ Other asthma related medication & $5.9(0.0-114.0)$ & $9.4(0.0-135.0)$ \\
Indirect non-medical costs & & \\
Absence from paid work (days) &
\end{tabular}

In Table 6.6 the mean health care costs in the first two years of life are shown. Hospital admission costs in the intervention group were on average about 1.25 times the outpatient specialist costs in the control group. The median costs in both groups were $€ 0$ (which indicates that the difference between both groups was caused by a small percentage of infants). Infants from the intervention group received on average more drug prescriptions than infants from the control group. This could be mainly attributed to prescriptions of 
bronchodilators and although very few diagnostic tests were performed, the maximum costs for diagnostic tests in the intervention group were nearly three times the maximum costs of the control group. All together the direct medical costs were slightly higher in the intervention group compared to the control group.

Table 6.6 Mean and range of costs $(€)$ in the first two years of life.

\begin{tabular}{lcc}
\hline & $\begin{array}{c}\text { Intervention group } \\
(\mathrm{n}=153)\end{array}$ & $\begin{array}{c}\text { Control group } \\
(\mathrm{n}=149)\end{array}$ \\
\hline Direct medical costs & & \\
GP contacts & $104(0-535)$ & $102(0-485)$ \\
Outpatient specialist contacts & $23(0-257)$ & $26(0-257)$ \\
Hospital admissions & $244(0-5029)$ & $193(0-4670)$ \\
Diagnostic tests & $1.9(0-100)$ & $1.8(0-37)$ \\
Drug prescription & $44(0-424)$ & $40(0-332)$ \\
$\quad$ Total direct medical costs & $416(0-5356)$ & $363(0-4690)$ \\
& & \\
Direct non-medical costs & $12(0-36)$ & $11(0-37)$ \\
OTC medication & $8(0-213)$ & $12(0-285)$ \\
Travelling costs & $1.1(0-35)$ & $0.8(0-37)$ \\
$\quad$ Nursing aids & $21(0-236)$ & $24(0-300)$ \\
& $207(0-3988)$ & $327(0-4722)$ \\
Total direct non-medical costs & & \\
Total indirect non-medical costs & & \\
\hline
\end{tabular}

Direct non-medical costs were comparable in both groups, although there was a tendency that in the intervention group slightly less traveling costs were made compared to the control group. Lower indirect non-medical costs were on average made in the intervention compared to the control group.

The mean total costs in the first two years of life were $€ 1564$ (IQ-range: $€ 669-€ 6499)$ in the intervention group, which was on average 1.6 times higher than in the control group (IQ-range: $€ 967$ ( $€ 29$ - $€ 7136)$ ) (Figure 6.1).

By use of a bootstrap analysis the uncertainty of the additional costs compared to the additional effects was determined (incremental cost-effectiveness ratios: ICER) for a GP diagnosis of asthma and for an asthma label based on the EPM definition. With both scatter plots (data not shown) the uncertainty around the cost-effectiveness estimate was large, indicating that there is no clear positive effect of the prevention program on the prevalence of asthma.

For both definitions all bootstrap estimations of the ICER were located in the north quadrants, which implies that in the first two years of life the PREVASC intervention group generates more costs than usual care. Cost-effectiveness calculations show that the incremental costs were $€ 597$. The incremental effects were -0.01 for the GP diagnosis and -0.06 for the EPM definition. Of all bootstrap replicates of the ICER, 37\% (GP diagnosis) and 13\% (EPM definition) 
were located in the northeast quadrant, showing that there is only a chance of $37 \%$ and $13 \%$ respectively that the PREVASC intervention is more effective than usual care in the first two years of life.

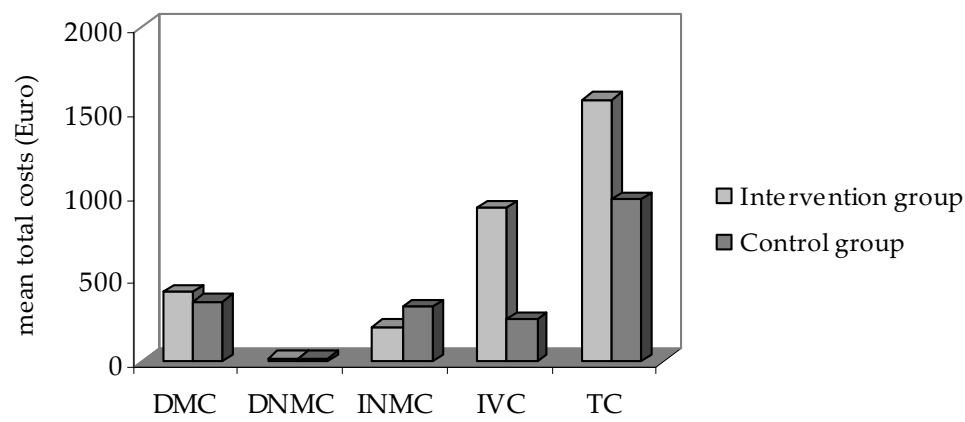

Figure 6.1 Mean total costs from a societal perspective.

DMC: Total Direct Medical Costs, DNMC: Total Direct Non-Medical Costs, INMC: Total Indirect Non-Medical costs, TIC: Total Intervention Costs, TC: Total Costs.

To prevent one infant from developing asthma the baseline incremental costeffectiveness was negative (related to a positive cost-difference and negative effectiveness difference indicating the experimental PREVASC intervention to be inferior to usual care) for both models and higher for a GP asthma diagnosis $(-€ 46,157)$ than for an asthma diagnosis based on the EPM definition $(-€ 9,671)$. The lack of dominance of the intervention program relative to usual care is supported by the cost-effectiveness acceptability curve, which shows that regardless of the societal willingness the probability that the PREVASC intervention is cost-effective compared to usual care remains $37 \%$ and $13 \%$ respectively (Figure 6.2). 


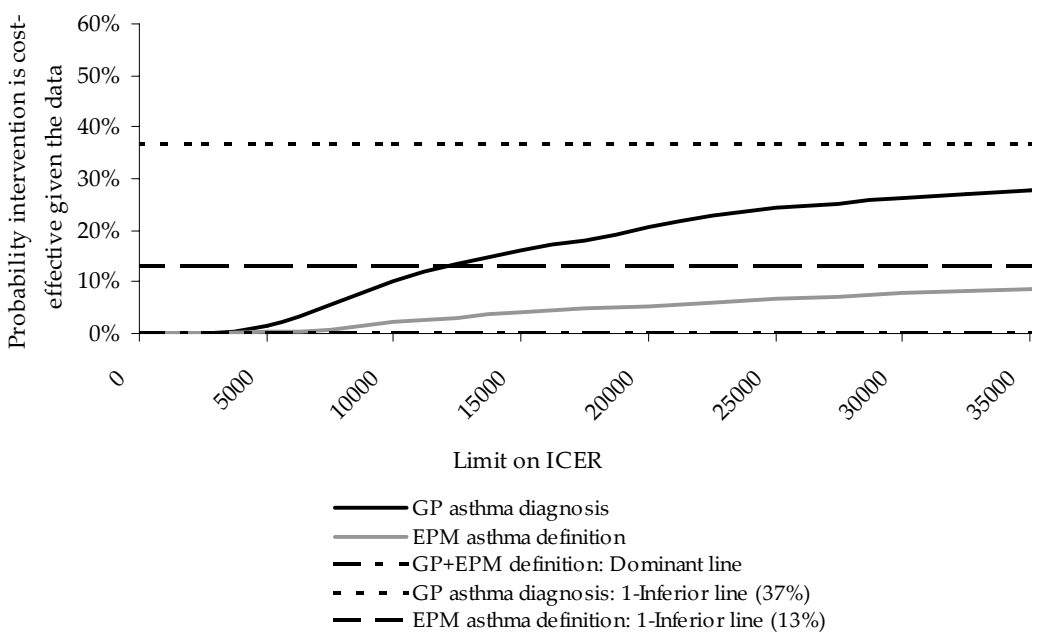

Figure 6.2 Cost-effectiveness acceptability curve concerning the asthma diagnosis. $\left(^{*}\right)$ The dominant line for the GP asthma diagnosis is located at the same position as the dominant line for the EPM definition.

\section{Discussion}

Primary prevention of asthma in the first two years of life is not (yet) costeffective. The definition of asthma, a GP diagnosis of asthma or an asthma diagnosis based on the EPM definition, did not influence the results.

For the calculation of the cost-effectiveness of the intervention program, a GP asthma diagnosis was taken as primary outcome measure, whereas the EPM definition was used as alternative. Using non-parametric bootstrap analysis methods to estimate the statistical uncertainty regarding the cost-effectiveness for both models it turned out that the intervention was more expensive than usual care in the first two years. Additionally, also for both models, there was only a small probability that the PREVASC intervention had a positive effect in this period.

This study had the advantage that information concerning costs, asthma related symptoms and asthma diagnosis was prospectively collected. Asthma was primarily diagnosed by the GP. An advantage of this method is that the GP has a comprehensive overview of the disease history of a child since, in the Netherlands, in almost all cases a patient stays with the same primary care practice for a long time. A disadvantage of this method is that for infants there are no objective test criteria for the diagnosis of asthma. Therefore the EPM definition was used as an alternative asthma diagnosis, although this model was developed for the prediction of asthma in children at school age. ${ }^{18}$ 
Using the two different definitions a difference was observed in the amount of infants who were diagnosed with asthma. Moreover an infant who was diagnosed with asthma according to the EPM definition was not necessarily diagnosed with asthma by the GP and vice versa. From those infants who were diagnosed with asthma according to the EPM definition only $28 \%$ received a GP asthma diagnosis. This may indicate that, although the GP based the asthma diagnosis on the advices given in the guidelines of the Dutch College of General Practitioners, ${ }^{16}$ there are other factors that lead the GP in his or her decision to label an infant with asthma. One of these factors may be that the GP is reluctant to give an asthma diagnosis to very young children in order to prevent chronic medication use.

Our study is the first concerning the costs and effects of a prenatally started primary multifaceted prevention program for asthma in infants in the first two years of life. Up till now there are no other studies in this field with this age group. Cost-effectiveness studies that have been performed in this field mainly concern interventions with medication ${ }^{24,25}$ and educational or self-management programs in older children or adults. ${ }^{26,27}$ There is one study in asthmatic children aged 5-11 years in which some of the prevention measures were similar as in the PREVASC study. The authors showed a statistically significant reduction in asthma symptom days over a 2-year period and the program was cost-effective. ${ }^{28}$

The relative prevalence of asthma in the Netherlands is $2.9 \%(2.6 \%$ for men and $3.1 \%$ for women). ${ }^{29}$ Per asthma patient the total costs in 2000 were approximately $€ 315 /$ yr. $^{29}$ With the assumption of a life expectancy of approximately 75 years, the total lifetime direct medical costs per asthma patient will be maximal $€ 23,625$ (not taking the principle of discounting into account). The direct medical costs in our study amounted approximately $60 \%$ of the total costs (intervention costs not included). When taking these numbers into account the total lifetime costs from a societal perspective per asthma patient will be $€ 39,125$. Taking a GP asthma diagnosis as primary outcome measure the costs to prevent one infant from developing asthma will be at least $€ 46,157$, which is at least 1.2 times the lifetime costs per asthma patient. Based on these findings the current advice on implementation of this program would be negative. The PREVASC program is not cost-effective during the first two years of life.

However, as described by Schönberger et al.,11 at two years, infants in the intervention group had significantly less current asthma symptoms than infants from the control group, which was most pronounced in girls. This indicates that in the long run the program may become effective. Furthermore, in this part of the study, the majority of the total costs existed of intervention costs. After the second birthday the intervention program becomes less intense (only mattress covers). From this point on the intervention costs will 
exclusively exist of mattress cover costs. For those infants who will finally develop asthma, it is expected that the costs to treat their asthma symptoms increase substantially in the coming years. If the PREVASC program turns out to be effective in the long run, it is expected that the total costs of the intervention group will be favourable as opposed to the control group. 


\section{References}

1. Polder JJ, Takken J, Merding WJ, Kommer GJ, Stokx LJ. Cost of illness in the Netherlands. RIVM report 270751005/2002 (www.rivm.nl/kostenvanziekten ).

2. The International Study of Asthma and allergies in Childhood (ISAAC) Steering Committee. Worldwide variation in prevalence of symptoms of asthma, allergic rhino conjunctivitis, and atopic eczema: ISAAC. Lancet 1998;351:1225-32.

3. Eldeirawi K, Persky VW. History of ear infections and prevalence of asthma in a national sample of children aged 2 to 11 years. Chest 2004;125:1685-92.

4. Beasley R, Crane J, Lai CKW, Pearce N. I. Epidemiology and genetics of asthma. Prevalence and etiology of asthma. J Allergy Clin Immunol 2000;105:S466-72.

5. Vermeire PA, Rabe KF, Soraiano JB, Maier WC. Asthma control and differences in management practices across seven European countries. Respir Med 2002;96(3):142-9).

6. Merikallio VJ, Mustalahti K, Remes ST, Valovirta EJ, Kaila M. Comparison of quality of life between asthmatic and healthy school children. Pediatr Allergy Immunol 2005;16(4):331-40.

7. Halterman JS, Yoos HL, Conn KM, Callahan PM, Montes G, Neely TL, Szilagyi PG. The impact of childhood asthma on parental quality of life. J Asthma 2004;41(6):645-53.

8. Heinzmann A, Deichmann KA. Genes for atopy and asthma. Curr Opinion Allergy Clin Immunol 2001:1(5):387-92.

9. Von Mutius E. The environmental predictors of allergic disease. J Allergy Clin Immunol 2000:105:9-19.

10. Jones CA, Holloway JA, Warner JO. Does atopic disease start in foetal life? Allergy 2000:55: 2-10.

11. Schönberger HJAM, Dompeling E, Knottnerus JA, Maas T, Muris JWM, van Weel C, van Schayck CP. The PREVASC study: the clinical effect of a multi-faceted educational intervention to prevent childhood asthma. Eur Respir J 2005;25(4):660-70.

12. Freiman JA, Chalmers TC, Smith H Jr, Kuebler RR. the importance of beta, the type II error and sample size in the design and interpretation of the randomized control trial. Survey of 71 'negative' trials. N Engl J Med 1978;299(13):690-4.

13. Briggs $\mathrm{AH}, \mathrm{O}^{\prime}$ Brien BJ. The death of cost-minimization analysis? Health Economics 2001;10:179-84.

14. Altman DG, Bland MJ. Statistics notes: absence of evidence is not evidence of absence. $\mathrm{Br}$ med J 1995;311:485.

15. Kuiper S, Maas T, van Schayck CP, Muris JWM, Schönberger HJAM, Dompeling E, Gijsbers B, van Weel C, Knottnerus JA. The primary prevention of asthma in children (PREVASC) study: Design of a multifaceted prevention program. Pediatr Allergy Immunol 2005;16(4):321-31.

16. Dirksen WJ, Geijer RMM, de Haan M, de Koning G, Flikweert S, Kolnaar BGM. [NHG guideline on asthma in children: treatment]. Huisarts \& Wetenschap 1998:41:130-43.

17. The WONCA classification committee. ICPC-2. International Classification of Primary Care. Oxford, Oxford University Press, 1998.

18. Castro-Rodriguez JA, Holberg CJ, Wright AL, Martinez FD. A clinical index to define risk of asthma in young children with recurrent wheezing. Am J Respir and Crit care Med 2000:162:1403-6.

19. Oostenbrink JB, Bouwmans CAM, Koopmanschap MA, Rutten FFH. Guidebook for cost investigation. Amstelveen, The Netherlands; Dutch College of Health Insurance: 2004.

20. Central Bureau of Statistics (www.cbs.nl/n/cijfers/kerncijfers).

21. Van Leusden HAIM. Diagnostic compass. Amstelveen, The Netherlands: Dutch College of Health Insurance: 2003 (www.cvzkompassen.nl).

22. Van Loenen AC. Pharmacotherapeutic compass. Amstelveen, The Netherlands: Dutch College of Health Insurance: 2005 (www.cvzkompassen.nl).

23. Saarinen UM, Kajosaari M. Breastfeeding as prophylaxis against atopic disease: prospective follow-up study until 17 years old. Lancet 1995346:1065-9. 
24. Bisgaard H, Price MJ, Maden C, Olsen NA. Cost-effectiveness of fluticasone propionate administered via metered-dose inhaler plus babyhaler spacer in the treatment of asthma in preschool-aged children. Chest 2001:120(6):1835-42.

25. Rutten van Mölken MP, van Doorslaer EK, Jansen MC, van Essen-Zandvliet EE, Rutten FF. Cost effectiveness of inhaled corticosteroid plus bronchodilator therapy versus bronchodilator monotherapy in children with asthma. Pharmacoeconomics 1993:4(4):257-70).

26. Schermer TR, Thoonen BP, van de Boom G, Akkermans RP, Grol RP, Folgering HT, van Weel C, van Schayck CP. Randomized controlled economic evaluation of asthma self-management in primary health care. Am J Respir Crit Care Med 2002:166:1062-72.

27. Windsor RA, Baily WC, Richards JM, Manzella B, Soong SJ. Evaluation of the efficacy and cost effectiveness of health education methods to increase medication adherence among adults with asthma. Am J Public Health 1990:80:1519-21.

28. Sullivan SD, Weiss K, Lynn H, Mitchel H Kattan M, Gergen PJ, Evans R. The costeffectiveness of an inner-city asthma intervention for children. J Allergy Clin Immuol 2002: 100:576-81.

29. Hoogendoorn EJI, Feenstra TL, Rutten-van Mölken MPMH. Resource use and costs of care for treating asthma and COPD in the Netherlands. RIVM report 260604001/2004. 


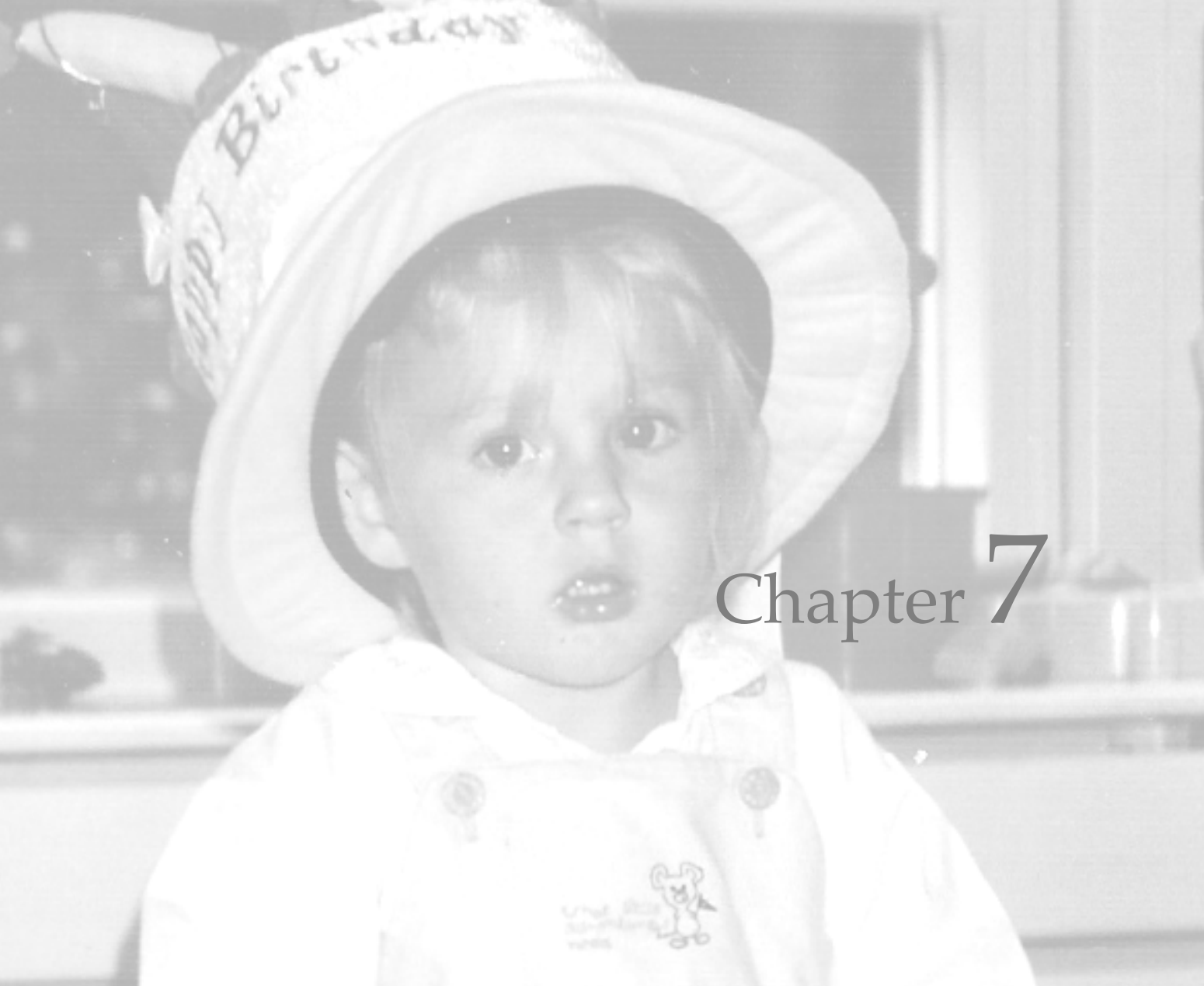

General discussion

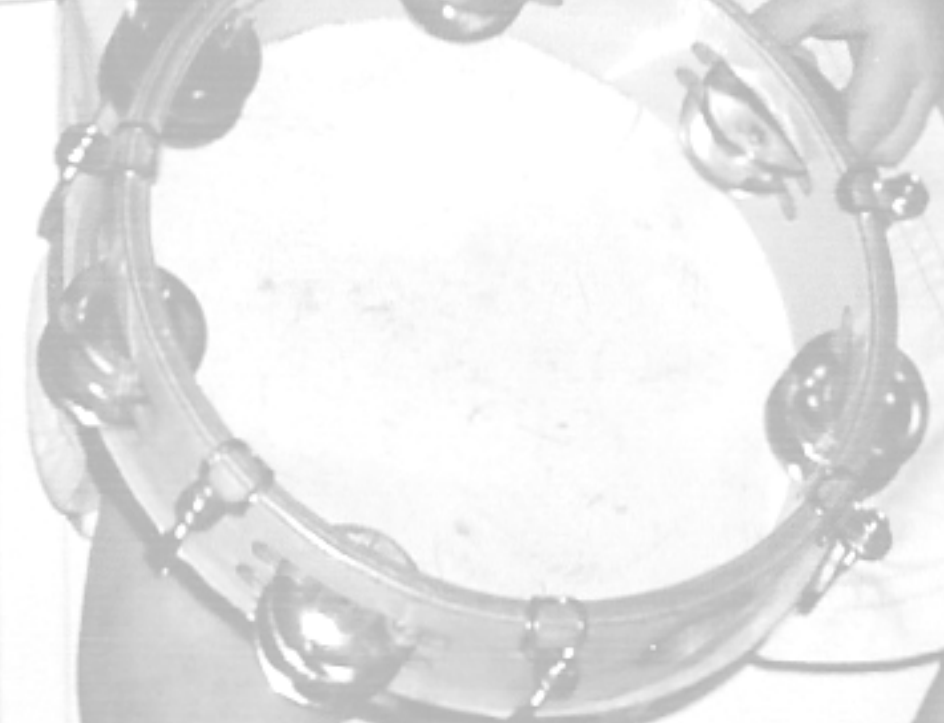


Chapter 7 


\section{General discussion}

In this thesis several aspects of the role of a first-degree family history of asthma, as determined in general practice, in infants during their first two years of life were evaluated. To study whether the relationship between a positive family history (PFH) as phenotypic feature of genetic predisposition, and another genetically driven risk factor, total $\mathrm{IgE}$, could be confirmed in a primary care population the effect of PFH on the occurrence of total IgE in newborns was studied. In addition, it was investigated whether the association between PFH and total IgE in newborns was influenced by other factors. Furthermore, PFH was studied as a risk factor for respiratory tract and asthma related morbidity during the first two years of life. In order to gain more insight into the relation between PFH and respiratory tract related morbidity as well as in the modifying effect of relevant environmental factors on this relationship, the interactive effect of family history of asthma with environmental factors was studied. To gain more insight into the modifying effect of family history on the relation between day-care attendance and respiratory tract related morbidity, the interactive effect of family history of asthma with day-care attendance was studied. Based on the assumption that the sensitivity and specificity of PFH are both high, PFH was used as selection criterion for the evaluation of a primary prevention program directed toward environmental factors, the PREVASC program. In this thesis it was evaluated whether the PREVASC program was (already) cost-effective during the first two years of life.

\section{Main conclusions}

Maternal asthma and being born in autumn are associated with elevated total $\mathrm{IgE}$ in newborns. The higher the total IgE cut-off level, the better newborns with maternal asthma can be distinguished from NFH newborns. Our findings concerning the association of total IgE in newborns with both maternal asthma and birth season confirm the idea that besides a genetic pathway, an environmental pathway is involved in the development of asthma (chapter 3). $\mathrm{PFH}$ is a significant risk factor for the occurrence of respiratory tract-related morbidity in infants during their first two years of life. The environmental factors, (postnatal) parental smoking and house dust mite increase the effect of PFH on 'wheezing ever' and 'attacks of wheezing'. This effect is even more pronounced when infants are exposed to both (postnatal) parental smoking and house dust mite. Formula feeding enhances the effect of PFH on the occurrence of tonsillitis and (acute) otitis media, whereas in breastfed infants the effect of PFH on these diagnoses seems to disappear (chapter 4). The effect 
of day-care attendance, a proxy for exposure to infections, seems to differ between PFH and NFH infants. In PFH infants there is no statistically significant effect of day-care attendance on respiratory tract and asthma-related morbidity and in NFH infants, day-care attendance increases the effect on respiratory tract and asthma-related morbidity (chapter 5).

Primary prevention of asthma, as performed in the PREVASC program, is not (yet) cost-effective in the first two years of life. The intervention is more expensive than usual care, and in addition, there is only a small probability that the PREVASC intervention has a positive effect in this period (chapter 6).

\section{Strenghts and limitations}

The PREVASC study is a longitudinal prospective birth cohort study in infants who were recruited prenatally from a GP-registered population. This design was chosen because, in the Dutch situation, GPs have a comprehensive overview of asthma concerning the families of the population registered with their practices. Asthma in parents and siblings was coded by the GP using the International Classification of Primary Care (ICPC) ${ }^{1}$ and diagnostic criteria based on the International Classification of Health Problems in Primary Care (ICHPPC-2). ${ }^{2}$ This method of documentation of family history differed from most other studies in this field, in which the mother usually reported information on family history. ${ }^{3-5}$ In these studies, objective information concerning the father's history was therefore often lacking, which may have led to reporting bias in these studies.

The design of the PREVASC study gave us the opportunity to prospectively document information regarding respiratory tract and asthma related morbidity as well as the costs, in a primary care population in early infancy. From both the parents and the GP, we collected information from birth up to two years of age. For the observations three different sources were used: parental reports, which were completed on a weekly basis, the internationally validated ISAAC questionnaire, completed by the parents on different timeintervals during the study period, and the GP records, for which registration was done at every consultation. In this way it was possible to get an extensive view of the health status of the participating infants.

To get a better understanding of the etiology of a family history of asthma, it is important to study the interactions between family history and environmental factors such as exposure to allergens, tobacco smoke and viruses.

The relationship between environmental factors and the appearance of respiratory tract-related morbidity already has been evaluated in other studies. 
However, interactions between family history and environmental factors were not always included. Moreover, the results of these studies did not always point the same direction. Explanations for these differences may be due to geographical variation, or based on differences in study design and statistical models that were used to study the relationship between environment and morbidity.

In our study (chapters 3 - 5) we considered potential confounders and looked into effect modification. Concerning confounders, we included only those (independent) factors that have shown to be risk factors for respiratory tract related morbidity in infants. In addition, risk factors were not included when they were part of the causal chain between the central determinant (i.e. family history of asthma) and respiratory tract related morbidity. For example, both $\mathrm{PFH}$ and total IgE in newborns positively affect respiratory tract related morbidity in infants. ${ }^{6}$ The presence of total IgE in newborns is influenced by a positive family history ${ }^{7}$, which makes total IgE in newborns a potential part of the causal chain between family history and respiratory tract related morbidity. Therefore, in chapters 4 and 5, total IgE in newborns was not included in the models.

As in every other study, there are some limitations on the PREVASC study. The selection procedure that was chosen for the study may have lead to misclassification. It might be that a definite asthma diagnosis could not have been given to siblings, since they were simply too young to undergo a lung function test, while other objective instruments to diagnose asthma were lacking. In addition, an underestimation of the asthma risk in the unborn infant from smaller families compared to those from larger families may have existed; more siblings increase the chance of PFH. However, this underestimation would have been even more pronounced had the definition of PFH been exclusively based on the incidence of asthma in parents. ${ }^{8}$ To account for the possible underestimation of the risk in our design, family size was included in the multiple logistic regression models of the studies discussed in this thesis.

$\mathrm{PFH}$ and NFH infants were recruited in different periods in time. PFH infants were recruited during the period 1997-1999, whereas recruitment of the NFH infants occurred between 2000 and 2002. These differences in recruitment time span may have lead to differences in basic characteristics between the groups, as for example the exposure to house dust mite. As is shown in the PIAMA study, the appearance of house dust mite varies from season to season and year to year. ${ }^{9}$ For example, in years with an extremely cold winter, house dust mite concentrations can be significantly lower than in a relatively warm winter. To take these factors into account we included exposure to house dust mite, cat 
and dog allergens, but also birth season in our multiple logistic regression models (chapters 4 and 5).

Concerning the questionnaires used in the study, the ISAAC questionnaire is the only internationally validated questionnaire that has been applied in many countries. For the purpose of international comparisons, it is an important questionnaire. However, this questionnaire was originally developed for children aged 6-7 and 13-14 years, with the purpose to collect information concerning the prevalence of asthma symptoms at a given moment but not for the follow-up of infants.

In addition, it assesses information in a retrospective manner. Parents were asked to report information concerning their child's respiratory tract and asthma related morbidity over the last 12 months. It is generally believed that recall over a time span longer than 6 months may lead to recall bias, which makes the ISAAC questionnaire sensitive to this type of bias. ${ }^{10}$ An advantage of the GP registration is that a professional healthcare worker prospectively documented symptoms and diagnoses, using the standardized criteria of the ICHPPC-2, which gives the information a more objective and critically valid character. However, it only assessed the presented morbidity to GPs of parents seeking medical care. Since both GPs and parents could not have been blinded to the study groups, there was a chance of classification and reporting bias. It might have been that parents and GPs of PFH infants were more focused on respiratory tract and asthma related morbidity than parents and GPs of NFH infants. Whether this phenomenon played a significant role can only be validated partly with objective tools, such as asthma diagnoses at the age of six.

Despite the fact that with the weekly reports, information was sampled in a prospective manner at regular, frequent time intervals, it might have been that parents gave other interpretations to symptoms such as wheezing or shortness of breath than physicians would have, which may have lead to registration bias. We could not find support for this impression since all sources of information we used pointed the same direction.

As shown in chapters 4 and 5, the study results were very consistent for the three sources used, indicating that recall bias and registration bias did not play a significant role. The possibility of classification and/or reporting bias however deserves attention. Therefore it is important to prospectively follow the infants to the age of six, when an objective and blinded asthma diagnosis can be made.

In this thesis, results concerning morbidity as well as the cost-effectiveness of the PREVASC program were presented over the first two years of life. During this study period it was not possible to diagnose asthma objectively, since 
objective test criteria for the diagnosis of asthma are lacking for this age group. Therefore in our study we used outcome measures that are considered to be related to the development of asthma, such as wheeze, cough, shortness of breath and eczema (chapters 4 and 5) or in the case of 'surrogate' asthma diagnoses, based on GP reports or an epidemiological asthma prediction model, which was originally developed for children of school age (chapter 6). ${ }^{11}$ An important advantage is that we now have a good view of respiratory tract and asthma related morbidity as well as a highly detailed view of the different cost aspects in early infancy. A limitation is that, to be able to get a complete picture of respiratory tract and asthma related morbidity in infancy, the outcome could not be limited to one or two parameters (chapters 4 and 5). As a consequence, multiple comparisons had to be performed, with the risk of results that might be based on chance. The latter is, however not likely, since the results were generally in the same direction, and, in addition, we found more significant interactions than would be expected by chance (chapters 4 and 5). Another limitation is that the 'surrogate' asthma diagnoses may have limited the possibility to generalize the results of the cost-effectiveness analysis (chapter 6).

\section{What our study adds}

Many studies have been performed in which an association between newborn IgE and atopy or asthma as well as birth season have been shown, ${ }^{12-22}$ although the results did not always point the same direction. When performing analyses with newborn IgE, it is impossible to evaluate this variable as continuous variable, since it is heavily skewed, even after logarithmic transformation. Therefore, standard testing methods are not sufficient. In most studies, IgE was dichotomised around a single cut-off point. Another approach was to compare groups on the basis of geometric means. In our opinion, neither approach gets close enough to a normal distribution. As a compromise and to get more insight of the continuous total IgE variable, we decided to present total IgE as a dichotomous variable with different cut-off levels. Using this approach in our primary care study we demonstrated that the association of maternal asthma and newborn IgE increased with increasing total IgE cut-off levels, indicating that the higher the total IgE cut-off level, the better high-risk newborns could be distinguished from low-risk newborns.

Would it be sensible to use total IgE from newborns together with a family history of asthma as instrument for the identification of those infants with the highest risk of asthma? Literature has been inconclusive on the issue of using exclusively IgE from newborns as screening instrument for atopic disease.13,15,16,18,23-29 However, the studies performed were generally in infants 
younger than six years of age. Sadeghnejad et al. ${ }^{29}$ and Croner et al..$^{30}$ followed infants from birth up to 10 and 11 years respectively. They showed that the risk of developing asthma increased with rising age in children with elevated levels of $\operatorname{IgE}(\geq 0.5 \mathrm{IU} / \mathrm{ml})$ at birth. It is to be expected that a combination of family history with elevated IgE at birth increases the predictive capacity of the instrument, and will thus be a better identification instrument to identify infants at high-risk than family history alone.

However, it would predominantly identify infants at risk for allergic asthma while infants at risk for non-allergic asthma might be missed. In the perspective of primary prevention, this combination instrument might not be useful since intervention should preferably start prenatally.

Although studies are not equivocal, ${ }^{31-33}$ some authors showed that environmental risk factors as environmental tobacco exposure, house dust mite, cat and dog allergens are associated with increased sensitisation and allergic disease, ${ }^{34-37}$ whereas breastfeeding is thought to have a protective effect. ${ }^{38}$ To our knowledge, the interactive effect of environmental factors and $\mathrm{PFH}$ on respiratory tract and asthma-related morbidity has not been evaluated. With our study, we demonstrated that environmental factors increased the effect of PFH on respiratory tract and asthma related morbidity. Our findings may have important implications for advice concerning preventive measures in infants with or without a family history of asthma. For example, if environmental factors increase respiratory tract related morbidity in PFH but not in NFH infants, this should strengthen the theory that preventive advice should be directed only to PFH infants, not only because PFH infants have the highest risk of developing asthma, but also because this type of intervention is not effective for NFH infants. However, to be able to give good advice, this research question should be studied from the intervention perspective.

The attendance of day-care has been shown to be related to the development of respiratory tract and asthma related morbidity. $39-42$

Whether the respiratory tract response to day-care attendance is the same in $\mathrm{PFH}$ and NFH infants was unknown until recently. With our study we showed that family history of asthma modifies the symptomatic response to day-care attendance in children aged 0-2 years, as day-care attendance is associated with increased respiratory symptoms and diagnoses in NFH children, whereas in $\mathrm{PFH}$ children no statistically significant effect of day-care attendance on respiratory symptoms and diagnoses is observed. If the observation that $\mathrm{PFH}$ and NFH children respond differently to day-care attendance persists when infants grow up, this could lead to different advice for day-care attendance for children with and without asthma in the family. In the worst case the advice would be negative for families without asthma. However, to gain more insight 
into this phenomenon, these observations should be replicated in further studies, in children of school age.

\section{Recommendations for future research}

The most important recommendation is that the infants in the current cohort should be followed until at least the age of six and, if possible, for many years thereafter. By the age of six persistent wheezers, or true asthmatics can be distinguished from transient wheezers ${ }^{43}$, and by using objective lung function tests an objective asthma diagnosis can be made. By following the infants for a longer period, the course of asthma-related morbidity and its association with several determinants can be mapped. Moreover, the effects of the randomized clinical trial on the prevention of asthma can be studied. The latter is already in progress.

With this information we can get an impression of the 'strength' and applicability of PFH as a predictor for childhood asthma, and, in addition, whether in our primary care study the respiratory tract and asthma related morbidity observed in early infancy is predictive for asthma at the age of six.

We showed from an etiological perspective that the environmental factors parental smoking, house dust mite and formula feeding modified the effect of $\mathrm{PFH}$ on respiratory tract and asthma related morbidity. From the scope of intervention this phenomenon should be studied from a preventive perspective, i.e. the potential modifying effect of PFH on the relation between environmental factors and respiratory tract and asthma-related morbidity.

Concerning day-care attendance it would be interesting to study whether the observed differences in response to day-care attendance between $\mathrm{PFH}$ and NFH infants persist when the infants grow older. When the differences persist, this information can be used in the advice regarding day-care attendance for families with and without asthma.

From the perspective of the cost-effectiveness of the PREVASC program it is very important to follow the infants until asthma can be diagnosed objectively. At the age of two, the program was not cost-effective and based on these findings the current advice should be not to recommend the program. However, since an objective asthma diagnosis could not be made in the first two years of life, misclassification of the asthma cases cannot be ruled out. This may have affected the outcome. In addition, as described by Schönberger et $\mathrm{al}^{44}$ at two years, PFH infants from the intervention group had significantly less current asthma symptoms than PFH infants from the control group. This 
was most pronounced in girls. These findings indicate that in the long run the program may become effective, at least in girls.

Concerning the intervention part, the intervention becomes less intense after the second birthday. This will have an effect on the intervention costs, which contained the majority of the total costs in the first part. For those infants who will finally develop asthma, it is expected that the costs to treat their asthma symptoms increase substantially in the coming years. Prevention of these asthma cases may significantly reduce the direct and indirect costs.

At the age of six, when an objective asthma diagnosis can be made, it can be determined whether the program is cost-effective in the first six years of life. If the PREVASC program turns out to be effective in the long run, it is expected that the total costs of the intervention group will be favourable as opposed to the control group. If this is the case this information may be an important tool in the decision whether to implement the PREVASC program into the society.

In the Netherlands, $20 \%$ of all newborns have at least one first-degree family member with asthma. According to our findings in the first two years of life, $30 \%$ of these infants might develop asthma (this thesis). Eighty percent of the newborns have no first-degree family member with asthma. In this group we demonstrated that about $8 \%$ might develop asthma in the first two years (this thesis). In other words, in a population of 1000 newborns, 60 infants with a family history of asthma and 64 infants without a family history of asthma will finally develop asthma.

Which implications does this have for 'family history of asthma' as selection instrument for intervention?

Fifty percent of the new asthma cases have a positive family history of asthma. Given the assumption that the (PREVASC) prevention program is $100 \%$ effective, there will be a reduction in asthma cases of $50 \%$. However, when the program is less effective, the asthma reduction will be lower. Thus to be able to take a balanced decision about whether intervention should be offered, we need information concerning the effectiveness and the cost-effectiveness of the prevention program. By connecting the outcome of the cost-effectiveness analysis to the prevalence of family history and the number of asthma cases in $\mathrm{PFH}$ and NFH infants, the efficiency of 'high-risk' identification and the expected cost-effectiveness of the completed program can be determined.

An advantage of directing a prenatally initiated intervention program to the entire population is that fewer potential cases of asthma will be missed. As a potential disadvantage, there is a risk of giving families erroneous advice regarding preventive measures. Moreover, the total intervention costs of a prevention program attributed to the whole population will be enormous, while the chance of adherence to the program might be low, because most parents are not familiar with the disease. Finally, it raises the question whether 
it is ethical to put complete families of individuals at 'low-risk' of asthma on such stringent restrictions.

By offering a prevention program to a specified 'high-risk' group exclusively, only those selected families with the highest risk of having a baby that will develop asthma are included and as a consequence the total intervention costs will be lower. The chance of adherence to the program may be higher in this specific group as well. However, the chance that children at risk will be missed is also increased.

To be able to give advice as to whom prevention should be offered, more insight is needed in the number of infants at risk that has be reached, the adherence to the prevention program, ethical aspects, the total intervention costs and, in addition, the way children with and without a family history of asthma react to environmental risk factors.

Another issue that should be studied is the age at which respiratory tract and asthma related symptoms start. We know from this and other studies that PFH infants have a higher frequency of and more severe respiratory tract and asthma related morbidity, than NFH infants. What we don't know is how early symptoms start and when the observed differences between PFH and NFH infants first appear. To be able to start intervention as early as possible this knowledge is important in the consideration of how to handle asthma-like symptoms in infants and how (severe) asthma can be best prevented.

Finally, as discussed earlier, in our study there might have been an underestimation of the asthma risk in the unborn since in some cases siblings were too young to obtain an objective diagnosis of asthma. It would be very interesting to study whether the 'asthma status' in family members changes with time. This information could give more weight to 'family history of asthma' as a selection instrument. 


\section{References}

1. ICPC: Lamberts $\mathrm{H}$, Wood $\mathrm{M}$ : the international classification of primary care. Oxford University Press, Oxford; 1983.

2. ICHPPC-2: Classification Committee of WONCA: ICHPPC-2 defined. International classification of health problems in primary care. Oxford University Press; 1983.

3. Arshad SH, Stevens M, Hide DW. The effect of genetic and environmental factors on the prevalence of allergic disorders at the age of two years. Clin Exp Allergy 1993;23:504-11.

4. Koopman LP, Strien RT van, Kerkhof M, Wijga A, Smit HA, de Jongste JC, Gerritsen J, Aalberse RC, Brunekreef B, Neijens HJ. Placebo-controlled trial of house dust miteimpermeable mattress covers: effects on symptoms in early childhood. Am J Respir Crit Care Med 2002;166:307-13.

5. Bosken $\mathrm{CH}$, Hunt WC, Lambert WE, Samet JM. A parental history of asthma is a risk factor for wheezing and nonwheezing respiratory illnesses in infants younger than 18 months of age. Am J Respir Crit Care Med 2000;161:1810-15.

6. Tariq SM, Arshad SH, Matthews SM, Hakim EA. Elevated cord serum IgE increases the risk of aeroallergen sensitization without increasing respiratory allergic symptoms in early childhood. Clin Exp Allergy 1999;29:1042-8.

7. Kuiper S, Maas T, van Schayck CP, Muris JWM, Schönberger HJAM, Dompeling E, Gijsbers B, van Weel C, Knottnerus JA. The primary prevention of asthma in children study: Design of a multifaceted prevention program. Pediatr Allergy Immunol 2005;16:321-31.

8. Burke W, Fesinmeyer M, Reed K, Hampson L, Carlsten C. Family history as a predictor of asthma risk. Am J Prev Med 2003;24:160-9.

9. Brunekreef B, van Strien R, Pronk A, Oldenwning M, de Jongste JC, Wijga A, Kerkhof M, Aalberse RC. La mano de DIPS...was the PIAMA intervention study intervened upon? Allergy 2005;60:1083-6.

10. Severens JL, Mulder J, Laheij RJF, Verbeek ALM. Precision and accuracy in measuring absence from work as a basis for calculating productivity costs in The Netherlands. Social Science \& Medicine 2000;51:243-9.

11. Castro-Rodriguez JA, Holberg CJ, Wright AL, Martinez FD. A clinical index to define risk of asthma in young children with recurrent wheezing. Am J Respir and Crit care Med 2000:162:1403-6.

12. Haus M, Heese HD, Weinberg EG, Potter PC, Hall JM, Malherbe D. The influence of ethnicity, an atopic family history, and maternal ascariasis on cord blood serum IgE concentrations. J Allergy Clin Immunol 1988;82:179-89.

13. Michel FB, Bousquet J, Greillier P, Robinet-Levy M, Coulomb Y. Comparison of cord blood immunoglobulin E concentrations and maternal allergy for the prediction of atopic diseases in infancy. J Allergy Clin Immunol 1980;65:422-30.

14. Bergmann RL, Schulz J, Günther S, Dudenhausen JW, Bergmann KE, Bauer CP, et al. Determinants of cord-blood IgE concentrations in 6401 German neonates. Allergy 1995;50: 65-71.

15. Croner S, Kjellman N-I M, Erkisson B, Roth A. IgE screening in 1701 newborn infants and the development of atopic disease during infancy. Arch Dis Childhood 1982;57:364-8.

16. Magnusson CGM. Cord serum IgE in relation to family history and as predictor of atopic disease in early infancy. Allergy 1988;43:241-51.

17. Johnson CC, Ownby DR, Peterson EL. Parental history of atopic disease and concentration of cord blood IgE. Clin Exp allergy 1996;26:624-9.

18. Kaan A, Dimich-Ward H, Manfreda J, Becker A, Watson W, Ferguson A, Chan H, ChanYeung M. Cord blood IgE: its determinants and prediction of development of asthma and other allergic disorders at 12 months. Ann Allergy Asthma Immunol 2000;84:37-42.

19. Hansen LG, Host A, Halken S, Holmskov A, Husby S, Lassen LB, et al. Cord blood IgE. I. IgE screening in 2814 newborn children. Allergy 1992;47:391-6.

20. Halonen M, Stern D, Lyle S, Wright A, Taussig L, Martinez FD. Relationship of total serum IgE levels in cord and 9-month sera of infants. Clin Exp Allergy 1991;21:235-41. 
21. Kimpen J, Callaert H, Embrechts P, Bosmans E. Cord blood IgE and month of birth. Arch Dis Child 1987;62:478-82.

22. Bjerke $T$, Hedegaard $M$, Henriksen $T B$, Nielsen BW, Schiotz PO. Several genetic and environmental factors influence cord blood IgE concentrations. Pediatr Allergy Immunol 1994;5:88-94.

23. Bergmann RL, Edenharter G, Bergmann KE, Guggenmoos-Holzmann I, forster J, Bauer CP, Wahn V, Zepp F, Wahn U.Predictability of early atopy by cord blood-IgE and parental history. Clin Exp Allergy 1997;27:752-60.

24. Hansen LG, Halken S,Host A, Moller K, Osterballe O. Prediction of allergy from family history and cord blood IgE levels. A follow-up at the age of 5 years. Cord blood IgE. IV. Pediatr Allergy Immunol 1993;4:34-40.

25. Ruiz RG, Richards D, Kemeny DM, Price JF. Neonatal IgE: a poor screen for atopic disease. Clin Exp Allergy 1991;21:467-72.

26. Eiriksson TH, Sigurgeirsson B, Ardal B, Sigfusson A, Valdimarsson H. Cord blood IgE levels are influenced by gestational age but do not predict allergic manifestations in infants. Pediatr Allergy Immunol 1994;5:5-10.

27. Edenharter G, Bergmann RL, Bergmann KE, Wahn V, forster J, Zepp F, Wahn U. Cord blood IgE as risk factor and predictor for atopic diseases. Clin Exp Allergy 1998;28:671-8.

28. Hide DW, Arshad SH, Twiselton R, Stevens M. Cord serum IgE: an insensitive method for prediction of atopy. Clin Exp Allergy 1992;22:506.

29. Sadeghnejad A, Karmaus W, Davis S, Kurukulaaratchy RJ, Matthews S, Arshad SH. Raised cord serum immuboglobulin $\mathrm{E}$ increases the risk of allergic sensitization at ages 4 and 10 and asthma at age 10. Thorax 2004;59:936-42.

30. Croner S, Kjellman NI. Development of atopic disease in relation to family history and cord blood IgE levels. Eleven year follow up in 1654 children. Pediatr Allergy Immunol 1990;1: 14-20.

31. Sears MR, Green JM, Willan AR, Taylor DR, Flannery E, Cowan JO, Herbison GP, Poulton R. Long-term relation between breastfeeding anddevelopment of atopy and asthma in children and young adults: a longitudinal study. Lancet 2002;360:901-7.

32. Hesselmar B, Aberg N, Aberg B, Eriksson B, Bjorksten B. Does early exposure to cat or dog protect against later allergy development? Clin Exp Allergy 1999;29:611-17.

33. Burr ML, Merrett TG, Dunstan FDJ, Maguire MJ. The development of allergy in high-risk children. Clin Exp Allergy 1997;27:1247-53.

34. DiFranza JR, Aligne CA, Weitzman M. Prenatal and postnatal environmental tobacco exposure and children's health. Pediatrics 2004;113:1007-15.

35. Wahn U, Lau S, Bergmann R, Kulig M, forster J, Bergmann K, Bouer CP, GuggenmoosHolzmann I. Indoor allergen exposure is a risk factor for sensitization during the first three years of life. J Allergy Clin Immunol 1997;99:763-9.

36. Vanto T, Koivikko A. Dog hypersensitivity in asthmatic children. Acta Paediatr Scand 1983;72:571-5.

37. Warner JA, Little SA, Pollock I, Longbottom JL, Warner JO. The influence of exposure to house dust mite, cat and pollen allergens in the homes on primary sensitisation in asthma. Pediatr Allergy Immunol 1991;1:79-86.

38. Chantry CJ, Howard CR, Auinger P. Full breastfeeding duration and associated decrease in respiratory tract infection in US children. Pediatrics 2006;117:425-32.

39. Krämer U, Heinrich J, Wijst M, Wichmann HE. Age of entry to day nursery and allergy in later childhood. Lancet 1999;353:450-4.

40. Ball TM, Castro-Rodriguez JA, Griffith KA, Holberg CJ, Martinez FD, Wright AL. Siblings, day-care attendance and the risk of asthma and wheezing during childhood. N Engl J Med 2000;343:538-543.

41. Koopman LP, Smit HA, Heijnen ML, Wijga A, van Strien RT, Kerkhof M, Gerritsen J, Brunekreef B, de Jongste JC, Neijens HJ. Respiratory infections in infants: interaction of parental allergy, childcare, and siblings - The PIAMA study. Pediatrics 2001;108(4):943-8. 
42. Infante-Rivard C, Amre D, Gautrin D, Malo JL. Family size, day-care attendance, and breastfeeding in relation to the incidence of childhood asthma. Am J Epidemiol 2001;153: 653-8.

43. Martinez FD, Wright AL, Taussig LM, Holberg CJ, Halonen M, Morgan WJ. Asthma and wheezing in the first six years of life. New Engl J Med 1995;332:133-8.

44. Schönberger HJAM, Dompeling E, Knottnerus JA, Maas T, Muris JWM, van Weel C, van Schayck CP. The PREVASC study: the clinical effect of a multi-faceted educational intervention to prevent childhood asthma. Eur Respir J 2005;25(4):660-70. 



\section{Summary}

In this thesis several aspects of the role of a first-degree family history of asthma, as determined in general practice, in infants during their first two years of life were evaluated.

\section{Chapter 1 Introduction}

This chapter describes the background of this thesis. We sustained the importance of preventing the development of (severe) asthma and described the state of art of the relationship between risk factors, family history of asthma and the susceptibility to develop asthma. In addition, we described that family history of asthma and its interaction with environmental triggers needed more attention and hypothesized that, children with- and without a first-degree family history of asthma may respond differently to environmental risk factors because of differences in their genetic backgrounds. Finally, we argued that insight in the way children with and without a family history of asthma react to environmental risk factors, and in addition, in the cost-effectiveness of preventing asthma may help us to develop an advice concerning whether and to whom prevention should be offered.

\section{Chapter 2 Design of the PREVASC program}

The PREVASC (Prevention of Asthma in Children) program is an ongoing research program that focuses on primary prevention of asthma in children. This program has four goals. First of all, it estimates the predictive value of a positive family history of asthma assessed in the prenatal period by the general practitioner (GP) for the development of respiratory tract related morbidity. In addition, it assesses the effectiveness of a prenatally started multi-faceted primary prevention program focused on reducing the exposure to indoor- and food allergens and environmental tobacco smoke in children at high-risk of developing asthma. Furthermore it evaluates whether optimising the intervention increases the adherence. Finally, the program studies the healtheconomic benefits of 'high-risk' identification and primary prevention of asthma.

The PREVASC study showed that infants with a positive family history (PFH) who received intervention were more breast-fed and/or received more hypoallergenic formula feeding than PFH infants in the control group. The first intake of solid food was more often postponed to the age of 6 months in the intervention group compared to the control group. Measurement of environmental exposure to house dust mite, cat and dog allergens showed that exactly 1 year after baseline measurements the concentration of house dust 
mite, cat and dog allergens, were decreased in the PFH intervention group, but not in the PFH control group.

\section{Chapter 3 Association between family history and total IgE in newborns}

This chapter had two goals. First of all it was studied whether there was an association between a positive family history of asthma, as determined in primary care, and increased level of total IgE in newborns. In addition, the influence of gender, family size, birth season, maternal smoking, birth weight, gestational age and maternal diet on total IgE in newborns was investigated.

We found, at different total IgE cut-off levels, that maternal asthma is a risk factor for increased levels of IgE. In addition, we found an association of total IgE in newborns with birth season (autumn), which confirms that besides a genetic pathway an environmental pathway plays a role.

\section{Chapter 4 The interactive effect of family history and environmental factors on respiratory tract related morbidity in early infancy}

In this chapter we discussed the interactive effect of a positive family history of asthma and environmental factors on the occurrence of respiratory tract related morbidity in early infancy. We showed that PFH infants had more respiratory tract and asthma related morbidity than NFH infants, which confirms that a positive family history is a risk factor for respiratory tract and asthma related morbidity in infants during their first two years of life. More importantly, we showed that postnatal exposure to parental smoking (PPS) and Derp1 each increased the odds ratio of a positive family history for wheezing ever and attacks of wheezing. Furthermore when both factors were present at the same time these odds ratios were even more increased. Breastfeeding decreased the odds ratios of PFH for tonsillitis and (acute) otitis media. We concluded that PPS and Derp1 increase the effect of PFH on respiratory tract and asthma related morbidity, while breastfeeding reduces this effect. Our findings may shed more light on the controversy concerning the effect of environmental factors.

\section{Chapter 5 Family history of asthma, day-care attendance and respiratory morbidity in infants}

In chapter 5 we elaborated further on the theme of interactions between family history and environmental factors in relation with respiratory tract and asthma related morbidity. In this chapter we studied the interaction from a more clinical instead of an etiological perspective, and investigated whether family 
history modified the contribution of day-care attendance to respiratory tract and asthma related morbidity early infancy.

In this chapter we showed that, although day-care attendance was associated with increased nocturnal cough, cough on exertion, common colds, attacks of wheezing, awakening by cough and allergic rhinoconjunctivitis in NFH infants, it had no statistically significant effect on appearance and frequency of symptoms in PFH infants. Although definite conclusions cannot be drawn, it might be that $\mathrm{PFH}$ and $\mathrm{NFH}$ infants may respond differently to day-care attendance. Confirmation of our findings by other investigators and prolongation of our results in children at school age, may lead to different advice on day-care attendance for children from families with and without asthma.

\section{Chapter 6 Cost-effectiveness of primary prevention of asthma}

In chapter 6, we used PFH as identification instrument for infants at 'high-risk' in a primary (prenatally started) prevention study. To investigate the societal perspective based cost-effectiveness of primary prevention of asthma in 'highrisk' infants up to two years of age (PREVASC), PFH infants were selected prenatally for a randomised controlled trial. Since, for children at the age of two, no instruments are available to diagnose asthma objectively, we used a clinical, general practitioner (GP) asthma diagnosis and an Epidemiological asthma diagnosis based Prediction Model (EPM). Using bootstrap analyses, the uncertainty around the incremental cost-effectiveness ratios was determined. With both definitions there was no difference in asthma diagnosis between $\mathrm{PFH}$ infants who received intervention compared to PFH from a control group. The incremental cost-effectiveness ratio of the program was higher for the GP diagnosis than for the EPM. However, with both the GP diagnosis and the EPM there was inferiority of the experimental situation. All bootstrap replications indicated that the PREVASC program is more costly, with a small chance that the program was more effective than usual care. We concluded that primary prevention of asthma in the first two years of life is not cost-effective, neither based on the GP diagnosis nor on the EPM. We advised to follow the children further until at least an age at which asthma can objectively be diagnosed and the costs and effects of the intervention have been more crystallized.

\section{Chapter 7 General discussion}

In this final chapter an overview of the conclusions and comments on the findings are described. We discussed the strengths and weakness of the study and gave recommendations for further research on the theme of 'family history of asthma'. 
Maternal asthma and being born in autumn are associated with elevated total IgE in newborns. The higher the total IgE cut-off level, the better newborns with maternal asthma can be distinguished from NFH newborns.

$\mathrm{PFH}$ is a significant risk factor for the occurrence of respiratory tract-related morbidity in infants during their first two years of life. Postnatal parental smoking and house dust mite increase the effect of PFH on wheezing ever and attacks of wheezing. Formula feeding enhances the effect of PFH on tonsillitis and (acute) otitis media, whereas in breastfed infants the effect of PFH on tonsillitis and (acute) otitis media seems to disappear.

Day-care attendance is associated with increased nocturnal cough, cough on exertion, cold, attacks of wheezing, awakening by cough and allergic rhinoconjunctivitis in NFH infants but has no effect in PFH infants.

Primary prevention of asthma, as performed in the PREVASC program, is not (yet) cost-effective in the first two years of life. The intervention is more expensive than usual care, and in addition, there is only a small probability that the PREVASC intervention has a positive effect in this period.

The PREVASC study is a longitudinal prospective birth cohort study, in which pregnant mothers were recruited predominantly from a GP-registered population. This design was chosen because, in the Dutch situation, GPs have a comprehensive overview of asthma in the families in the population registered with their practices.

Information concerning respiratory tract and asthma related morbidity was prospectively documented by the parents and the GP, which gave us the opportunity to get an extensive view of the frequency and duration of respiratory tract and asthma related morbidity in infants during their first two years of life.

Limitations of our study might have been an underestimation of the asthma risk, due to family size, differences in recruitment time span, classification and reporting bias by the parents and GP, the fact that both could not be blinded for the study, but also the lack of test criteria for an objective asthma diagnosis in siblings below the age of six. The underestimation would have been even more pronounced had the definition of PFH been exclusively based on incidence in parents. To account for the possible underestimation of the risk in our design, family size was included in the multiple logistic regression models of the studies discussed in this thesis. The possibility of classification and/or reporting bias deserves attention. Therefore it is important to prospectively follow the infants to the age of six, when an objective (blinded) asthma diagnosis can be made. 
The most important research recommendation is that the infants in the current PREVASC cohort should be followed until at least the age of six and, if possible, for many years thereafter. With a prolonged follow-up we can get a better impression of the 'strength' and applicability of PFH as a predictor for childhood asthma, and, in addition, whether in our primary care study the respiratory tract and asthma related morbidity observed in early infancy is predictive for asthma at the age of six. Moreover, information concerning the (different) responses of PFH and NFH infants to environmental triggers, can help us to formulate advices for children from families with and without asthma regarding day-care attendance and environmental agents as parental smoking, allergens and breastfeeding. Finally, when an objective asthma diagnosis can be made, it can be determined whether the PREVASC program is cost-effective in the long run. With this information together with information concerning the prevalence of family history and the number of asthma cases in PFH and NFH infants, the efficiency of 'high-risk' identification and the expected cost-effectiveness of the completed program can be determined, which gives us the opportunity to take a balanced decision whether to implement this multifaceted primary prevention program. 
Samenvatting 


\section{Samenvatting}

In dit proefschrift worden verschillende aspecten besproken, betreffende de rol van $1^{\mathrm{e}}$ graads familiale belasting voor astma, vastgesteld door de huisarts, bij kinderen in de eerste twee levensjaren.

\section{Hoofdstuk 1 Introductie}

Dit hoofdstuk geeft een beschrijving van de achtergrond van dit proefschrift. Het belang van het voorkómen van de ontwikkeling van (ernstig) astma wordt bevestigd en er wordt een overzicht gegeven van de stand van zaken betreffende de relatie tussen risicofactoren, familiale belasting voor astma en de kans astma te ontwikkelen. Daarnaast wordt aangeven meer aandacht te besteden aan de interactie tussen familiale belasting en omgevingsfactoren. Kinderen met en zonder $1^{\mathrm{e}}$ graads familiale belasting voor astma kunnen, vanwege het verschil in genetische achtergrond, mogelijk verschillend reageren op risicofactoren uit de omgeving.

Tenslotte wordt betoogd dat inzicht in de wijze waarop kinderen, met en zonder familiale belasting voor astma, reageren op risicofactoren uit de omgeving waardevolle informatie kan opleveren bij de ontwikkeling van een advies aan wie een interventie eventueel zou moeten worden aangeboden.

\section{Hoofdstuk 2 Design van het PREVASK programma}

Het PREVASK (primaire PREVentie van AStma bij Kinderen) programma is een onderzoeksprogramma dat zich richt op de primaire preventie van astma bij kinderen. Het programma heeft vier belangrijke doelstellingen. Ten eerste wordt een inschatting gemaakt van de voorspellende waarde van familiale belasting voor astma, vastgesteld door de huisarts tijdens de prenatale periode, op de ontwikkeling van respiratoire morbiditeit. Ten tweede wordt de effectiviteit vastgesteld van een prenataal gestart primair preventief programma dat gericht is op de reductie van blootstelling aan inhalatie- en voedingsallergenen en passief roken. Daarnaast wordt geëvalueerd of een geoptimaliseerde interventie de 'adherentie' aan het programma verhoogd. Tenslotte worden de potentiële gezondheidseconomische voordelen van 'hoogrisico' identificatie en van primaire preventie van astma bestudeerd.

Uit de eerste resultaten van de PREVASK studie is gebleken dat kinderen met een $1^{\mathrm{e}}$ graads familiale belasting voor astma ( $\mathrm{PFH}$ ) die tot de interventiegroep behoorden inderdaad vaker borstvoeding en/of hypoallergene voeding kregen dan PFH kinderen die tot de controlegroep behoorden. Het 'eerste hapje' vast voedsel werd in de interventiegroep in vergelijking met de controlegroep vaker uitgesteld tot de leeftijd van zes maanden. Wat betreft de blootstelling 
aan huisstofmijt, katten en honden allergenen bleek dat exact één jaar na de eerste meting, de concentratie aan huisstofmijt, katten en honden allergeen in de interventiegroep was afgenomen en in de controlegroep gelijk was gebleven.

\section{Hoofdstuk 3 Associatie tussen familiale belasting en totaal $\operatorname{IgE}$ bij pasgeborenen}

Dit hoofdstuk had twee doelstellingen. In de eerste plaats werd bestudeerd of er een associatie bestond tussen een $1^{\text {e }}$ graads familiale belasting voor astma, vastgesteld in de $1^{\text {e }}$ lijn, en een verhoogde waarde van totaal $\operatorname{IgE}$ bij pasgeborenen. In de tweede plaats werd bestudeerd of de factoren geslacht, gezinsgrootte, geboorteseizoen, roken door de moeder, geboortegewicht, zwangerschapsduur en maternale voeding van invloed waren op de waarde van totaal IgE bij pasgeborenen.

In deze studie werd aangetoond dat maternaal astma een risicofactor is voor een verhoogde waarde van totaal IgE. Dit geldt niet voor paternaal astma of astma bij broertjes en/of zusjes. Tevens werd een associatie gevonden tussen totaal IgE bij pasgeborenen en het geboorteseizoen (herfst). Deze laatste bevinding bevestigt de gedachte dat naast genetische- ook omgevingsaspecten een belangrijke rol spelen bij aanwezigheid van totaal IgE bij pasgeborenen.

\section{Hoofdstuk 4 Het interactieve effect van familiale belasting en omgevingsfactoren op respiratoire morbiditeit bij jonge kinderen}

In dit hoofdstuk is het interactieve effect bestudeerd van een $1^{\mathrm{e}}$ graads familiale belasting voor astma en omgevingsfactoren op het vóórkomen van respiratoire en astma gerelateerde morbiditeit bij jonge kinderen.

Kinderen met een $1^{\mathrm{e}}$ graads familiale belasting voor astma $(\mathrm{PFH})$ bleken meer respiratoire en astma gerelateerde morbiditeit te hebben dan kinderen zonder deze familiale belasting (NFH). Deze bevindingen bevestigen dat in de eerste twee levensjaren PFH een risicofactor is voor respiratoire en astma gerelateerde morbiditeit.

Daarnaast is aangetoond dat postnatale blootstelling aan tabaksrook alsmede aan huisstofmijt de odds ratio van PFH voor de klachten 'piepen ooit' en 'aanvallen van piepen' deed toenemen. Blootstelling aan beide risicofactoren tegelijkertijd verhoogde de odds ratio's voor beide klachten nog verder. Borstvoeding verlaagde de odds ratio's van PFH voor keel- en oorontsteking. Uit deze studie werd verder geconcludeerd dat blootstelling aan tabaksrook en huisstofmijt het effect van familiale belasting op respiratoire en astma gerelateerde morbiditeit versterkte, terwijl borstvoeding juist een reducerend effect had. Onze bevindingen kunnen mogelijk verheldering bieden voor de 
controversiële effecten die zijn gevonden in studies naar de effecten van omgevingsfactoren.

\section{Hoofdstuk 5 Familiale belasting voor astma, kinderdagverblijf bezoek en respiratoire morbiditeit bij jonge kinderen}

In hoofdstuk 5 is het thema betreffende de interactie tussen familiale belasting en omgevingsfactoren in relatie tot respiratoire en astma gerelateerde morbiditeit verder uitgewerkt. De interactie is in dit hoofdstuk vanuit een meer klinisch perspectief bestudeerd. Onderzocht is de vraag of familiale belasting het effect van kinderdagverblijf bezoek (KDV) op respiratoire en astma gerelateerde morbiditeit bij jonge kinderen modificeert.

In deze studie werd aangetoond dat KDV bezoek bij kinderen zonder familiale belasting leidt tot een toename van klachten als hoesten, verkoudheden, aanvallen van piepen en allergische rinoconjunctivitis is, maar dat KDV bezoek géén statistisch significant effect op respiratoire klachten heeft bij kinderen met een $1^{\text {e }}$ graads familiale belasting. Kinderen met- en zonder familiale belasting voor astma reageren dus mogelijk verschillend op KDV bezoek. Wanneer deze bevindingen worden bevestigd door andere onderzoeksgroepen en wanneer de gevonden effecten ook gelden voor oudere kinderen, dan zou dit kunnen leiden tot verschillende adviezen met betrekking tot KDV bezoek voor kinderen met- en zonder familiale belasting.

\section{Hoofdstuk 6 Kosten-effectiviteit van primaire preventie van astma}

In hoofdstuk 6, is 1e graads familiale belasting voor astma gebruikt als identificatie instrument voor 'hoog-risico' in een studie naar de kosteneffectiviteit van primaire preventie van astma bij kinderen. Voor deze studie is uitsluitend gebruik gemaakt van kinderen met een 1e graads familiale belasting voor astma, die prenataal geselecteerd waren voor een gerandomiseerde trial en gevolgd zijn tot en met de leeftijd van twee jaar.

Aangezien er voor twee jarigen (nog) geen instrumenten zijn om een objectieve diagnose te stellen, is er gebruik gemaakt van een klinische, door de huisarts (GP) op basis van symptoomregistratie vastgestelde, astma diagnose, alsmede van een astma diagnose gebaseerd op een epidemiologisch predictie model (EPM).

Met behulp van een bootstrap analyse is de onzekerheid rondom de incrementele kosteneffectiviteit ratio bepaald. Met geen van beide diagnosen werd een verschil in astma tussen de interventie en de controlegroep gevonden. De incrementele kosteneffectiviteit ratio was hoger wanneer de GP astma diagnose werd gebruikt dan wanneer het EPM werd gebruikt. Echter bij 
beide benaderingswijzen was sprake van inferioriteit van de experimentele situatie.

Alle bootstrap replicaties duiden erop dat het PREVASK programma kostbaarder is dan wanneer niet wordt geïntervenieerd, waarbij er slechts een kleine kans bestaat dat het programma dan ook effectiever is. De conclusie van deze studie was dat, met geen van beide methoden voor astma, het PREVASK programma kosteneffectief is gedurende de eerste twee levensjaren. Gezien het feit dat er op twee jarige leeftijd geen objectieve astma diagnose gesteld kan worden en gezien het feit dat de intensiteit van de interventie in de loop der jaren minder wordt, is het van belang de kinderen langer te volgen.

\section{Hoofdstuk 7 Discussie}

In dit afsluitende hoofdstuk wordt een overzicht gegeven van de conclusies en commentaren op de bevindingen. De sterke en zwakke punten worden bediscussieerd en er worden aanbevelingen gedaan voor toekomstig onderzoek betreffende het thema 'familiale belasting voor astma'.

Er is aangetoond dat pasgeborenen die een moeder met astma hebben of zijn geboren in de herfst vaker aantoonbaar IgE hebben dan kinderen die geen moeder met astma hebben of in een ander seizoen zijn geboren. Hoe hoger het gekozen afkappunt voor IgE, hoe beter pasgeborenen die een moeder met astma hebben kunnen worden onderscheiden van pasgeborenen die géén 1e graads familieleden met astma hebben.

In de eerste twee levensjaren is familiale belasting voor astma een significante risicofactor voor respiratoire en aan astma gerelateerde morbiditeit. Postnatale blootsteling aan tabaksrook en huisstofmijt versterken het effect van familiale belasting voor de symptomen 'piepen ooit' en 'aanvallen van piepen'. In tegenstelling tot borstvoeding, versterkt flesvoeding het effect van familiale belasting op de symptomen keel- en oorontsteking.

Bij kinderen die géén 1e graads familiale belasting voor astma hebben, is een associatie gevonden tussen kinderdagverblijfbezoek en een toename van de klachten 'nachtelijk hoesten', 'hoesten bij inspanning', 'wakker worden door hoesten', verkoudheid, 'aanvallen van piepen', en allergische rhinoconjunctivitis. Deze associatie werd niet gevonden bij kinderen met een 1e graads familiale belasting voor astma.

In de eerste twee levensjaren is primaire preventie, zoals uitgevoerd in de PREVASK studie, (nog) niet kosteneffectief. De interventie is duurder dan de standaard behandeling en er is slechts een kleine kans dat in deze periode de interventie een positief effect op de gezondheid heeft. 
De PREVASC studie is een longitudinaal prospectief geboorte cohort, waarin zwangere vrouwen voornamelijk via de huisarts werden gerecruteerd. De keuze van dit onderzoeksdesign is gebaseerd op het feit dat, in de Nederlandse situatie, huisartsen een uitvoerig overzicht hebben van de aanwezigheid van astma in de bij hun praktijken geregistreerde families.

Informatie betreffende respiratoire en aan astma gerelateerde morbiditeit is door zowel de ouders als de huisarts prospectief vastgelegd. Hierdoor was het mogelijk uitgebreid inzicht te krijgen in de frequentie en duur van respiratoire en aan astma gerelateerde morbiditeit in de eerste twee levensjaren van kinderen met- en zonder 1e graads familiale belasting voor astma.

Er zijn een aantal mogelijke beperkingen aan deze studie. Er kan sprake zijn van een onderschatting van het astma risico, vanwege de verschillen in de grootte van de families tussen de PFH en NFH groep. Daarnaast spelen een classificatie- en rapportagebias door zowel de ouders als de huisarts mogelijk een rol omdat zowel de ouders als de huisarts niet konden worden geblindeerd voor de studie en vanwege het gebrek aan test criteria om een objectieve astma diagnose bij broertjes en zusjes jonger dan zes jaar te stellen. Ten slotte zou de verschillende tijdspanne waarin kinderen met- en zonder 1e graads familiale belasting voor astma zijn gerekruteerd tot enige vertekening van de resultaten kunnen hebben geleid.

Wanneer de definitie van 1e graads familiale belasting voor astma uitsluitend zou zijn gebaseerd op astma bij de ouders, dan was de (mogelijke) onderschatting van het astma risico nog groter geweest. Om te kunnen corrigeren voor een mogelijke onderschatting van het astma risico in ons studiedesign, is de grootte van de families meegenomen in de multiple logistische regressie modellen van de studies die in dit proefschrift zijn bediscussieerd. De mogelijkheid dat classificatie en/of rapportage bias optreedt kan niet uitgesloten worden. Het is daarom van groot belang de kinderen prospectief te blijven volgen tot tenminste een leeftijd van zes jaar, zodat een objectieve (geblindeerde) astma diagnose gesteld kan worden.

De belangrijkste onderzoeksaanbeveling die uit dit proefschrift naar voren komt is de kinderen uit het PREVASK cohort te volgen tot tenminste de leeftijd van zes jaar, en, indien mogelijk, voor een nog veel langere tijd.

Met een langere follow-up kan een beter beeld worden verkregen van de 'waarde' en de toepasbaarheid van '1e graads familiale belasting voor astma', als voorspeller voor astma bij jonge kinderen. Daarnaast kan worden vastgesteld of in deze eerstelijns studie, de respiratoire en aan astma gerelateerde morbiditeit die op jonge leeftijd is vastgesteld, voorspellend is voor astma op 6-jarige leeftijd. 
Informatie betreffende de (verschillende) wijze waarop PFH en NFH kinderen op langere termijn reageren op omgevingsstimuli kan, voor kinderen met- en zonder 1e graads familiale belasting voor astma, nuttig zijn bij de formulering van adviezen betreffende kinderdagverblijf bezoek en omgevingsfactoren, zoals blootstelling aan tabaksrook, allergenen en borstvoeding.

Tenslotte, wanneer een objectieve astma diagnose kan worden gesteld, kan worden vastgesteld of het PREVASK programma op langere termijn kosteneffectief is.

Met deze informatie en met de informatie betreffende de prevalentie van '1e graads familiale belasting voor astma' en het aantal astmagevallen in de groepen kinderen met- en zonder 1e graads familiale belasting voor astma, kan de efficiëntie van 'hoog-risico' identificatie alsmede de verwachte kosteneffectiviteit van het complete programma worden bepaald. Met behulp van deze complete informatie kan een weloverwogen beslissing worden genomen, of het multigefaseerde primaire preventie programma, PREVASK, in de samenleving geïmplementeerd zou moeten worden. 
Publications 


\section{Publications}

Kuiper S, van Pelt J, Verheesen PE, Rentsch HU, Stockbrügger R, van der Linden SM. Patients with Ankylosing Spondylitis and healthy relatives do not show increased small intestinal permeability with the Lactulose-mannitol test. Clin Exp Rheumatol 1993;11:413-6.

Van de Loo FAJ, Kuiper S, van Enckevort FH, Arntz OJ, van den Berg WB. Interleukin-6 reduces cartilage destruction during experimental arthritis. A study in interleukin-6 deficient mice. Am J Pathol 1997;15:177-99.

Van den Berg WB, Kollias G, Kuiper S, Joosten LAB, van de Loo FAJ. Reduction of cartilage damage in arthritis in IL-1 $\beta$ deficient mice; Comparison with TNF $\alpha$ deficient mice. $44^{\text {th }}$ Annual meeting Orthopaedic Research Society, March 16-19, 1998, New Orleans, Louisiana.

Kuiper S, Joosten LAB, Bendele A, Edwards III KK, Arntz AJ, Helmsen MMA, van de Loo FAJ, van den Berg WB: Different roles of tumor necrosis factor- $\alpha$ and interleukin-1 in murine Streptococcal cell wall arthritis. Cytokine 1998;10:690-702.

Kuiper S, van Gestel AM, Swinkels HL, de Boo TM, da Silva JAP, van Riel PLCM. Influence of sex, age, and menopausal state on the course of early Rheumatoid Arthritis. J Rheumatol 2001;28:1809-16.

Kuiper S, Maas T, van Schayck CP, Muris JWM, Schönberger HJAM, Dompeling E, Gijsbers B, van Weel C, Knottnerus JA on behalf of the PREVASC group. The primary prevention of asthma in children (PREVASC) study: Design of a multifaceted prevention program. Pediatr Allergy and Immunol 2005;16(4):321-31.

Schönberger HJ, Dompeling E, Knottnerus JA, Kuiper S, van Weel C, Schayck $\mathrm{CP}$. Prenatal exposure to mite and pet allergens and total serum IgE at birth in high-risk children. Pediatr Allergy Immunol. 2005; 16(1): 27-31.

Kuiper S, Muris JWM, Dompeling E, Schönberger HJAM, van Schayck CP, Wesseling G, Knottnerus JA. Association between first-degree familial predisposition of asthma and atopy (IgE) in newborns. Clin Exp Allergy 2006; 36:594-601. 


\section{Manuscripts submitted for publication}

Kuiper S, van Schayck CP, Knottnerus JA, Muris JWM, Kester AD, Schönberger HJ, Maas T, Wesseling G, Dompeling E. Family history modifies the effect of day-care on respiratory morbidity in preschool children.

Kuiper S, Muris JWM, Dompeling E, Kester ADM, Wesseling G, Knottnerus JA, van Schayck CP. Interactive effect of family history and environmental factors on respiratory tract related morbidity in infancy.

Kuiper S, Severens JL, Muris JWM, Dompeling E, Knottnerus JA, van Schayck $\mathrm{CP}$. Cost-effectiveness of primary prevention of asthma in high-risk infants: 0-2 years. 
Dankwoord 


\section{Dankwoord}

Eindelijk zijn we aangekomen op de plaats waar ik iedereen kan bedanken die heeft bijgedragen aan de totstandkoming van dit proefschrift. Een aantal mensen wil ik hierbij in het bijzonder noemen.

Pap en mam Jullie liefde, warmte en onvoorwaardelijke steun, hebben mij gebracht waar ik nu sta. Daar waar het nodig was stonden jullie altijd onmiddellijk voor ons klaar en boden jullie een warm en veilig nest.

Onno van Schayck Jij bent, samen met Huub, de initiator van het PREVASK programma, waarvan het RAKKER project een onderdeel vormt. Vanaf het begin af aan was je bij het project betrokken. Van jou heb ik geleerd hoe belangrijk het is je werk goed te verkopen. De ruimte die ik van je heb gekregen om mezelf, op mijn eigen wijze, te ontwikkelen heb ik erg gewaardeerd.

André Knottnerus De samenwerking met jou is in de loop der tijd steeds intensiever geworden. Je kritische blik, in het bijzonder op het gebied van de methodologie en statistiek, je zorgvuldigheid, rust, betrokkenheid en enthousiasme hebben mij steeds gemotiveerd door te gaan en er iets moois van te maken.

Jean Muris Een samenwerkingsverband van Limburgers en Amsterdammers is vragen om moeilijkheden, 'zeggen ze'. Ik denk dat wij hebben aangetoond dat een dergelijke samenwerking juist een fantastische uitdaging is. Verschillende mensen zijn gekomen en (soms tijdelijk) gegaan gedurende de looptijd van het project. Jij was er vanaf het begin. Zorgzaam, rustig, eerlijk, bescheiden, vol humor, ook kritisch maar vooral aanwezig. Ik heb genoten van de samenwerking met jou en ben blij dat jij tot 'mijn' team van co-promotoren hoort.

Edward Dompeling Jij raakte iets later intensief als co-promotor bij het project betrokken. Met veel plezier denk ik terug aan onze, soms stevige, discussies over bruikbare astmamodellen en de wijze waarop we het day-care artikel zouden vormgeven. Naast een fijne samenwerking op zakelijk gebied waardeer ik je humor, oprechtheid, teamspirit en het feit dat je tussen al je drukke werkzaamheden 'oog' probeert te houden voor het wel en wee van 'jouw' mensen.

Hans Severens Onze samenwerking beperkte zich tot slechts één artikel. Mijn gebrek aan ervaring met gezondheidseconomische vraagstukken vormde voor jou geen belemmering om de samenwerking met mij aan te gaan. Je enthousiasme was aanstekelijk, je laagdrempeligheid maakte dat ik je vaak rond middernacht nog overspoelde met mails, die je altijd direct beantwoordde. Je zeer kritische houding ten opzichte van onderzoek heeft mij enorm gestimuleerd en bij de les gehouden. Het was vaak moeilijk een afspraak met je te plannen, maar, 'waar zouden we zijn zonder ......', onze 
'treinmeetings' gaven mij regelmatig de gelegenheid om je een half uur lang te bestoken met vragen.

Geertjan Wesseling Als lid van de projectgroep had je een bescheiden rol. Je frisse blik, en kritisch opmerkingen hebben me regelmatig gestimuleerd om een en ander nog eens onder de loep te nemen.

Arnold Kester en Jildou Sijbrandij Voor statistische problemen kon ik altijd bij jullie terecht. Jullie kritische en zorgvuldige houding, maar ook jullie geduld om iets nog een keer uit te leggen heb ik zeer gewaardeerd.

Kitty van der Meer en Jacqueline Pisters Met veel plezier denk ik terug aan onze samenwerking. Jullie voortvarendheid, zelfstandigheid, humor en openheid gaven een enorme impuls aan het project. Jullie vriendschap heeft er toe geleid dat er altijd ruimte was voor een lach, een traan of een kritische noot. Samen vormden we een echt (RAKKER-) team en ik ben dan ook blij dat jullie mijn paranimfen zijn.

Uiteraard waren er veel meer mensen betrokken bij het totale PREVASK programma. Guido van den Boom, Frieda Waasdorp, Mieke Witte, Mariken Dorsemagen, Sven Schulte, Laura Polman, Alfons Schrooten, Tanja Maas, Huub Schönberger, Kittie Coolen, Annemarie Spaninks, Carin Groot, Annemiek Nijholt, Lisette van den Bemt, Barbara Gijsbers, Steven Stapel, Jannie de Vrieze, Wiet Koren, huisartsen en assistenten van het RNH, NMP en Cell, bedankt voor jullie inbreng en ondersteuning.

Door interne verhuizingen heb ik heel wat kamergenoten 'versleten'. Na Frieda kwamen Lonneke van Heurn, Sjoerd Hobma, Ben van Steenkiste, Rogier Hopstaken, Wim Verstappen en Loes van Bokhoven. Lonneke en Sjoerd, het was kort maar gezellig. Wim, wij wisselden elkaar een beetje af, maar de keren dat we er samen waren heb ik veel plezier aan je beleefd. Rogier, onze rollen zijn enigszins veranderd. Jij bij SGE en ik bij PoZoB. Ik hoop dat we samen met alle andere medewerkers in het Eindhovense, in de komende jaren iets moois kunnen gaan neerzetten. Ben, in vele proefschriften ben je al genoemd, de teddybeer, de alleskunner, de hulp bij ingewikkelde problemen. Wat mij betreft ben je gewoon een fantastische vent en ik ben blij dat ik een poosje kamergenoot van je heb mogen zijn. Loes, als laatste neergestreken in de rij kamergenoten. Het was weer even wennen, een dame, na zoveel heren, maar zeker zo plezierig. Je hielp mij soms de zaken in het juiste perspectief te plaatsen, en had altijd oog voor het wel en wee van anderen.

Mijn collega's van PoZoB. Jullie warme ontvangst, jullie positieve instelling en steun hebben mij geholpen de laatste loodjes er in een verhoogd tempo doorheen te jassen.

Pauline, Anne-Marie en Jacqueline, bedankt dat ik jullie Rakkers heb mogen 'lenen' voor de omslag van mijn proefschrift.

Inez Jouw jarenlange vriendschap is zeer waardevol voor mij. Onze discussies zijn vaak heftig en zet ons geregeld tot nadenken. Ik vond het 
heerlijk om bij jou in Engeland mijn laatste artikelen in alle rust te kunnen afmaken. Nog veel heerlijker vond ik je zorgzaamheid, het licht dat gewoon door je werd uitgedaan als ik te lang doorging en de gezellige en ontspannende activiteiten die je organiseerde tijdens mijn verblijf, bedankt hiervoor.

Beth Door jouw enthousiasme over mijn werk ben ik gaan geloven dat het voor anderen ook interessant is om te lezen. Bedankt dat je de moeite hebt willen nemen je door mijn artikelen te worstelen, mijn Engels aan te scherpen en positief kritische noten te plaatsen.

Anke van Gestel, Joyce, Nicole, Astrid, Arjen, Debby, Anke Hukkelhoven, Lian, Edith en Angret, jullie vriendschap, steun en motiverende berichtjes hebben mij de afgelopen jaren enorm geholpen om door te gaan op het gekozen pad.

Kees en Nel Ook een paar woorden voor jullie. Bedankt voor de opbeurende en ondersteunende gesprekjes die we af en toe hadden. Jullie zijn heerlijke schoonouders.

Pim en Lisa Jullie lieten mij iedere dag opnieuw zien dat er naast werk nog zó veel ander moois in de wereld is. Pim, natuurlijk is het veel leuker om een potje te gaan schaken met je vader dan te luisteren naar de verdediging van mamma's proefschrift. Toch ben ik heel blij dat je er bij bent.

Jaap Jij en ik, zijn het niet zo gewend met complimenten naar elkaar te strooien. Een oprecht kritische houding past ons beter. Jij was dan ook veruit mijn allergrootste criticus tijdens het promotietraject. Dit patroon wil ik graag doorbreken. In de afgelopen jaren heb je steeds achter mij gestaan en mijn keuzes gesteund. Als ik weer eens het hele weekend wilde werken nam je zonder al te veel morren de zorg voor Pim en Lisa alleen op je. Wanneer ik even ruimte nodig had, kreeg ik die en ook dan regelde je de zaken in je eentje. Dank zij jou, kunnen Pim en Lisa al jaren op een relaxte manier ontbijten en komen ze ook nog op tijd op school. Muziek speelt een belangrijke rol in ons leven. Voor mij ben jij de allerbeste 'piano man'.

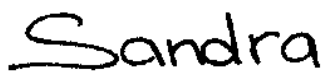


Curriculum vitae 


\section{Over de auteur}

Sandra is op 18 december 1966 vlak achter de Albert Cuyp markt in Amsterdam geboren. In 1970 was ze blij dat ze eindelijk 4 werd en naar de kleuterschool 'de Klimop' (Amsterdam) mocht. Twee en een half jaar later volgde aan de overkant op de 'Vancouver' school het basisonderwijs. In 1979 ging zij naar de O.S.G. de Rietlanden te Lelystad, waar ze in 1984 haar HAVO en in 1987 haar VWO diploma behaalde. In september van datzelfde jaar verhuisde ze naar 'het diepe zuiden' Maastricht om daar de studie 'Gezondheidswetenschappen' aan de Universiteit Maastricht te volgen. In het $2^{\mathrm{e}}$ studiejaar koos zij voor de afstudeerrichting 'Biologische Gezondheidkunde'. $\mathrm{Na}$ haar stages bij de afdelingen reumatologie en gastro-enterologie aan de Universiteit Maastricht en bij het farmaceutische bedrijf Anergen in Redwood City, VS, studeerde zij in 1993 af.

Van 1994 tot 1999 heeft ze aan de Katholieke Universiteit Nijmegen bij de afdeling Experimentele Reumatologie (thans: Experimental Rheumatology and Therapeutics) en de afdeling Reumatologie respectievelijk experimenteel en epidemiologisch onderzoek gedaan. Vervolgens heeft zij van oktober 1999 tot februari 2006 bij de Capaciteitsgroep Huisartsgeneeskunde van de Universiteit Maastricht en de afdeling Kindergeneeskunde van het academisch ziekenhuis Maastricht gewerkt aan het onderzoeksproject waarvan dit proefschrift het resultaat is. Sinds maart 2006 is Sandra als senior onderzoeksmedewerker werkzaam bij PoZoB (Praktijkondersteuning Zuidoost-Brabant) te Eindhoven. 